\title{
Self-directed workbooks: Evaluating their efficacy in a U.S. probation setting
}

by

Stephanie M. Biro

A thesis submitted to the Faculty of Graduate and Postdoctoral Affairs in partial fulfillment of the requirements for the degree of

Master of Arts

in

Psychology

Carleton University

Ottawa, Ontario

(C) 2018, Stephanie M. Biro 


\begin{abstract}
Interactive Journaling ${ }^{\circledR}$ and other structured journaling interventions have been utilized successfully in a variety of settings (e.g., mental health, addiction) and recent research has indicated that journaling with incarcerated offenders may be beneficial in reducing recidivism (e.g., Proctor, Hoffman, \& Allison, 2012). The purpose of the current study was to implement and examine the effectiveness of a set of five self-directed workbooks in a community supervision context and evaluate their utility from the clients' point of view. These workbooks, based on criminogenic needs, were developed to assist parole and probation officers in increasing the community success of offenders. Each workbook targets a different factor (e.g., criminal attitudes, motivation to change) essential to managing offender behaviour. Despite organizational changes impeding implementation at one site and a low participation rate $(N=32)$, which led to issues of power during analyses, the preliminary results combined with previous research do suggest that selfdirected workbooks may have potential in reducing both technical violations and recidivism among supervised offenders. Implications, limitations, and directions for future research are discussed.
\end{abstract}

Keywords: journaling, probation, community supervision, offender change 


\section{Acknowledgements}

I would like to start by thanking my supervisor, Dr. Ralph Serin, for his

enthusiasm for this research, as well as the constant support throughout this degree. I am very grateful for the amount of time and effort that he spent to review drafts of this document. I could not have completed this project without your guidance. I also appreciate the advice and recommendations from my committee member, Dr. Julie Blais, whose comments indisputably improved the quality of this project. I also appreciate the knowledge and perspective shared by Dr. Diana Majury, who took the time to act as my external examiner. Thank you both for your understanding of the challenges that I faced during the data collection process. Dr. Andrew Howard, thank you for taking the time to chair my defense.

This project would not have been possible without the cooperation of the individuals at both the Texas and Iowa sites. I truly appreciate the assistance that was provided throughout the various stages of the project. In addition, I would like to thank the Social Sciences and Humanities Research Council, the province of Ontario, and Carleton University for the generous funding I received to complete this degree.

A special thank you should also be extended to Dr. Leslie Anne Keown for her words of advice and encouragement over the last few years. You have had a substantial impact on my ability to grow as a researcher.

Finally, thank you to my family and friends for their support throughout this entire process, especially given the distance between most of us. Your constant love and encouragement was instrumental to get me through this process. Thank you for your patience as I took on the role of student for longer than we all anticipated. 


\section{Table of Contents}

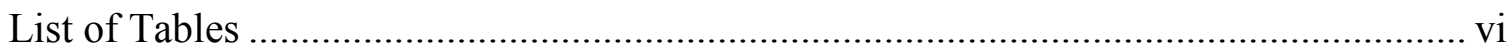

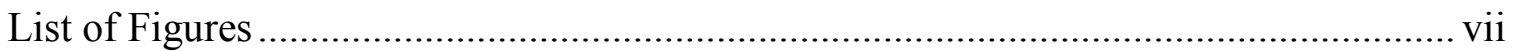

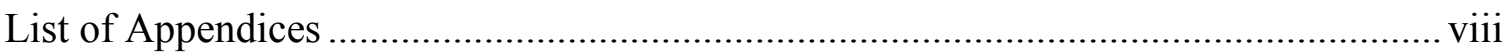

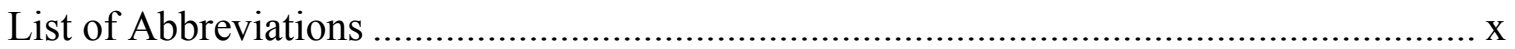

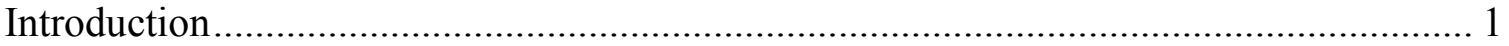

Rationale for Evidence Based Practice and Policy .................................................. 3

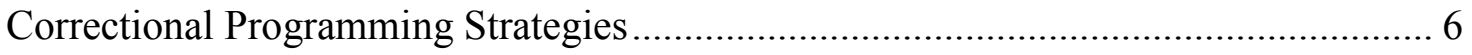

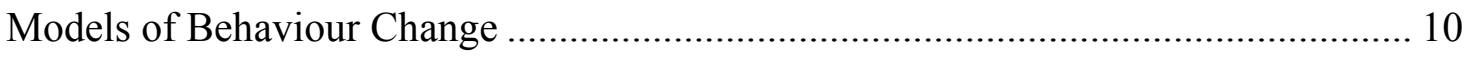

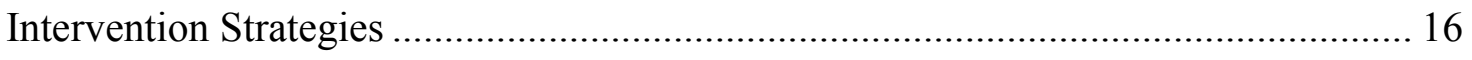

Structured Self-directed Journaling ................................................................. 19

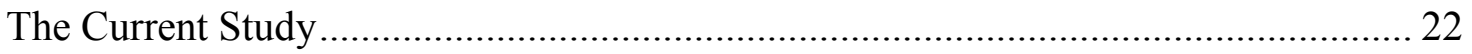

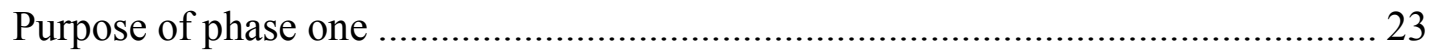

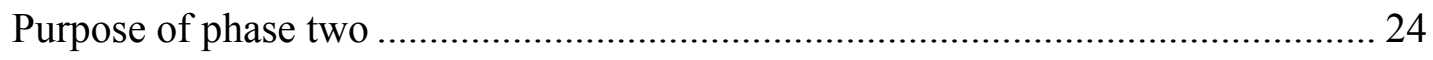

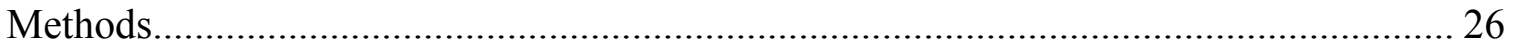

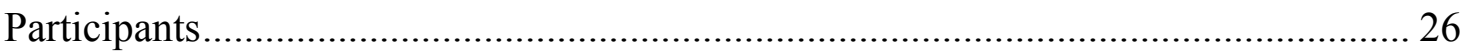

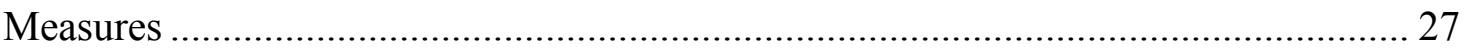

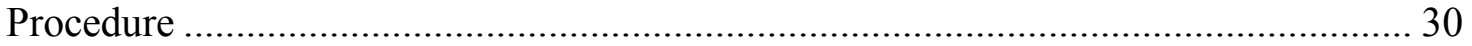

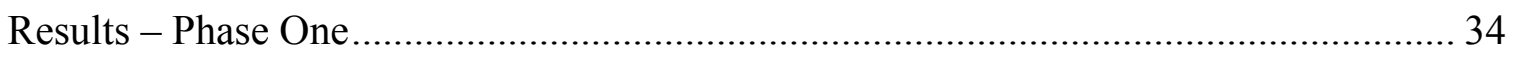

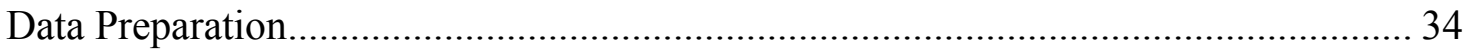

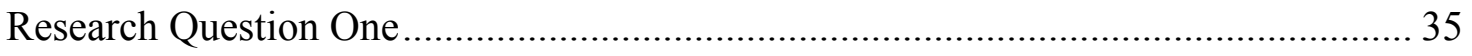




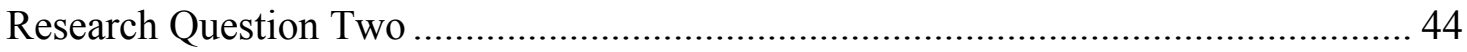

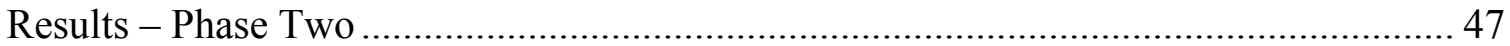

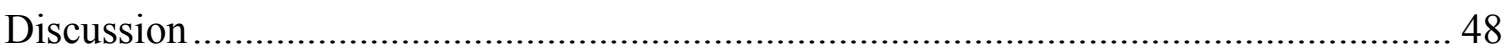

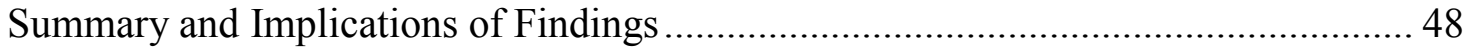

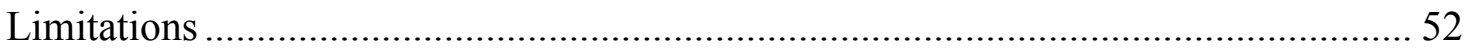

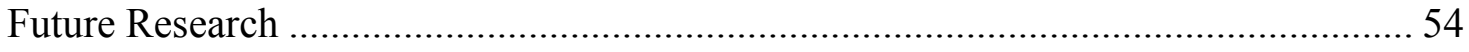

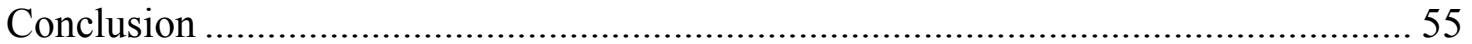

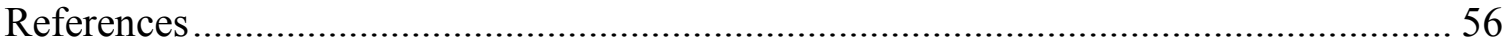




\section{List of Tables}

Table 1. Covariates of Criminal Behaviour.............................................................. 7

Table 2. Summary of Theories of Behaviour Change ................................................ 15

Table 3. Participant Characteristics across Condition ................................................ 27

Table 4. Readability of the Self-directed Workbooks..................................................... 29

Table 5. Research Questions, Proposed and Actual Analyses...................................... 35

Table 6. Results of Independent Samples t-tests and Fisher's exact tests for Age, Gender, Race, Education and Previous Offence across Condition ...................................... 39

Table 7. Results of Fisher's exact tests for Technical violations and Any New Charges

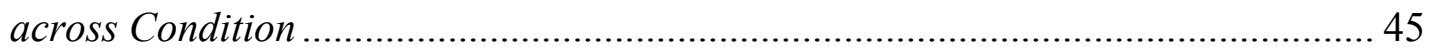




\section{List of Figures}

Figure 1. Histogram of Age Across the Control Condition. ............................................ 39

Figure 2. Histogram of Age Across the Experimental Condition. .................................. 40

Figure 3. Relative frequencies of Age Groups Across Condition. .................................. 40

Figure 4. Relative frequencies of Gender Across Condition.......................................... 41

Figure 5. Relative frequencies of Race Across Condition............................................. 41

Figure 6. Histogram of Education Across the Control Condition. .................................. 42

Figure 7. Histogram of Education Across the Experimental Condition. ......................... 42

Figure 8. Relative frequencies of Level of Education Across Condition. ........................ 43

Figure 9. Relative frequencies of Previous Offence Across Condition........................... 43

Figure 10. Relative frequencies of Technical Violation Across Condition...................... 45

Figure 11. Relative frequencies of Any New Charges Across Condition......................... 46 


\section{List of Appendices}

Appendix A Client Handbook Series

Appendix B (Online) Client Satisfaction Survey: Evaluating the Self-Directed

Workbooks

Appendix C Text for Email to Texas PO's

Appendix D Texas Probation Officer Informed Consent

Appendix E Instruction Manual and Script to Recruit Participants from Texas

Correctional Sites

Appendix F Texas Client Informed Consent

Appendix G Example Participant Log for Interactive Client Workbook Study with

Carleton University - Texas

Appendix H Debriefing Form for Texas Probation Clients 148

Appendix I Research Assistant Confidentiality Agreement

Appendix J Instruction Manual and Script to Recruit Participants from Iowa Correctional

Sites

Appendix K Iowa Client Informed Consent

Appendix L Example Participant Log for Interactive Client Workbook Study with

Carleton University - Iowa .

Appendix M Debriefing Form for Iowa Probation Clients..... 160

Appendix N Client Recruitment Letter. 


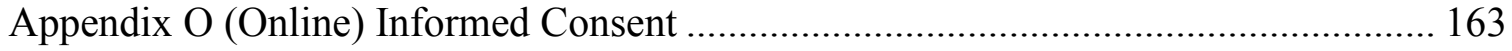

Appendix P Online Debriefing Form for Texas Survey ........................................... 165

Appendix Q Online Debriefing Form for Iowa Survey …..................................... 167 


\section{List of Abbreviations}

EBP Evidence Based Practice

CPAI Correctional Program Assessment Inventory

RNR Risk Need Responsivity principles

LS-CMI Level of Service/Case Management Inventory

DRAOR Dynamic Risk Assessment for Offender Re-entry

ORAS Ohio Risk Assessment System

COMPAS Correctional Offender Management Profile for Alternative Sanctions

SPIn Service Planning Instrument

SCT Social Cognitive Theory

SDT Self-determination Theory

GPCSL General Personality and Cognitive Social Learning

CBT Cognitive Behaviour Theories

TTM Transtheoretical Model of Behaviour Change

MORM Multifactor Offender Readiness Model

RFC Readiness for Change Framework

MI Motivational Interviewing

DUI Driving under the Influence

DWI Driving while Intoxicated

TCC Taking a Chance on Change

PO Probation Officer

CSR Community Service Restitution credits 


\section{Introduction}

Over 6.8 million adults were under the supervision of the adult correctional system at yearend 2014 in the U.S., with over 4.6 million of those offenders under community supervision (i.e., either probation or parole; Kaeble, Glaze, Tsoutis \& Minton, 2015). Comparatively, approximately $36 \%$ of the Canadian federal offender population was under community supervision in 2016 (i.e., day parole, full parole, statutory release and a long term supervision order; Public Safety Canada, 2016). An examination of long-term trends in the U.S. suggests that the number of offenders on community supervision has increased by $1.3 \%$ annually, on average, from 2000 to 2012 (Herberman \& Bonczar, 2014). Though there was a 1.3\% decrease in this population at yearend 2015, this was due to a drop in the probation population; the parole population continued to rise with a 1.5\% increase (Kaeble \& Bonczar, 2016). In Canada, the population of offenders in the community under supervision has increased over the past three years (Public Safety Canada, 2016).

The supervision of clients within the community has been shown to be significantly more cost effective than incarceration, with incarceration costing eight times more (i.e., $\$ 3,909$ annually per offender on average versus $\$ 30,621$; U.S. Courts, 2015). In 2014, almost every jurisdiction in the U.S. had more than half of their correctional population under community supervision (i.e., a national average of $66 \%$; Kaeble et al, 2015). Given the proportion of offenders under community supervision, as well as the difference in cost when compared to incarceration, the continual improvement of community interventions utilized to promote prosocial behaviour change should continue to be a major focus for correctional agencies and policymakers. Based on these numbers, even a minimal increase in the effectiveness of both client management techniques and intervention strategies will produce significant cost savings 
for correctional agencies in both the U.S. and in Canada. Furthermore, improvement in management and intervention strategies of offenders may significantly improve the quality of the their lives.

Over the last few decades, considerable research has provided a theoretical perspective to understanding criminal behaviour, as well as a set of principles that intend to guide the management and treatment of offenders (Bonta \& Andrews, 2017), which has received considerable empirical support (e.g., Andrews, Bonta, \& Hoge, 1990; McGuire, 2002; Prendergast, Pearson, Podus, Hamilton, \& Greenwell, 2013). This body of literature has led to the defining and identification of criminogenic needs (i.e., factors empirically related to recidivism; Bonta \& Andrews, 2017), as well as a plethora of risk assessment tools developed to assess offenders' likelihood of reoffending and the risk they pose to the public in terms of reoffending (e.g., Andrews, Bonta \& Wormith, 2006; Yang, Wong, \& Coid, 2010). Not only has this theoretical perspective and set of principles informed the management and treatment of offenders in custody, but it has also been expanded to offenders who are under community supervision (e.g., Bourgon \& Gutierrez, 2012).

The current understanding of how individuals become involved in criminal activity has also informed research exploring the variables that describe the offender who has desisted from crime through the development of prosocial habits. The literature suggests that the transition into a criminal lifestyle and the transition out of one are quite different processes (e.g., Serin, Lloyd, \& Hanby, 2010; Stouthamer-Loeber, Wei, Loeber, \& Masten, 2004). While current interventions are successful at reducing the risk of recidivism, there is considerable room for improvement when it comes to understanding what motivates an offender to change behaviour (i.e., lead a prosocial life), as well as the interventions that agencies can provide to assist in this process. The 
present study examines the effectiveness of interactive workbooks after their implementation in a community supervision context. Previous research has suggested journaling is an effective intervention to target general recidivism among incarcerated offenders (e.g., Proctor, Hoffmann, \& Allison, 2012).

\section{Rationale for Evidence Based Practice and Policy}

The last few decades have seen an increase in focus on the importance of evidence-based practice (EBP) among various components of the criminal justice system (Bonta \& Andrews, 2017; Porporino, Robinson, Millson, \& Weekes, 2002). The term EBP initiated in the medical field, when Cochrane (1972) suggested that empirical research should be considered in the decision-making process surrounding limited medical resources. EBP are practices that represent the amalgamation of research evidence with clinical expertise and client values (Friedmann, Taxman, \& Henderson, 2007). In other words, EBP is the notion that policy, and practice (i.e., including decision-making) should align with current empirical research in order to best achieve the desired outcomes and to make the most efficient use of financial resources (Taxman, 2012). This focus on EBP has been facilitated by the development of theoretical frameworks in which to categorize empirical research and interventions, as well as statistical methods that allow us to summarize the findings across studies to determine effect sizes (Taxman, 2012).

The initial expectation was that once an EBP was identified, agencies would eagerly work to implement them. However, the reality is that it can take years for EBP to become a part of an agency's practice. In the case of community corrections and addiction treatment, EBP presented two unique challenges: a) two disciplines were affected and b) correctional agencies were required to embrace offender change and rehabilitation. Unfortunately, within corrections, EBP has a history of poor implementation (Gendreau, Goggin, \& Smith, 1999). 
Correctional Program Assessment Inventory. One major advancement in the correctional field has been the Correctional Program Assessment Inventory (CPAI; Gendreau \& Andrews, 2001), an instrument designed to assess the ability of correctional programs to reduce recidivism by examining the degree to which the programs meet the principles of effective intervention (Bonta \& Andrews, 2017). The CPAI assesses the correctional programs on eight dimensions: 1) organizational culture, 2) program implementation/maintenance, 3) management/staff characteristics, 4) client risk/need practices, 5) program characteristics, 6) dimension of core correctional practices, 7) inter-agency communication, and, 8) evaluation. Various researchers have assessed the predictive validity of the CPAI. After reviewing a sample of 173 studies relating to offender treatment, a mean correlation of $r=.46$ was found between the overall CPAI score and recidivism (Nesovic, 2003). Similarly, Lowenkamp, Latessa and Smith (2006) also utilised the CPAI in the examination of 38 offender interventions and reported a mean correlation of $r=.42$ between overall CPA score and recidivism. Despite this, an examination of previous findings using the CPAI suggests that a large proportion of correctional programs would be rated as "unsatisfactory" (e.g., Lowenkamp et al., 2006; Matthews, Hubbard, \& Latessa, 2001); these interventions would likely not lead to successful outcomes postintervention.

The CPAI not only provides a standardized method for the evaluation of correctional programs, it also provides concrete recommendations for their improvement. Furthermore, new instruments were developed based on the items from the CPAI that have been validated. For example, the Correctional Program Checklist (CPC), in various forms, was created by researchers from the University of Cincinnati and has been utilised to evaluate programs across the U.S (e.g., Lowenkamp, 2004; Lowenkamp, Latessa, \& Smith, 2006; Nesovic, 2004). Finally, 
the results from the CPAI can assist policy-makers and government agencies in choosing which programs to invest resources in (i.e., decision-making based on program effectiveness).

Successful reintegration. An examination of offenders released across 30 states during 2005 indicated that approximately 68\% were rearrested within three years and approximately 77\% within five years (Durose, Cooper, \& Snyder, 2014). Furthermore, more than one third $(37 \%)$ of those who recidivated within five years were rearrested within the first six months postrelease. Similarly, an examination of successful completion rates of U.S. probationers and parolees during 2015 indicates that only $33-36 \%$ of offenders either successfully completed their supervision or were discharged early (Kaeble \& Bonczar, 2016). The high number of offenders that fail to complete their community supervision (i.e., commit a new offence or incur a technical violation) is of concern as it results in many new crimes being committed, increased victimization rates, and an increase in spending. The low rates of successful supervision completion and frequent returns to custody suggest that there is room for improvement regarding the efficacy of current practice. One strategy is to increase the availability of EBPs that are lowcost and simple to implement, thereby increasing the success of offender's reintegration into communities. One potential option is to utilize structured journaling techniques in the offender re-entry process, as they have demonstrated their effectiveness with incarcerated offenders (e.g., Proctor, Hoffmann, \& Allison, 2012).

Satisfies policy requirements. While the organization of the U.S. federal judiciary is largely decentralized, with day-to-day operations being managed locally, the federal probation system has adopted an outcome-based approach in order to reduce crime (Alexander \& VanBenschoten, 2008). New policies were developed based on a set of recommendations in order to improve community supervision strategies and develop a framework for measuring the 
progress towards the two primary goals (i.e., community protection and reducing recidivism; e.g., Alexander \& VanBenschoten, 2008; Taxman, Shepardson, \& Byrne, 2004). These policies and procedures were developed based on the Charter for Excellence framework that states the goals and values by which the system and its probation and pre-trial service officers stand by. The goal of these new policies is to assist offenders to transition into the community safely and effectively. Accordingly, strategies to develop efficient innovations in programming and client behaviour change should be a priority among correctional agencies.

\section{Correctional Programming Strategies}

The Risk, Need, Responsivity principles (RNR; Bonta \& Andrews, 2017) are a wellknown model for effective correctional interventions that has received considerable empirical support (e.g., Bonta \& Andrews, 2017; Dowden \& Andrews, 2004; Smith, Gendreau, \& Swartz, 2009). The risk principle recommends that correctional facilities match the offender's level of risk to the treatment level that is provided (i.e., higher risk offenders should receive a higher intensity treatment). This principle has the ability to assist probation and parole officers in the identification of an appropriate level of supervision for each particular client (i.e., offenders with higher levels of risk would require a higher frequency of contact; Carter \& Sankovitz, 2014). The need principle states that only criminogenic needs (i.e., risk factors that are empirically related to recidivism; see Table 1) should be targeted. More specifically, dynamic risk factors that are changeable through treatment are important to both risk assessment and risk management given their empirical relationship to recidivism. Finally, the responsivity principle suggests matching the type of intervention to the offender's learning style, abilities, level of motivation, and strengths in an attempt to maximize the offender's ability to change their behaviour (Bonta \& Andrews, 2017). Responsivity is often divided into general (i.e., using skill-based and cognitive- 
behavioural programs) and specific (i.e., interventions targeted to specific offender characteristics like cognitive ability) responsivity.

This model has received substantial empirical support regarding the effectiveness of correctional interventions, both within correctional institutions (e.g., Dowden \& Andrews, 2004) and community corrections (e.g., Bourgon \& Gutierrez, 2012). Specifically, recidivism rates have been observed to decrease as significantly as $35 \%$ in community settings when the intervention adheres to all three of the described principles (e.g., Bonta \& Andrews, 2017).

French and Gendreau (2006) also found that the higher number of criminogenic needs a program targets, the larger the reduction in recidivism (i.e., effect size $r=.26$ ).

Table 1.

Covariates of Criminal Behaviour.

\begin{tabular}{|c|c|c|}
\hline Type & Factor & Risk \\
\hline Static & $\begin{array}{l}\text { History of antisocial } \\
\text { behaviour }^{\mathrm{a}}\end{array}$ & $\begin{array}{l}\text { Early and ongoing involvement in various } \\
\text { antisocial behaviours }\end{array}$ \\
\hline \multirow[t]{7}{*}{ Dynamic } & $\begin{array}{l}\text { Antisocial personality } \\
\text { pattern }^{\mathrm{a}}\end{array}$ & Weak self-control, pleasure seeking \\
\hline & Antisocial cognition $^{\mathrm{a}}$ & $\begin{array}{l}\text { Attitudes, beliefs and rationalizations that are in } \\
\text { favour of crime; cognitive emotional states of } \\
\text { anger and defiance. }\end{array}$ \\
\hline & Antisocial associates ${ }^{\mathrm{a}}$ & $\begin{array}{l}\text { Immediate social support for crime; Larger } \\
\text { proportion of criminal peers to prosocial peers. }\end{array}$ \\
\hline & Family and/or marital & Poor supervision and low levels of nurturance \\
\hline & School and/or work & Low levels of performance in school and/or work \\
\hline & $\begin{array}{l}\text { Leisure and/or } \\
\text { recreation }\end{array}$ & $\begin{array}{l}\text { Low levels of involvement and enjoyment in } \\
\text { prosocial leisure activities }\end{array}$ \\
\hline & Substance abuse & Abuse of alcohol and or drugs \\
\hline
\end{tabular}

a These variables are coined the 'Big Four' and are considered major predictors of criminal behaviour. 
Dynamic risk/needs assessment. The risk assessment of offenders is imperative as the results produced by these tools are utilized in all stages of the judicial process (e.g., by judges, jail and prison administrators, and probation and parole officers). The risk assessment process in the criminal justice field has gone from utilizing subjective evaluations to one that is more objective and based on theoretically informed, standardized statistical methods. More specifically, there have been a number of generations of risk assessment instruments (i.e., unstructured clinical judgement, actuarial tools that focus on static risk factors, and actuarial tools that also incorporate dynamic risk factors) over the last few decades. The most recent generation of tools integrate offender monitoring and treatment with the assessment of a larger range of risk factors and responsivity factors. To further increase utility, these instruments emphasize the link between assessment and case management through adherence to the risk principle, the targeting of criminogenic needs, and by allowing for case planning that is developed directly from the results of the assessment (Andrews \& Bonta, 2010; Latessa \& Lovins, 2010).

There are a number of risk assessment instruments that have been developed, such as the Level of Service/Case Management Inventory (LS-CMI; Andrews, Bonta, \& Wormith, 2004), the Dynamic Risk Assessment for Offender Re-entry (DRAOR; Serin, 2007), the Ohio Risk Assessment System (ORAS; Latessa, Smith, Lemke, Makarios, \& Lowenkamp, 2009), the Correctional Offender Management Profile for Alternative Sanctions (COMPAS; Brennan \& Oliver, 2000), and the Service Planning Instrument (SPIn; Orbis Partners, 2003). This generation of risk assessments are designed not only for recidivism prediction, but to also guide case management practices. It does so through the effective monitoring of the most problematic dynamic risk factors and by capturing fluctuations in risk, which assists probation officers to 
more accurately judge when that individual is at risk and determine how to intervene to mitigate that risk (Douglas \& Skeem, 2006). In other words, these risk assessments can be utilized to inform relevant treatment targets for offenders over time.

However, there is disagreement among the existing research surrounding the definition of dynamic risk factors. A dynamic risk factor is defined as a factor that is not only related to recidivism and changeable through treatment, but that change in the factor results in a change in the likelihood of recidivism (Monahan \& Skeem, 2013). While most research uses this term to describe hypothetical factors that have been assessed once (e.g., pre-treatment), Harris and Rice (2003, 2015) advocate for a more rigorous definition. More specifically, they state that in order to be considered a dynamic risk factor, the variable needs to 1) demonstrate change over time, with a minimum of two assessments, and 2) that the resulting change had to improve on the accuracy of simply using the best available static actuarial instrument to predict recidivism (Harris \& Rice, 2003). This definition requires a strong methodology but would allow the field to make more definitive statements regarding change due to treatment.

Currently, the available evidence appears insufficient to conclude that change in dynamic risk factors as a result of intervention improved accuracy. For example, de Vries Robbé and colleagues (2015) examined the ability of treatment in reducing violent recidivism among 108 forensic psychiatric patients one year and 11 years post-discharge. While they found that pretreatment scores alone predicted violent recidivism, the addition of post-treatment scores to their models added incremental predictive accuracy. Similarly, Olver and colleagues (2014) examined change among a large sample of sex offenders and reported that improved change scores were significantly associated with decreases in both sexual and violent recidivism. While these findings appear to demonstrate the impact that change in dynamic risk factors has on offender 
outcomes, Harris and Rice (2015) make the argument that ideal predictive accuracy was achieved with only pre-treatment scores measured by a purely static actuarial instrument. Furthermore, others have found it difficult to demonstrate that changes in dynamic risk factors cause corresponding changes in recidivism (Kroner \& Yessine, 2013; Vachon, Lunam, \& Jonson, 2014). Thus, while it is reasonable to hypothesize that interventions can be utilized to target certain dynamic risk factors leading to changes in recidivism, the current empirical literature needs to be significantly expanded before firm conclusions can be made.

\section{Models of Behaviour Change}

It is important to also consider program staff's ability to build strong relationships with clients (Ross, Polaschek, \& Ward, 2008) and the quality of the intervention (Andrews \& Dowden, 2004; Lowenkamp, Latessa, \& Smith, 2006). Furthermore, it is important to consider the offender's treatment readiness (i.e., their ability to engage with treatment; Ward, Day, Howells, \& Birgden, 2004), as well as techniques that will help to increase their motivation to change (McMurran, 2009). This distinction between motivation, which implies the offender acknowledges that a problem exists, and readiness to change, where the individual has the tools required to fully engage in treatment (e.g., knowledge, skills, social support; Mossiere \& Serin, 2014), is important as there is some confusion in the terminology in the literature.

The initial interest in the motivation to change appears to stem from the addictions literature in response to treatment compliance issues. Treatment noncompliance was previously viewed as a lack of motivation and was considered a stable personality trait related to maladaptive defence mechanisms (DiCicco, Unterberger, \& Mack, 1978; Clancy, 1961). However, the findings that therapist-related variables appeared to have a larger impact in comparison to individual personality characteristics (e.g., Miller, 1985), has lead the field to 
focus on developing techniques to assist therapists in promoting change among their clients. Among the correctional rehabilitation literature, motivation was identified as an essential factor in engaging offenders in treatment (e.g., Wexler, Melnick, Lowe, \& Peters, 1999). As well, motivation is described as one of the key concepts of the responsivity principle (Bonta \& Andrews, 2017).

There are a variety of theories of behaviour change that attempt to explain the mechanisms through which interventions may target recidivism and can be classified as either motivation theories or action theories (see Table 2). Motivation theories attempt to explain behaviour change among offenders who do not yet possess the intention to change. For example, Social Cognitive Theory (SCT; Bandura, 1977) and Self-determination Theory (SDT; Deci \& Ryan, 1985) fall within this category. Several constructs of SCT are identified as key constructs in the General Personality and Cognitive Social Learning (GPCSL; Bonta \& Andrews, 2017) perspective of criminal behaviour. GPCSL theory has been significant in the criminal justice field as these key concepts have helped guide the development of risk assessment and core correctional programming (Bonta \& Andrews, 2017).

Knowledge identifies the risks related to offending and the benefits of prosocial behaviour and is a pre-requisite for change. Self-efficacy provides the belief that one's actions are sufficient to bring forth the change in behaviour. Outcome expectations denote the costs and benefits of both specific offending and prosocial behaviours. Proximal and distal goals include broad social goals, as well as specific personal goals based on the individual's own values. Finally, perceived facilitators and impediments are the personal and situational factors of an individual that have the potential to determine behaviour.

Action theories attempt to explain behaviour change among those individuals who are 
already motivated to change. For example, the various generations of Cognitive Behaviour Theories (CBT; e.g., Roth \& Pilling, 2008), Self-regulation Theory (Baumeister \& Vohs, 2007), and the Transtheoretical Model of behaviour Change (TTM; Prochaska \& Velicer, 1997) are all considered action theories of behaviour change.

The theories reviewed highlight several factors that are posited to be linked to reductions in criminal behaviour. As an example, GPCSL suggests that as rewards for pro-social behaviour increase and the cost of committing crime increase, the likelihood of an individual engaging in crime should decrease. Furthermore, the desistance literature has highlighted several external and internal factors that are expected to assist with an offender desisting from crime (i.e., no longer engaging in criminal behaviour).

External factors. Social bonds are said to provide offenders a reason to desist from criminal activity. Bonta and Andrews (2017) theorized that marriage would impact criminal behaviour by increasing the perceived cost associated with antisocial behaviour. It has also been stated that stable and adequate employment can also increase both social bonds and time spent with prosocial peers, resulting in desistance from crime (Wright \& Cullen, 2004). Furthermore, these two factors have been said to reduce criminal activity by restricting the time an offender spends in temptation-filled situations (e.g., drinking at a bar; Horney, Osgood, \& Marshall, 1995).

Internal factors. Internal factors, such as readiness to change, are more difficult to research as they require self-report information from offenders. Though there are a variety of descriptions of internal change, the key component to desistance from crime appears to be a change in identity. That is, the individual begins to view himself or herself as a law-abiding citizen versus a criminal (Kazemian \& Maruna, 2009). 
There are a number of frameworks that conceptualize treatment readiness/responsivity within the literature. For example, the Multifactor Offender Readiness Model (MORM; Ward et al., 2004) acknowledges that readiness is both a feature of the intervention setting and a characteristic of the individual client and attempts to identify means to enhance both offender engagement and overall treatment effectiveness. The Readiness for Change Framework (RFC; Burrowes \& Needs, 2009) was developed in response to the authors' critique of the TTM and its' reliance on stages. The RFC makes the argument that change can take a variety of forms and can be affected by both internal and external factors or by the consequences of an earlier experience. Though this framework is not yet validated, it has the potential to assist practitioners by indicating not only when an offender is ready for change, but also any potential barriers to change that the individual may be experiencing.

Trans-theoretical Model of behaviour change. Previously, behaviour change was thought of as a discrete event (e.g., quitting smoking or drinking). The Trans-theoretical Model of behaviour change (TTM) construes change as a process, one that progresses through a series of stages over time (e.g., Prochaska \& Velicer, 1997). Despite a multitude of reasons for an individual's resistance to behaviour change (e.g., rigid thinking, short-term focus; Oreg, 2003), research actually suggests that a linear path is not followed, even among individuals pursuing significant changes (Prochaska, DiClemente, \& Norcross, 1992). Research primarily stemming from the substance addiction literature has utilized the TTM in order to examine behaviour change (e.g., DiClemente, Schlundt, \& Gemmell, 2004).

The TTM, which was developed through a comparative analysis of the leading theories of psychotherapy, utilizes stages of behaviour change (i.e., pre-contemplation, contemplation, determination/preparation, action, and maintenance) in an attempt to integrate the processes and 
principles of change from these various theories of treatment (Prochaska, 1984). The goal behind the development of this model was to integrate the theories of psychotherapy, as they had expanded to more than 300 models to explain changing behaviour. For example, according to Bandura (1982), self-efficacy is a situation-specific confidence that allows individuals to cope with high-risk situations without relapsing to their former behaviours/habits. However, the TTM has been criticized for its lack of complexity (Whitelaw, Baldwin, Bunton, \& Flynn, 2000), measurement inconsistencies (Sutton, 2001), conceptual flaws, and a lack of empirical evidence to support this model (Weinsten, Rothman, \& Sutton, 1998). McMurran (2009) has also critiqued the TTM, suggesting that it does not in fact reflect offender change given that change rarely occurs in genuine stages. Despite these critiques, the TTM is intuitively appealing and commonly used in the context of offending to assist practitioners in assessing an individual's readiness and modify treatment towards their current state of preparedness (Burrowes \& Needs, 2009). However, empirical support for the use of the TTM among correctional populations is still significantly lacking. 
Table 2.

Summary of Theories of Behaviour Change.

\begin{tabular}{|c|c|c|}
\hline \multirow[t]{2}{*}{ Grouping } & \multicolumn{2}{|r|}{ Summary } \\
\hline & For a review see & Implications for promoting offender change \\
\hline \multicolumn{3}{|l|}{ Motivation Theories } \\
\hline Self-determination Theory & Deci \& Ryan (1985) & $\begin{array}{l}\text { - Differences between external and internal motivation and the } \\
\text { impact on successful behaviour change } \\
\text { - Identifies methods to increase motivation }\end{array}$ \\
\hline Social Cognitive Theory & Bandura (1977) & $\begin{array}{l}\text { - Highlights the role of self-efficacy in initiating and maintaining } \\
\text { change } \\
\text { - Illustrates how an individuals skills can be utilised to develop new } \\
\text { ones } \\
\text { - Modeling of positive behaviours/responses by therapist can } \\
\text { promote behaviour change in client }\end{array}$ \\
\hline $\begin{array}{l}\text { General Personality and } \\
\text { Cognitive Social Learning }\end{array}$ & Bonta \& Andrews (2017) & $\begin{array}{l}\text { - Suggests that a combination of an individual's characteristics and } \\
\text { their social learning environment to be the underlying cause of } \\
\text { criminal behaviour } \\
\text { - Identifies four factors most predictive of criminal behaviour: } \\
\text { history of criminal behaviour, antisocial attitudes, antisocial peers } \\
\text { and antisocial personality traits }\end{array}$ \\
\hline \multicolumn{3}{|l|}{ Action Theories } \\
\hline Cognitive Behaviour Theories & Roth \& Pilling (2008) & $\begin{array}{l}\text { - Identifies potential treatment targets by identifying maladaptive } \\
\text { schemas and cognitive distortions that may be implicated in the } \\
\text { development of offending behaviour }\end{array}$ \\
\hline Self-regulation Theory & $\begin{array}{c}\text { Baumeister \& Vohs } \\
\text { (2007) }\end{array}$ & $\begin{array}{l}\text { - Provide a framework for behaviour change using processes such as } \\
\text { goal setting, self-monitoring and self-evaluation } \\
\text { - Model of self-regulation failure can be applied to different offence } \\
\text { types }\end{array}$ \\
\hline $\begin{array}{l}\text { Transtheoretical Model of } \\
\text { Behaviour Change }\end{array}$ & $\begin{array}{c}\text { Prochaska \& Velicer } \\
\text { (1997) }\end{array}$ & $\begin{array}{l}\text { - Stages and processes of change provide treatment methods for } \\
\text { addressing interpersonal and intrapersonal conflicts and } \\
\text { maladaptive cognitions } \\
\text { - Identifies specific techniques to increase motivation to change for } \\
\text { each stage of change }\end{array}$ \\
\hline
\end{tabular}




\section{Intervention Strategies}

Interventions that align with the RNR principles have continually been demonstrated to significantly reduce recidivism (e.g., Bonta \& Andrews, 2017; Lowenkamp, Latessa, \& Smith, 2006; refer to Smith, Gendreau \& Swartz, 2009 for a systematic review). However, the challenge becomes how best to provide these effective interventions in community correctional settings. A need for expanded access to evidenced-based interventions is apparent given the high rates of substance abuse issues among offenders but low rates of access to interventions (e.g., offenders are approximately four times more likely to have substance use disorders in comparison to the general population; SAMHSA, 2013). Structured journaling was developed as a response to this gap. While much effort has been done to produce meta-analyses of findings, listing evidencebased interventions and providing manuals or training, less has been done regarding the issues surrounding the dissemination process to various agencies (e.g., feasibility of implementation due to time/cost and ongoing policy changes in real-world settings; e.g., Taxman et al., 2004).

Based on effect sizes, current interventions are somewhat successful at reducing the risk of recidivism (Smith, Gendreau, \& Swartz, 2009), but there is room for improvement. Experimental disclosure, where individuals disclose information and thoughts about personal, meaningful topics, has been utilized successfully in a variety of settings (e.g., mental health, addiction, and education; Frattaroli, 2006), in both verbal and written formats. Recent research has indicated that self-directed journaling, based on cognitive behavioural therapy and motivational interviewing principles, may be successful at reducing recidivism with incarcerated offenders (e.g., an absolute difference of $15 \%$ in recidivism rates was observed; Proctor, Hoffmann, \& Allison, 2012). 
Motivational interviewing. The primary mode of psychotherapy and counselling has been spoken language, utilised through talk therapy techniques as a way to promote mental health (Kohlenberg \& Tsai, 2007). Motivational interviewing (MI) is a person-centered approach that cultivates change by helping an individual explore and resolve ambivalence (Miller \& Rollnick, 2013), and functions on the premise that individuals are more likely to achieve this change when motivation comes from within (i.e., versus through the prompting of a clinician; Miller \& Rollnick, 2013). More specifically, it is an evidence-based communication technique that correctional facilities are now utilising to promote positive behaviour change among offenders. MI borrows from client-centered counselling (i.e., focusing on empathy, optimism and respect for the clients' choice; Rogers, 1961), as well as self-perception theory (i.e., the verbal stance an individual takes will impact how committed they are to an action; Bem, 1972). MI was developed in order to facilitate behaviour change along a continuum (i.e., construes change as a process, one that progresses through a series of stages over time) by helping individuals build self-efficacy through the elicitation of "change talk".

A meta-analysis found that the strongest support for MI efficacy was in its use as a treatment for substance abuse (i.e., with a mean $d=.41$ posttreatment across 32 trials; Hettema, Steele, \& Miller, 2005). This is not surprising as it was originally designed as an intervention for this issue (Miller, 1983). However, there is also emerging research to suggest MI may be effective for a variety of addictive behaviours (e.g., smoking, pathological gambling; Hettema, Steele, \& Miller, 2005). As well, several studies have reported large effect sizes (e.g., values ranging from .67 to .77 ) in MI's ability to promote treatment engagement, retention, and adherence and these effects appear to increase over time when combined with other effective treatment (e.g., Brown \& Miller, 1993). MI has also been found to be effective in enhancing 
motivation to change among high-risk offenders (e.g., Austin, Williams, \& Kilgour, 2011).

However, while Austin, Williams, and Kilgour (2011) observed a significant improvement in the motivation to change among offenders who received the Short Motivation Program (SMP; $d=$ .31 ), actual behaviour change (e.g., reduced recidivism) following the implementation of the SMP was not assessed.

Experiential disclosure. Though spoken language is the most commonly utilised form of psychotherapy, written language has also been shown to have therapeutic value. The positive effects of therapeutic writing have also been extensively explored. Therapeutic writing techniques, or experimental disclosure can be described as individuals revealing information and cognitions regarding personal, meaningful matters. For example, Pennebaker (1997) found that reflective writing on topics that were meaningful to the person significantly improved physical and emotional well-being. More importantly, it appeared that these benefits required translating experiences into words (e.g., through the writing process). There is also evidence to suggest that spreading the writing over a longer period of time, versus writing for the same length of time at one time point, is associated with larger effect sizes (e.g., Pennebaker, 1997; Smyth, 1998).

Initial research on this topic was typically conducted on healthy university/college students and university employees in order to assess its benefits (e.g., Pennebaker \& Beall, 1986). Notable benefits that were identified among this sample were a reduction in visits to health centres (Pennebaker, Colder, \& Sharp, 1990) and improved immune system functioning (Pennebaker, Kiecolt-Glaser, \& Glaser, 1988). Over the last few decades, the examination of the benefits of experimental disclosure has expanded to members of the general public who had experienced a job loss (e.g., assisted unemployed engineers find employment more quickly; Spera, Buhrfeind, \& Pennebaker, 1994). Benefits of experimental disclosure were then extended 
to individuals with medical ailments, such as rheumatoid arthritis and asthma (Smyth, Stone, Hurewitz, \& Kaell, 1999) and incarcerated offenders (e.g., reduced trips to the institutional hospital; Richards, Beal, Seagal, \& Pennebaker, 2000). As well, the benefits of therapeutic writing materials have been demonstrated for depression (e.g., Cuijpers, 1997; Scogin, Jamison, \& Cochneaur, 1989), alcohol abuse issues (Apodaca \& Miller, 2003), anxiety (Bower, Richards, \& Lovell, 2001), and sexual dysfunction (Marrs, 1995).

\section{Structured Self-directed Journaling}

While experiential disclosure can be relatively unstructured, there has been a shift to more structured interventions that involve the use of workbooks to assist with the therapeutic journaling process. This type of structured journaling has been utilised as both a selfadministered resource or as a complement to individual or group counselling (Davidson, Crawford, \& Kerwood, 2008).

Interactive Journaling ${ }^{\circledR}$. A structured and experiential writing process known as Interactive Journaling ${ }^{\circledR}$, based on the TTM, cognitive behavioural therapy, and motivational interviewing principles, aims to reduce substance abuse and substance-related behaviours (e.g., recidivism) by motivating and guiding individuals towards positive life change. Interactive Journaling $^{\circledR}$ is also included in SAMHSA's National Registry of Evidence-based Programs and Practices (SAMHSA, 2014). While it received a high Readiness for Dissemination rating (i.e., 4.0 on a 4.0 scale), it received a low Quality of Research rating (i.e., 2.5 on a 4.0 scale), given the little empirical research that has been conducted.

Recent research has indicated that Interactive Journaling ${ }^{\circledR}$ with incarcerated offenders may be successful at reducing recidivism (e.g., Proctor, Hoffmann, \& Allison, 2012). Proctor, Hoffmann, and Allison (2012) evaluated the impact of Interactive Journaling ${ }^{\circledR}$ on recidivism, 
while also attempting to identify significant predictors of recidivism, among a sample of 183 incarcerated male offenders. These individuals all met the criteria for substance dependence, had substance involvement in their current offence, and had at least one previous incarceration within the past 12 months. The interested participants were randomly assigned to either the experimental condition (i.e., journaling condition) or the control condition (i.e., a government pamphlet discussing substance use disorders and criminal behaviour). The proportion of those in the control group who were booked at the local detention facility in the 12-months following their participation in the study was significantly different compared to the proportion of those who received the journal (i.e., 66\% versus 51\%). Proctor, Hoffmann, and Allison (2012) found that approximately one in seven fewer offenders in the journaling group did not reoffend in comparison to the control group. Furthermore, although it was found that some demographic (e.g., employment status) and clinical (e.g., PTSD) characteristics had significant associations with recidivism, the Interactive Journaling ${ }^{\circledR}$ appeared to have an independent effect on the rate of recidivism for substance dependent offenders.

Scheck, Hoffmann, Proctor, and Couillou (2013) sought to evaluate the acceptability of Interactive Journaling ${ }^{\circledR}$ as a brief intervention among a sample of 872 offenders who had a driving under the influence (DUI) or driving while intoxicated (DWI) charge. All participants had been previously mandated to receive an alcohol intervention given the nature of their convictions. Over half of the participants $(52 \%)$ rated the journals as 'very valuable' and approximately $79 \%$ indicated that they had learnt 'a lot' from the program. Furthermore, approximately $25 \%$ of participants indicated that they had shared the journaling content with someone else, and another $55 \%$ indicated that they had plans to do so in the future. Finally, the majority of offenders (95\%) stated that the journals would help to change their drinking 
behaviours and $88 \%$ planned to keep the journals after program completion. Overall, DUI and DWI offenders rated the journals as useful for assisting in behaviour change.

One limitation to this study was that data was only available to the researchers for those individuals who had completed all 24 hours of the mandated program and unfortunately, data regarding dropout rates (and the characteristics of those individuals) was not available. However, the researchers address this potential concern by suggesting that due the fact that regaining driving privileges was contingent on program completion, it was suspected that program completion rates were higher than most interventions.

Self-directed intervention. More recently, Folk and colleagues (2016) examined the effectiveness of a self-administered, cognitive-behavioural intervention targeting criminal thinking in a sample of 273 offenders residing in segregated housing at correctional institutions. The research question was whether changes in criminal thinking were predictive of changes in disciplinary infractions. As well, individual differences on characteristics such as age, education, and sentence length were examined to determine whether certain offenders were experiencing greater reductions. It was hypothesized that this intervention would decrease general criminal thinking over time. More specifically, it was expected that those offenders who displayed reactive criminal thinking would have larger reductions than those who displayed proactive criminal thinking. It was also hypothesized that the intervention would result in a decrease in disciplinary infractions.

Criminal thinking was assessed pre- and post-intervention and the intervention, Taking a Chance on Change (TCC), was a structured intervention designed to be completed by offenders residing in segregated or long-term restrictive housing. TCC is comprised of eight units that target preparing for change, self-awareness and goal setting, identifying and changing mistaken 
beliefs, effective problem-solving, effective communication, anger management, stress management, and relapse prevention. Linear regressions were conducted using change scores (i.e., an individuals post-intervention score minus their pre-intervention score) as the criterion. Moderate, negative correlations were observed between the change scores and pre-intervention general criminal thinking $(r=-.45)$, pro-active criminal thinking $(r=-.45)$, reactive criminal thinking $(r=-.48)$, and disciplinary infractions $(r=-.82)$. Both years of education and age were found to significantly predict changes to all aspects of criminal thinking during the intervention. More specifically, holding pre-intervention criminal thinking scores constant, the intervention was more effective for older and more educated offenders.

\section{The Current Study}

This project consisted of one study to be implemented at two U.S. probation sites, with two phases: (1) implementation of the intervention program and (2) a user satisfaction survey targeting the clients who chose to participate. While there were slight implementation differences between the two sites, the overall purpose of the study remained the same. However, there were organizational changes at one probation site leading to implementation delays that ultimately resulted in the study being dropped from that site. This will be discussed further. It is also important to note one reason that the U.S. was chosen that relates to implementation. The process to gain access to correctional institutions and offenders under the supervision of the Correctional Service of Canada (CSC) for research is complex and can be time-consuming. While in Canada one must submit their proposal through a more formal process to the Research Branch at CSC, individual sites have the abilitity to approve research proposals in the U.S. Given the application process involved in Canadian research and the short timeframe required to complete a masters 
thesis, I was able to benefit from the research contacts of my supervisor who reside in other jurisdictions.

Purpose of phase one. In the interest of public safety, and improving access to putatively effective intervention strategies, the purpose of phase one was to implement a set of five recently developed workbooks at two U.S. probation sites in order to examine their effectiveness at reducing recidivism and technical violations. The present study sought to fill the apparent gap in the literature regarding the evaluation of self-directed journaling as an intervention to reduce general criminal recidivism among a sample of probation clients. The workbooks focused on various criminogenic needs (e.g., criminal attitudes, substance abuse) essential to managing offender behaviour (Bonta \& Andrews, 2017). Recent studies have suggested that journaling is an effective intervention to target general criminal recidivism among incarcerated offenders (e.g., Proctor, Hoffmann, \& Allison, 2012) and the current study implemented and examined the effectiveness of recently developed interactive workbooks in a community supervision context with low-moderate risk offenders.

While there is no agreed upon definition for what a low-intensity psychological intervention specifically entails, there do appear to be some common features among those addressing mental health concerns (for a discussion, see National Institute for Health and Clinical Excellence, 2011). First and foremost, low-intensity interventions use minimal resources, or, in the case of self-directed programs, virtually none. Secondly, these interventions typically utilize a learning tool, such as a physical or online workbook or audiotapes (e.g., Blenkiron, 2001). Finally, the majority of low-intensity interventions are based on the principles of CBT with the goal of changing thought processes and behaviour to improve daily functioning. These workbooks would be considered a low-intensity intervention and, as such, are likely to be 
beneficial to low-moderate risk offenders who typically need minimal intervention in comparison to their moderate and high-risk counterparts (Bonta \& Andrews, 2017).

\section{Research Question 1: Do the individuals in the workbook group differ on} demographic characteristics compared to those in the control group?

Hypothesis 1: Given that clients voluntarily participated in this study and the random assignment to conditions, it was expected that there would be no major demographic differences between the experimental and control groups. Although a process was implemented to ensure random assignment to conditions (i.e., in order to ensure that any differences between and within the two groups did not result from the recruitment process), it was necessary to test the effectiveness of this process in order to be sure that any differences in outcome between the groups that were observed could be assumed to be a result of the intervention.

\section{Research Question 2: Is there a significant difference in both the recidivism rates} and the time to failure between the workbook and the control groups?

Hypothesis 2: The individuals in the workbook groups would have lower rates of recidivism (i.e., either technical violations or new crimes) and longer time to failure in comparison to the control groups.

Purpose of phase two. The purpose of phase two was to evaluate the usefulness of the self-directed workbooks from the client's perspective. As these specific workbooks had not been implemented previously, feedback from the clients regarding both the content and usability of the workbooks would allow us to make any necessary improvements prior to any future implementations.

Research Question 3: What are the general views of the clients in terms of the content and usability of the self-directed workbooks? 
Hypothesis 3: Given previous feedback from clients on similar interventions (e.g., Scheck et al., 2013), it was hypothesized that clients would be satisfied with the structure and usefulness of the workbooks.

Research Question 4: Did client views differ between the two probation sites?

Hypothesis 4: No differences were expected. 


\section{Methods}

\section{Participants}

For the purpose of the current study, a sample of 32 probation clients from a probation site in Texas was recruited in person between January 2017 and April 2017. Participants were low-moderate risk probationers who had previously been assessed using the Texas Risk Assessment System (Criminal Justice Connections, 2015), which combines and interprets an individual's criminal history and criminogenic needs to create the most effective case management plan. Each participant was randomly assigned to either the control (i.e., current probation practices only) or experimental group (i.e., self-directed workbooks alongside current probation practices).

Of the final sample $(n=32)$, seven identified as female and the remaining 25 identified as male (see Table 3). The participants' age ranged from 22 to $59(M=36.97, S D=10.15)$. The sample was comprised of approximately $84 \%$ identified as Caucasian $(n=27)$, while the other $16 \%(n=5)$ identified their race as other. Furthermore, $53 \%$ of the participants identified their ethnicity as Hispanic. It is important to note that race and ethnicity are not mutually exclusive variables (i.e., of the individuals who were identified as Caucasian, 56\% identified as Hispanic). Approximately $68 \%$ of participants indicated that they had a grade twelve education or less $(M=$ 12.50 years, $S D=2.27$ ) and $59 \%$ had a previous offence that was a felony.

As previously mentioned, our study was unable to be implemented at the Iowa probation site. The intended procedural differences between the two sites will be discussed briefly despite the lack of implementation at the second site. 
Table 3.

Participant Characteristics across Condition

\begin{tabular}{|c|c|c|c|c|}
\hline \multirow{2}{*}{ Demographics } & & \multicolumn{2}{|c|}{ Condition } & \multirow{2}{*}{ Total } \\
\hline & & Control & Experimental & \\
\hline \multirow[t]{3}{*}{ Age (years) } & Mean $(S D)$ & $38.50(10.35)$ & $36.27(10.22)$ & $37.97(10.15)$ \\
\hline & Minimum & 27 & 22 & 22 \\
\hline & Maximum & 59 & 55 & 59 \\
\hline \multicolumn{5}{|l|}{ Age (grouped) } \\
\hline & $20-29$ & $20 \%(2)$ & $32 \%(7)$ & $28 \%(9)$ \\
\hline & $30-39$ & $40 \%(4)$ & $36 \%(8)$ & $38 \%(12)$ \\
\hline & $40-49$ & $20 \%(2)$ & $23 \%(5)$ & $22 \%(7)$ \\
\hline & $50-59$ & $20 \%(2)$ & $9 \%(2)$ & $12 \%(4)$ \\
\hline \multicolumn{5}{|l|}{ Gender } \\
\hline & Male & $60 \%(6)$ & $86 \%$ (19) & $78 \%(25)$ \\
\hline & Female & $40 \%(4)$ & $14 \%(3)$ & $22 \%(7)$ \\
\hline \multicolumn{5}{|l|}{ Race } \\
\hline & Caucasian & $90 \%(9)$ & $82 \%(18)$ & $84 \%(27)$ \\
\hline & Other & $10 \%(1)$ & $18 \%(4)$ & $16 \%(5)$ \\
\hline \multicolumn{5}{|c|}{ Level of Education (years) } \\
\hline & Mean $(S D)$ & $12.50(2.84)$ & $12.50(2.04)$ & $12.50(2.27)$ \\
\hline & Minimum & 7 & 10 & 7 \\
\hline & Maximum & 16 & 16 & 16 \\
\hline \multicolumn{5}{|c|}{ Level of Education (grouped) } \\
\hline & $\begin{array}{l}\text { Less than grade } \\
12\end{array}$ & $30 \%(3)$ & $36 \%(8)$ & $34 \%(11)$ \\
\hline & Grade 12 & $40 \%(4)$ & $32 \%(7)$ & $34 \%(11)$ \\
\hline & $\begin{array}{l}\text { Any higher } \\
\text { education }\end{array}$ & $30 \%(3)$ & $32 \%(7)$ & $31 \%(10)$ \\
\hline \multicolumn{5}{|c|}{ Previous Offence } \\
\hline & Misdemeanour & $50 \%(5)$ & $36 \%(8)$ & $41 \%(13)$ \\
\hline & Felony & $50 \%(5)$ & $64 \%(14)$ & $59 \%(19)$ \\
\hline Total & & 10 & 22 & 32 \\
\hline
\end{tabular}

\section{Measures}

Intervention. Given the success of Interactive Journaling ${ }^{\circledR}$ and other structured selfadministered journaling interventions among incarcerated offenders in recidivism reduction (e.g., Proctor, Hoffmann, \& Allison, 2012), a set of five self-directed workbooks (i.e., clients can 
complete the exercises within each workbook with little staff contact; see Appendix A) that make up the Client Handbook Series was used as the intervention in the current study. These workbooks were recently developed by my colleagues in Carleton's Criminal Justice Decision Making laboratory to assist parole and probation officers in increasing client access to interventions/programming. The workbooks were based on criminogenic needs identified through previous research (e.g., Bonta \& Andrews, 2017) and each workbook targets a different factor (e.g., criminal attitudes, substance abuse) essential to managing offender behaviour. The workbook format was based on similar journals that were created as a pre-treatment tool for a substance abuse intervention (Proctor, Hoffmann, \& Allison, 2012). The idea behind the workbooks stems from the TTM (Prochaska \& Velicer, 1997), a theoretical model of behaviour change that describes the ways in which individuals move through the stages of change in order to adopt and maintain a particular behaviour. These workbooks are designed to assist clients in reflecting on the different choices and thought processes that have led them to their involvement in the criminal justice system. Clients are to work through them at their own pace. The goal of the workbooks is to provide alternative, more pro-social ways of thinking and behaving in a variety of situations specific to the individual that result in successful community reintegration (i.e., the individual desists from crime). Furthermore, it is hoped that this change in thought process and behaviour will lead to the overall improvement in the clients' quality of life (e.g., improved sense of self-efficacy).

The workbooks were developed in accordance to the Flesch-Kincaid scale so that individuals with lower level reading skills would be able to complete them (see Table 4). Scores computed by this formula range from 0 to 100 , where higher scores indicate reading material that is easier to read. 
Table 4.

Readability of the Self-directed Workbooks

\begin{tabular}{lcc}
\hline \multirow{2}{*}{ Workbook Topic } & \multicolumn{2}{c}{ Flesch-Kincaid Scale } \\
\cline { 2 - 3 } & Grade Level & Reading Ease $^{\mathrm{a}}$ \\
\hline Motivation & 5.2 & 79.7 \\
Anger & 4.5 & 80.9 \\
Criminal Attitudes & 6.2 & 72.6 \\
Peer Relationships & 5.3 & 75.7 \\
Substance Abuse & 6.0 & 73.0 \\
\hline
\end{tabular}

${ }^{a}$ Higher scores indicate easier readability. Scores of 65 indicate plain English.

Within each workbook, the content is organized hierarchically from basic to more advanced. More specifically, the first few pages of the workbooks help the clients learn the core concepts and reflect on the choices and behaviours that have lead to their current situation. In the next set of pages the clients apply the core concepts to their specific life situations through a variety of activities (e.g., 'make a list of three factors that hold the highest risk for you' or 'what are your reasons for abstaining completely'). The clients are encouraged to reflect on these experiences and their responses. Finally, each workbook ends with a summary of what they've learned. Skill development is a process (i.e., awareness of new concepts, learning those new concepts, applying those new concepts to ones everyday activities) and these workbooks attempt to help to build the skills these individuals require to remain crime free in the community.

Outcome data. Initially, both probation sites were to provide a de-identified dataset that would list all of the charges each client had acquired approximately four months after the implementation of the workbooks; this timeframe was extended to seven months postimplementation. The number of charges for each individual was expected to vary, so the Cormier/Lang method, which assigns a weight to each charge type, was going to be used to code the most serious charge (Harris, Rice, Quinsey, \& Cormier, 2015). Next, the charges were to be recoded into four new variables: (1) technical violations (e.g., breach of supervision restrictions), 
(2) general recidivism, (3) violent recidivism and (4) any recidivism (i.e., technical violations or a new charge). For the current study, general recidivism was to include all charges for drug-, driving- or property-related offences, while violent recidivism was to include any charges related to assault, sexual assault, domestic abuse, robbery and armed robbery, or manslaughter and homicide. However, given the extremely small sample size, the data were recoded into: 1) technical violations and 2) any new charges.

Finally, time at risk was to be calculated using the supervision start date and the date of the new charge. For those individuals who did not receive a new charge, time at risk was to be calculated to the end of the follow-up period (i.e., December 2017). Unfortunately, while the supervision start date was provided in the dataset, the date of the new charge was not, meaning time at risk was unable to be calculated.

Client Satisfaction Survey. For the purposes of the current study, the Client Satisfaction Survey (see Appendix B) was developed in order to evaluate the usefulness of the self-directed workbooks. More specifically, the survey consisted of 10 Likert-scale questions that assessed participant views on the content and usability of each workbook (i.e., the same 10 questions are asked regarding each of the five workbooks). Clients were to provide responses for questions relating to each workbook that they had the opportunity to use. The specific survey used for the current study was compiled from other surveys and as such, normative data are unavailable. Therefore, the results of the survey were intended only to be descriptive and to aid in the improvement of the workbooks for future use, similar to work by Scheck et al. (2013)

\section{Procedure}

Phase one. The first phase of the current study required the implementation of the workbooks at the two probation sites. At the first site (Texas), an email recruitment notice (see 
Appendix C) was sent to the PO's that also included the informed consent (see Appendix D). PO's that consented to participate were then working with clients from both the control and experimental groups, as well as with those who choose not to participate. The PO's were given an instruction manual and script (see Appendix E) and attempted to recruit participants from their caseload. Once a participant agreed to participate and gave written consent (see Appendix F), the PO assigned the client a participant number that had previously been randomly assigned to either group using an online randomizer (see Appendix G). If the participant was assigned to the experimental group, they were provided the self-directed workbooks to use alongside the current probation services. At this location, POs acted as a support for using the workbooks - if clients had questions or wished to discuss the workbooks with their PO, they were encouraged to do so. If the participant was assigned to the control group, they followed the current community supervision of that site only. All clients who chose to participate received 10 hours of Community Service Restitution (CSR) credits, whether they were assigned to the control or the experimental group. Clients were then debriefed through an internal bulletin board notice that was posted partway through participant recruitment (see Appendix H).

At the second site (Iowa), the recruitment and implementation of the workbooks was to be consistent with one main difference; the PO's were to be unaware of whether or not the clients are participating. At this site, the clients were to work through the workbooks autonomously and any questions or concerns would be directed to a research assistant. However, a client may choose to self-identify to their PO their participation in the study. As we would have been unable to control for this situation occurring, it would have been an important consideration when comparing results of the two sites. The research assistant, who was to have signed a confidentiality agreement (see Appendix I) and would have received an instruction manual and 
script (see Appendix J), would recruit participants. Once a participant had agreed to participate and had given written consent (see Appendix K), the research assistant was to assign the client to a participant number that had been randomly assigned to either group using an online randomizer (see Appendix L). If the participant had been assigned to the experimental group, they were to be provided the self-directed workbooks to use alongside the current probation services. If the participant had been assigned to the control group, they were to follow the current correctional practices of that site only. Clients were to then be debriefed through an internal bulletin board notice that would be posted partway through participant recruitment (see Appendix M). Unfortunately, implementation at this probation site did not happen for a variety of reasons outside of the control of the researchers. Though analyses could not be conducted, expected results based on previous research will be discussed, as well as suggestions for future studies to consider in order to prevent a similar scenario from occurring.

Phase two. The second phase of the study was to take place approximately four months after the implementation of the workbooks. This portion of the study was to be conducted through the use of Qualtrics, an online survey tool. Qualtrics employs multiple tiers of security in an effort to ensure that all data remain secure. All accounts are password protected and Qualtrics employees are unable to access the accounts without expressed permission from the account owner. Participants were to be given an ID number once entering the Qualtrics system, which would allow them to retain anonymity. Firstly, an email recruitment letter (see Appendix N) was t obe sent out to the experimental group participants via their PO's. The email would briefly describe the nature of the study and would include a link to the client satisfaction survey (see Appendix B). In the event that a participant felt any discomfort or anxiety regarding the questions, participants would be presented with the option to leave the survey at any time by 
selecting 'I wish to leave the survey'. The selection of this button at any point during the survey would have lead participants directly to the debriefing form.

Once the participants arrived at the website, they would be required to read over the purpose of the study and to indicate that they understood, thus providing informed consent (see Appendix O). Participants would be informed that any identifying information provided during the course of the survey would not be disclosed to any third party individual or group and would also made aware of their right to withdraw from the study at any time, without consequence. If the participant did not consent, he or she would have been taken to the debriefing page (see Appendix P and Appendix Q). Once consent was provided, the participants would be asked to answer a short questionnaire about their views on the content and usability of each workbook. They would also be asked to provide basic demographic information (see Appendix B). Upon completion of the survey, participants would be taken to the debriefing page (see Appendix P and Appendix Q). The entire survey would have taken no more than 15 minutes.

Finally, outcome data (i.e., new offences and/or technical violations) was collected for all participants at the Texas site seven months after implementation was complete (i.e., December 2017). As stated previously, the probation site provided a de-identified dataset that would list charges each client had acquired since the sharing of the workbooks. 


\section{Results - Phase One}

\section{Data Preparation}

Missing data. First, key variables were screened for missing values. All key variables were complete, except the assigned PO variable that contained one missing value. Given the small amount of missing information, it was likely that the value was missing at random. However, a $t$-test and a chi-square analysis were conducted to determine whether the age and gender of the participant missing data on the PO variable differed from the age and gender of participants with completed data on the PO variable. No significant differences were identified ( $p$ $>.05)$, suggesting that the missing value was in fact missing at random. Data were also examined for accuracy across the key variables. There were no out of range values on any of the key variables.

Normality. Data were then screened for normality. Tabachnick and Fidell (2013) suggest that skewness and kurtosis become a concern when the ratio exceeds \pm 3.29 . Skewness and kurtosis ratios fell between the acceptable range (i.e., -3.29 and 3.29) for the age and education variables. Kolmogorov-Smirnov and Shapiro-Wilk tests were conducted in order to determine whether the data significantly differed from a normal distribution. The Kolmogorov-Smirnov and Shapiro-Wilk tests were not significant, which suggests that the current data did not significantly differ from a normal distribution $(\mathrm{p}>.01)$. Despite the small sample size $(N=32)$, violations or normality were not a concern.

Outliers. Data were then screened for univariate outliers. No extreme univariate outliers were identified upon visual inspection of boxplots and histograms. Z-scores were then calculated for age and education to confirm the absence of potential univariate outliers. There were no cases 
that had z-scores exceeding the standard cut-off (i.e., \pm 3.29 ; Tabachnick \& Fidell, 2013), suggesting that univariate outliers are not a concern.

Given the exploratory nature and very limited sample size of the current study, the research questions were addressed using relative frequencies, graphical representations, independent samples t-tests, and Fisher's exact tests. A brief comparison of the proposed and actual analyses is provided in Table 5.

Table 5.

Research Questions, Proposed and Actual Analyses

\begin{tabular}{|c|c|c|}
\hline Research Question & Proposed Analyses & Actual Analyses \\
\hline $\begin{array}{l}\text { 1. Do the individuals in the workbook } \\
\text { group differ on demographic } \\
\text { characteristics compared to those in the } \\
\text { control group? }\end{array}$ & $\begin{array}{l}\text { Chi-square and t-test } \\
\text { analyses }\end{array}$ & $\begin{array}{l}\text { Fisher's exact test and } \\
\text { t-test analyses }\end{array}$ \\
\hline $\begin{array}{l}\text { 2. Is there a significant difference in the } \\
\text { recidivism rates and time to failure } \\
\text { between the workbook and the control } \\
\text { groups? }\end{array}$ & Survival analyses & $\begin{array}{l}\text { Fisher's exact tests, } \\
\text { Unable to examine } \\
\text { time to failure }\end{array}$ \\
\hline $\begin{array}{l}\text { 3. What are the general views of the } \\
\text { clients in terms of the content and } \\
\text { usability of the self-directed workbooks? }\end{array}$ & Qualitative/Descriptive & Unable to conduct \\
\hline $\begin{array}{l}\text { 4. Do client views differ between the two } \\
\text { probation sites? }\end{array}$ & Qualitative/Descriptive & Unable to conduct \\
\hline
\end{tabular}

\section{Research Question One}

In order to examine whether the individuals in the workbook group differed on demographic characteristics compared to those in the control group, independent samples $t$-tests and Fisher's exact tests were conducted. Odds ratios and Cohen's $d$ were used to examine effect size. 
First, the assumptions for an independent samples $t$-test were examined. Each observation is independent of one another and normality was examined above and satisfied. Homogeneity of variance was examined using Levene's Test for Equality of Variances and was found to be nonsignificant (i.e., $p>.01$ ). All assumptions were met.

Next, the assumptions for a Pearson's chi-square test of independence were examined. Given that the results of one participant are independent on another participant's results, the condition was met. Next, the size of expected frequencies were examined as small values can potentially increase the probability of making a type 1 error (i.e., rejecting the null hypothesis when one should not). There is some debate among the literature as to what constitutes a small sample size, as well as how a small sample size will affect the results. For example, Gravetter \& Wallnau (2016) assert that if cell frequencies are less than five the chi-square test should not be used, while other researchers suggest that as long as the total sample size is larger than 8 , one should be less concerned about type 1 errors. Howell (2012) states that in cases of small cell sizes, having sufficient power to reject the null hypothesis will be a greater concern.

However, after an examination of the data, Fisher's exact test was utilised given expected cell sizes were less than 5 . This procedure is typically used on a 2 X 2 contingency table (i.e., two variables, each with two levels) with small samples, as the sampling distribution of the test statistic will be too divergent from a chi-square distribution to be useful. Thus, it was determined that this was the appropriate method of analyses.

An independent samples $t$-test was performed to examine the relationship between age and condition (see Table 6). The relationship between age and condition was not significant, $t(30, N=32)=.57, p>.01, d=.22,95 \%$ CI $[-.96, .54]$. However, the effect size was found to exceed Cohen's (1988) convention for a small effect $(d=.20)$. The distribution of age was 
examined using histograms separately for each group (see Figure 1 and Figure 2). The distribution was similar across each condition, with individuals in the experimental group being slightly younger than those in the control condition. Finally, an examination of the relative frequencies was conducted using age as a grouped variable (see Figure 3). The percentage of participants in the 30-39 years and 40-49 years age groups were similar across the two conditions. Twenty percent of the participants in the control condition were between the ages of 20-29 years, compared to $32 \%$ of the participants in the workbook condition. Finally, $20 \%$ of the participants in the control condition were between the ages of 50-59 years, compared to $9 \%$ of the participants in the workbook condition.

A Fisher's exact test was performed to examine the relationship between gender and condition (see Table 6$)$. The relationship between gender and condition was not significant $(N=$ $32, p>.01$, two-tailed. An examination of the relative frequencies was conducted next (see Figure 4). There were some gender differences across the conditions. In comparison to the control condition, the workbook condition had a higher percentage of males (i.e., $86 \%$ compared to $60 \%$ ) and a lower percentage of females (i.e., $14 \%$ compared to $40 \%$ ). Furthermore, men were 4.22 times more likely to be in the experimental group $(\mathrm{OR}=4.22,95 \% \mathrm{CI}[0.73,24.44])$.

A Fisher's exact test was performed to examine the relationship between race and condition (see Table 6). The relationship between race and condition was not significant $(N=32$, $p>.01$, two-tailed). An examination of the relative frequencies was conducted next (see Figure 5). In comparison to the control condition, the workbook condition had a lower percentage of Caucasian participants (82\% compared to $90 \%)$ and a higher percentage of participants who identified their race as other (18\% compared to $10 \%)$. Individuals who identified as Caucasian were .50 times more likely to be in the experimental group $(\mathrm{OR}=.50,95 \% \mathrm{CI}[.05,5.15)$. 
An independent samples $t$-test was performed to examine the relationship between education and condition (see Table 6). The relationship between education and condition was not significant, $t(30, N=32)=.00, p>.01, d=.00,95 \% \mathrm{CI}[-.75, .75])$. This was supported by the fact that the effect size did not exceed Cohen's (1988) convention for a small effect $(d=.20)$. The distribution of education was examined using histograms separately for each group (see Figure 6 and Figure 7). The distribution was similar across each condition, with individuals in the experimental group being slightly younger than those in the control condition. An examination of the relative frequencies was also conducted (see Figure 8). There was only slight variation in the education level of participants across the conditions. There was a higher percentage of participants who had less less than grade 12 (i.e., 36\% versus 30\%) and any level of higher education (i.e., 32\% versus 30\%), and a lower percentage of participants who had a grade 12 education (i.e., $32 \%$ versus $40 \%$ ).

A Fisher's exact test was performed to examine the relationship between previous offence and condition (see Table 6). The relationship between previous offence and condition was not significant, $(N=32, p>.01$, two tailed $)$. An examination of the relative frequencies was conducted next (see Figure 9). The workbook condition had a higher percentage of participants whose previous offence was a felony (i.e., $64 \%$ compared to $50 \%$ in the control condition) and a lower percentage of those with a misdemeanour (i.e., $50 \%$ compared to $36 \%$ ). Individuals whose previous offense was a felony were 1.75 times more likely to be in the experimental group $(\mathrm{OR}=$ $.1 .75,95 \%$ CI $[.39,7.95])$. 
Table 6.

Results of Independent Samples t-tests and Fisher's exact tests for Age, Gender, Race, Education and Previous Offence across Condition

\begin{tabular}{|c|c|c|c|c|c|}
\hline \multicolumn{2}{|l|}{ Demographics } & $t$ & $p$ & Effect size & $95 \% C I$ \\
\hline \multicolumn{2}{|l|}{ Age (years) } & $.57^{\mathrm{a}}$ & .57 & $.22^{\mathrm{c}}$ & {$[-.96, .54]$} \\
\hline \multicolumn{6}{|l|}{ Gender } \\
\hline & $\begin{array}{l}\text { Male } \\
\text { Female }\end{array}$ & - & $.17^{\mathrm{b}}$ & $4.22^{\mathrm{d}}$ & {$[0.73,24.44]$} \\
\hline Kace & $\begin{array}{l}\text { Caucasian } \\
\text { Other }\end{array}$ & - & $.99^{b}$ & $.50^{\mathrm{d}}$ & {$[.05,5.15]$} \\
\hline \multicolumn{2}{|c|}{ Level of Education (years) } & $.00^{\mathrm{a}}$ & .00 & $.00^{\mathrm{c}}$ & {$[-.75, .75]$} \\
\hline \multicolumn{6}{|c|}{ Previous Offence } \\
\hline & $\begin{array}{l}\text { Misdemeanour } \\
\text { Felony }\end{array}$ & - & $.70^{\mathrm{b}}$ & $1.75^{\mathrm{d}}$ & {$[.39,7.95]$} \\
\hline
\end{tabular}

${ }^{\mathrm{a}} t$-statistic. ${ }^{\mathrm{b}} p$ value for Fisher's exact test. ${ }^{\mathrm{c}}$ Cohen's $d$ value. ${ }^{\mathrm{d}}$ Odds ratio.

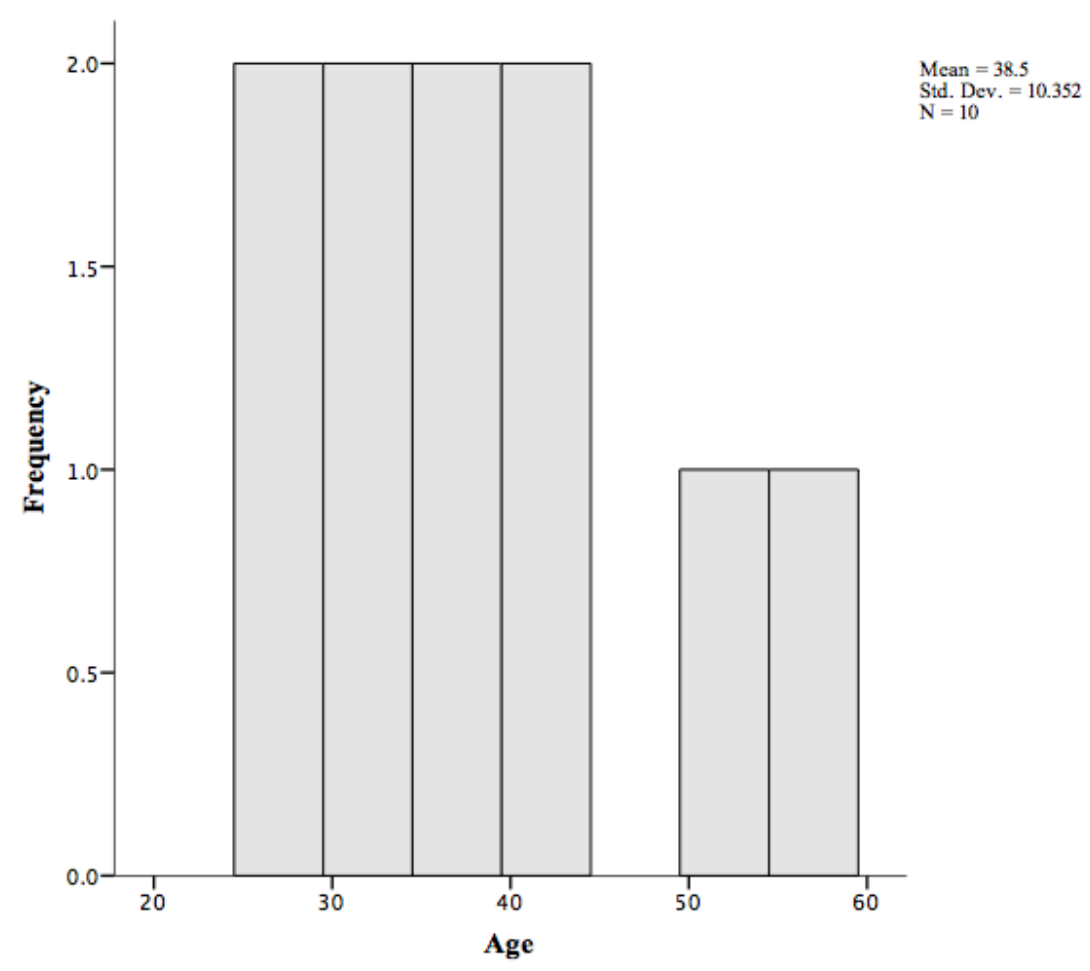

Figure 1. Histogram of Age Across the Control Condition. 


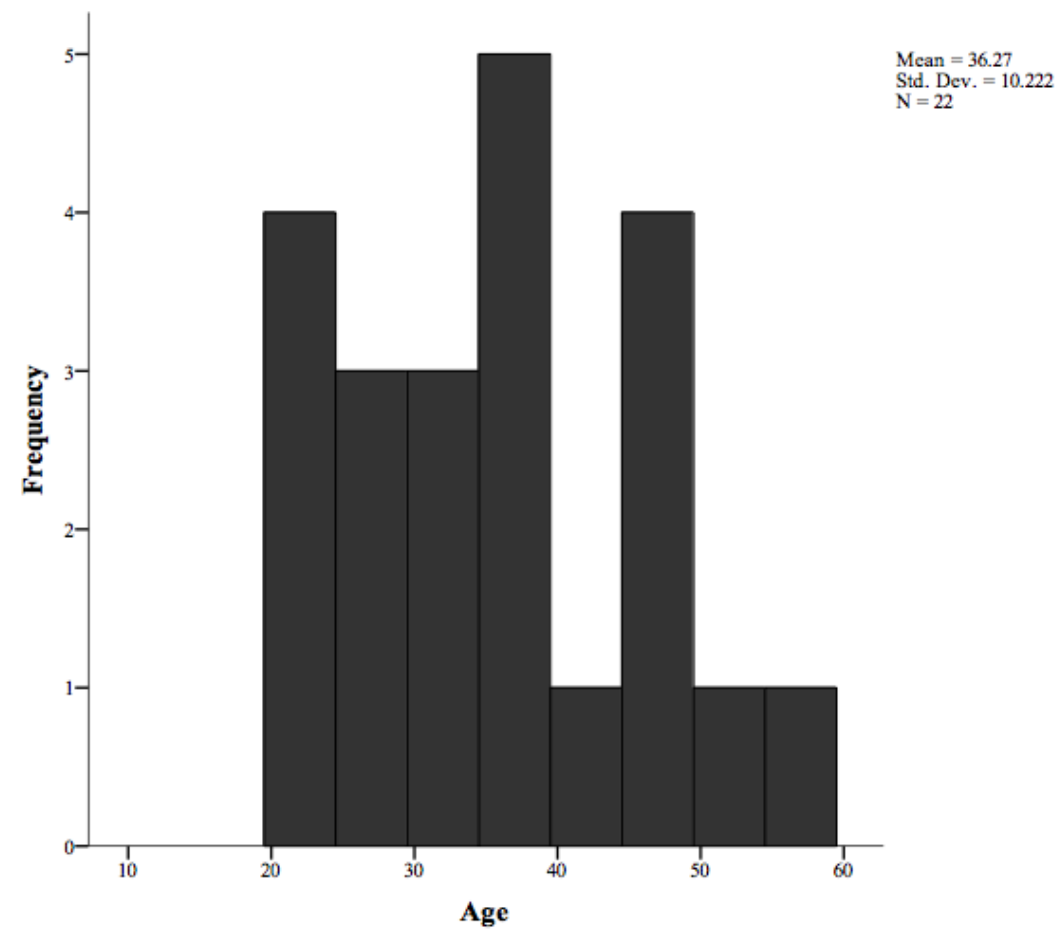

Figure 2. Histogram of Age Across the Experimental Condition.

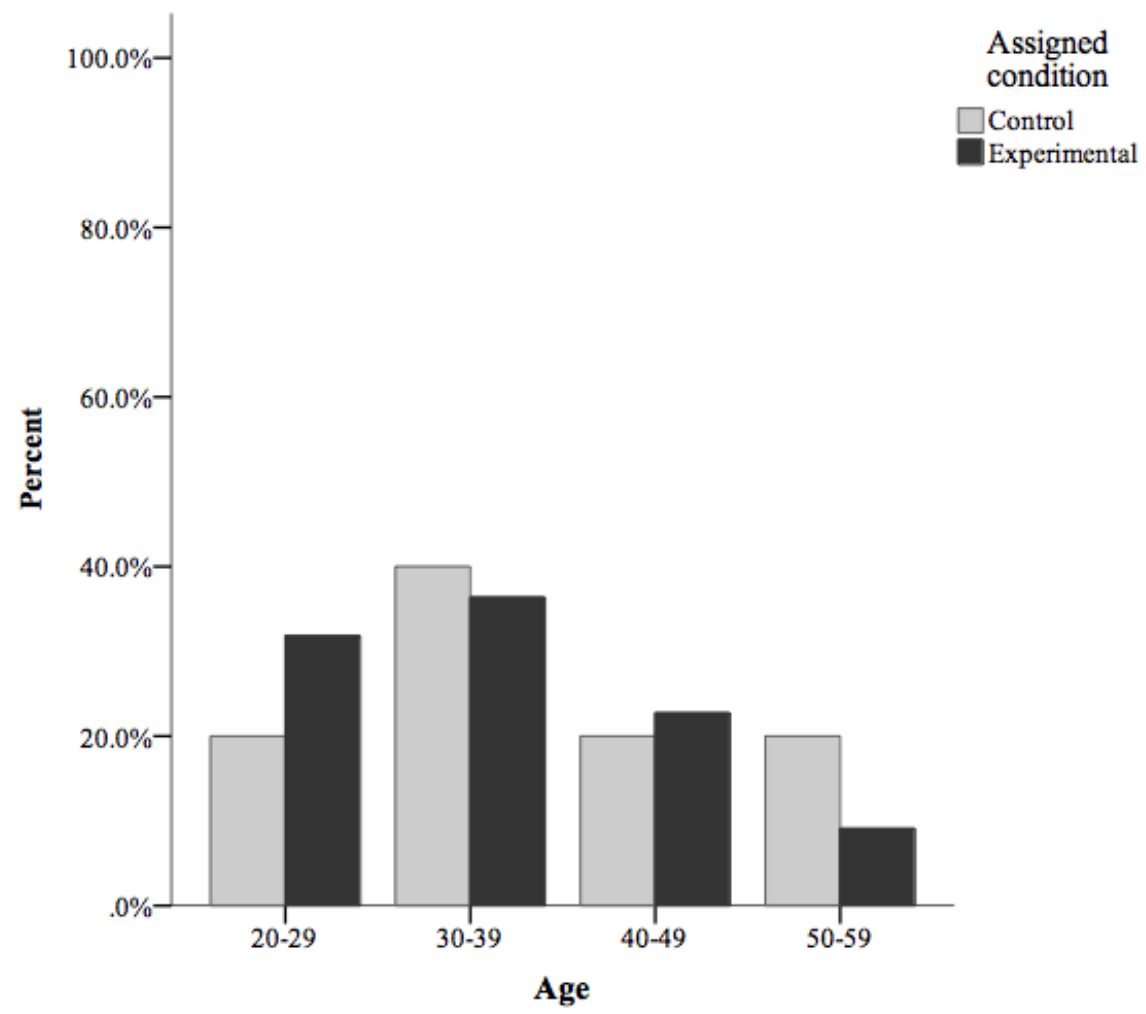

Figure 3. Relative frequencies of Age Groups Across Condition. 


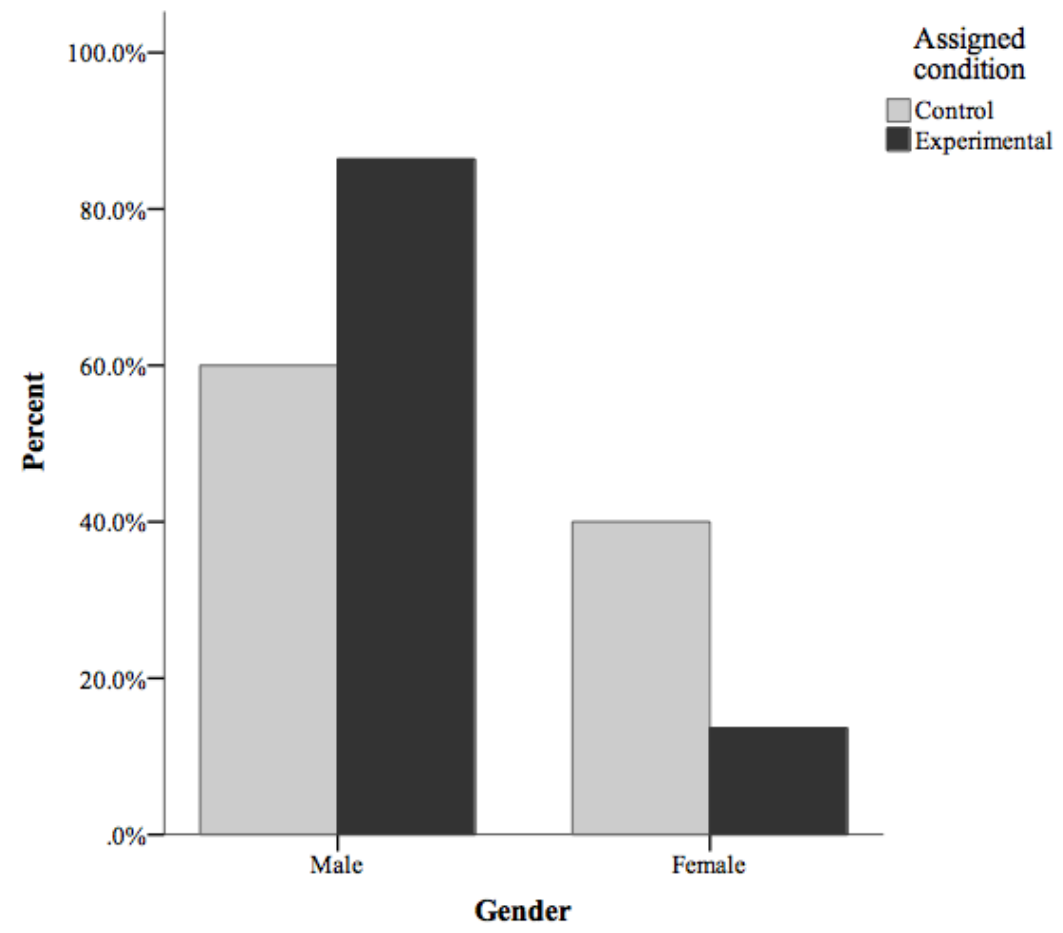

Figure 4. Relative frequencies of Gender Across Condition.

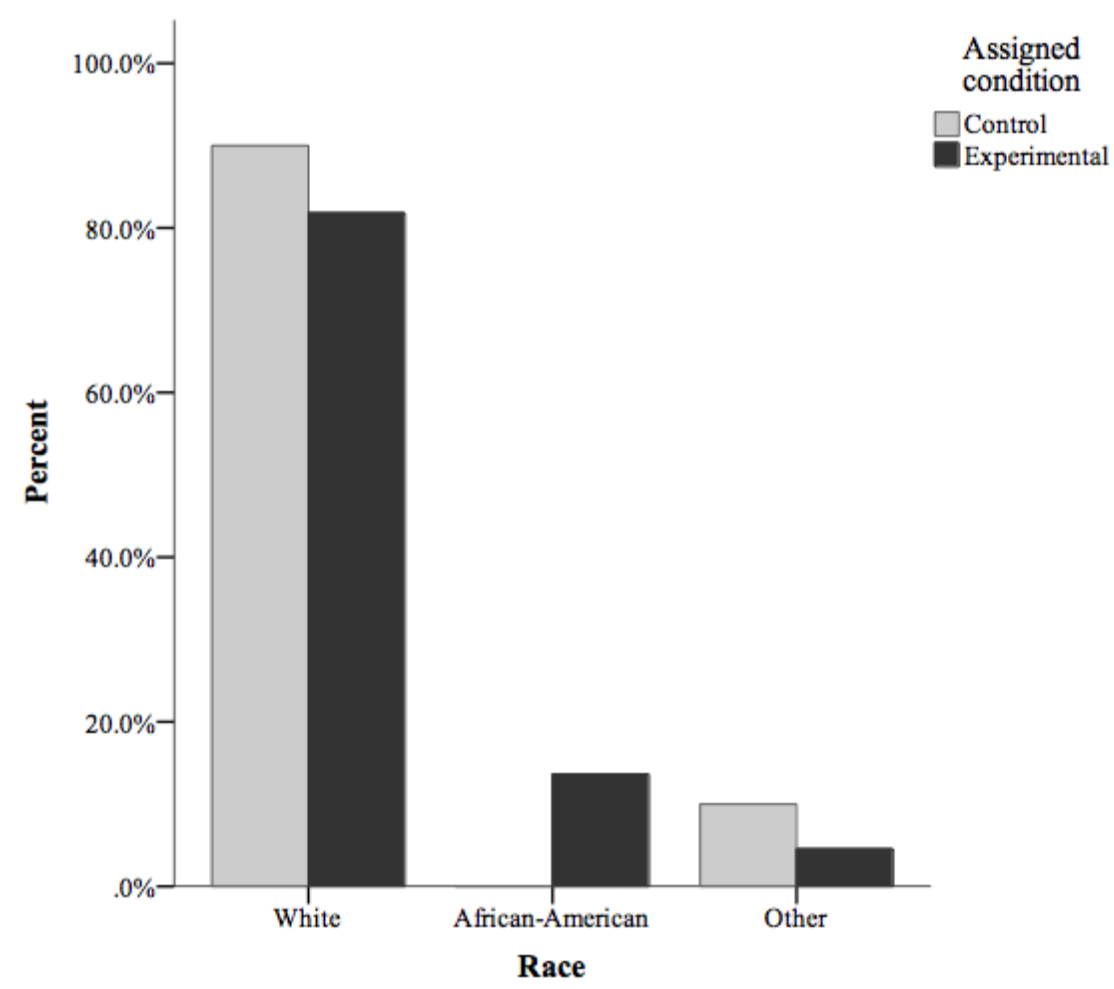

Figure 5. Relative frequencies of Race Across Condition. 


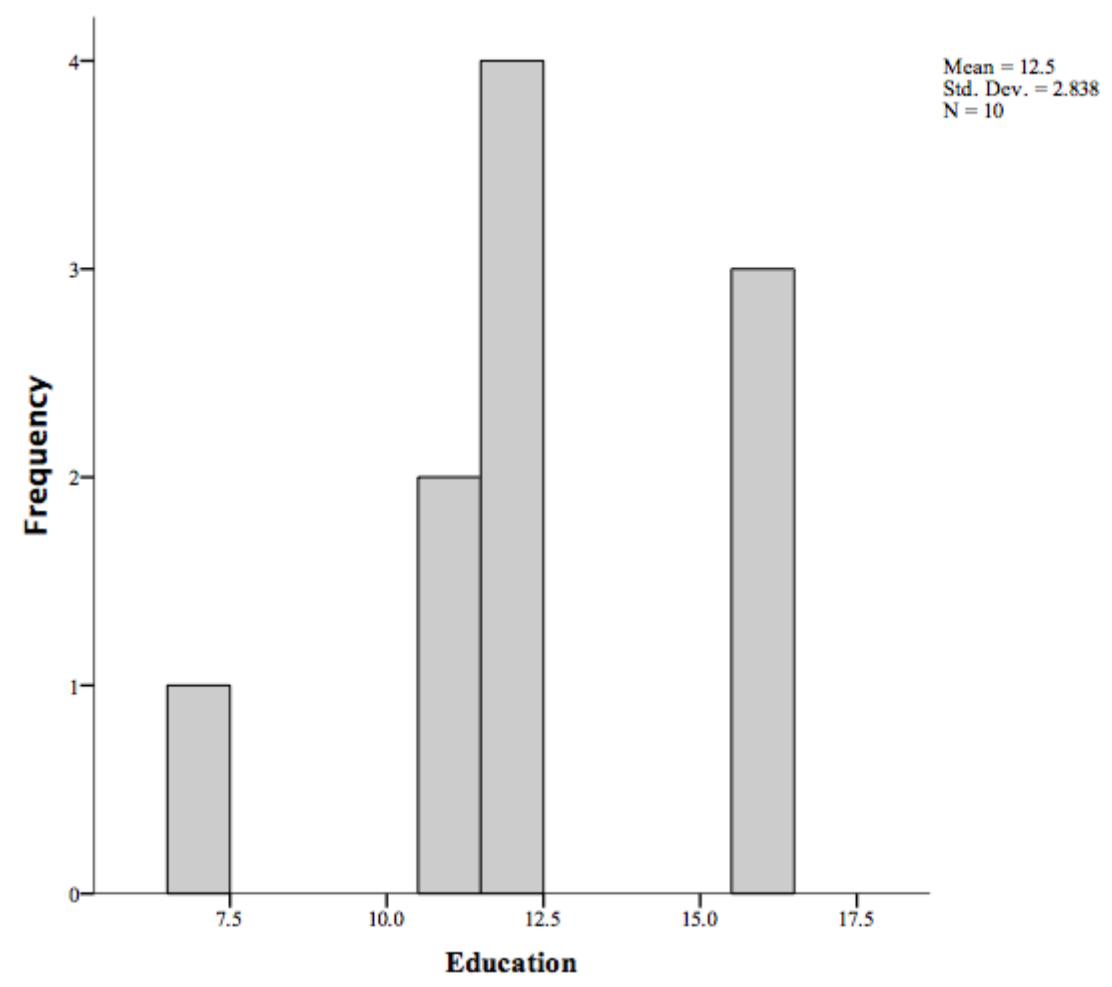

Figure 6. Histogram of Education Across the Control Condition.

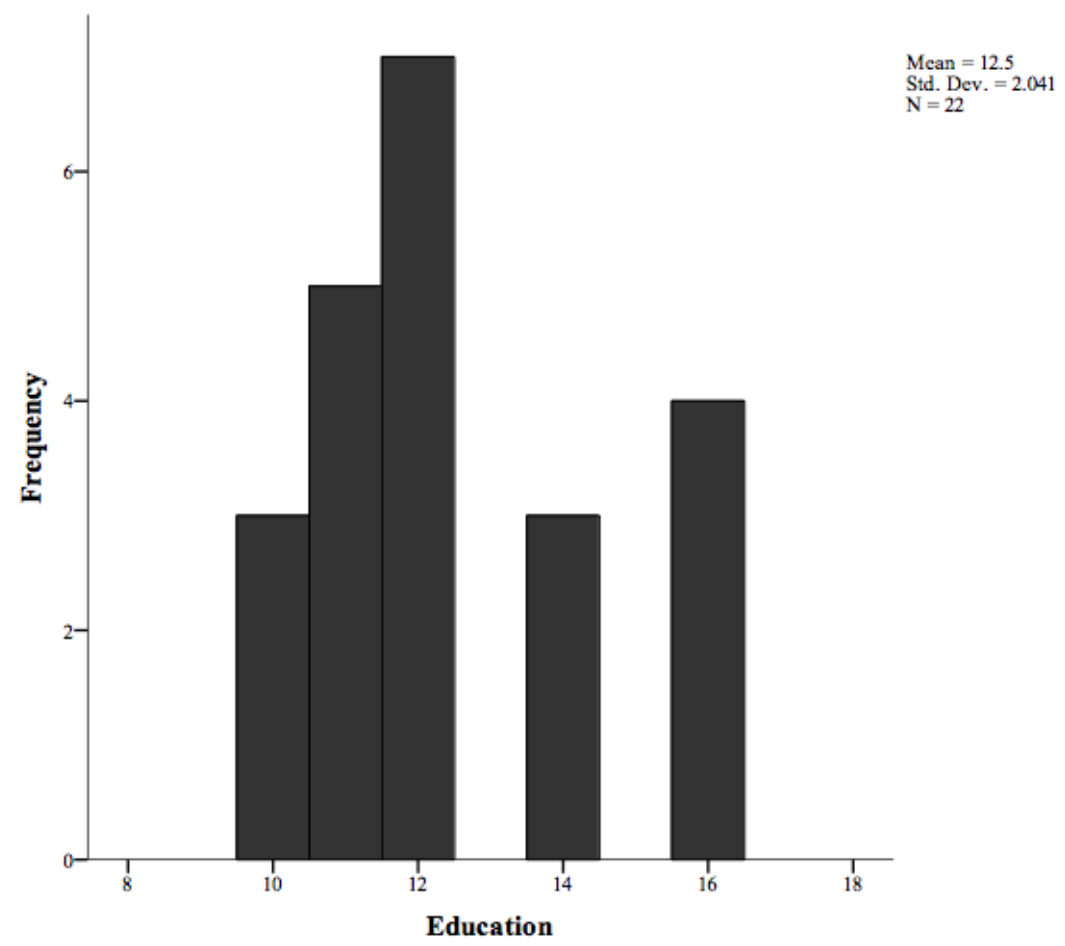

Figure 7. Histogram of Education Across the Experimental Condition. 


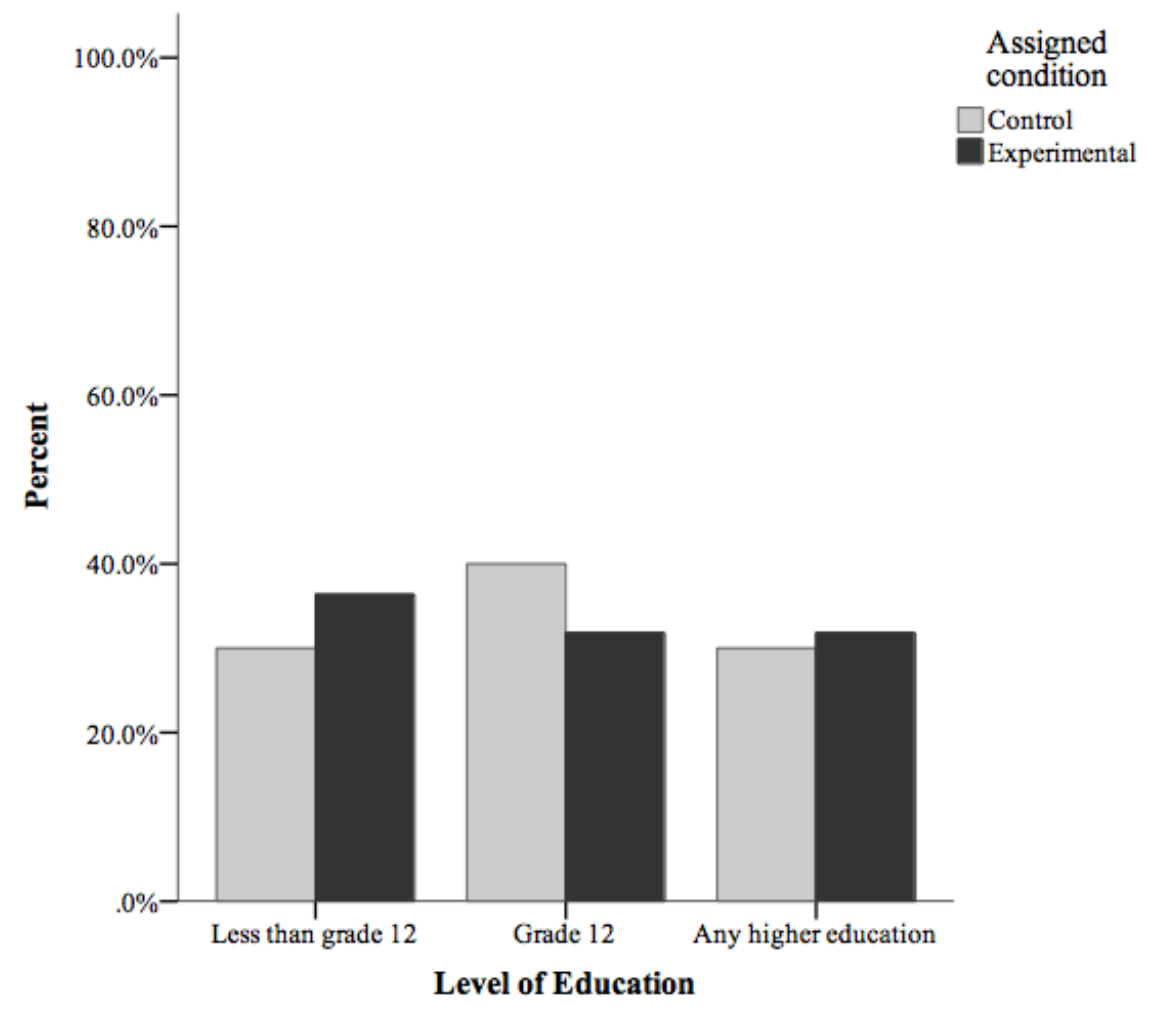

Figure 8. Relative frequencies of Level of Education Across Condition.

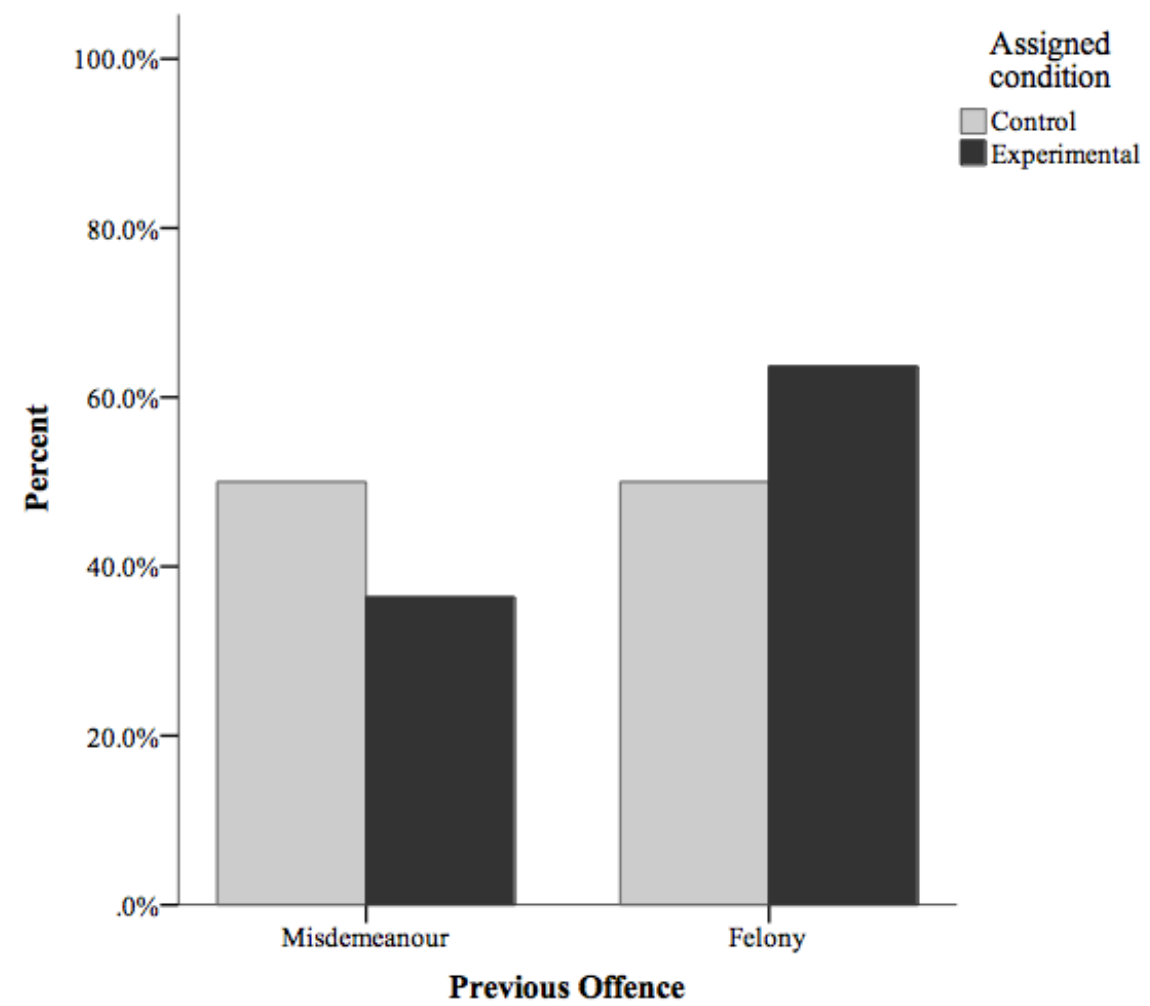

Figure 9. Relative frequencies of Previous Offence Across Condition. 


\section{Research Question Two}

In order to examine whether the individuals in the workbook condition significantly differed in technical violations or any new charges compared to those in the control group, Fisher's exact tests were conducted. Given the small sample size and the nature of the data that was received from the probation site, an examination of the time to failure across the conditions was unable to be conducted.

Differences between the conditions on recidivism. Comparisons were made between those in the experimental condition and those in the control condition for both technical violations and any new charges. Fisher's exact test was utilised to examine technical violations across the experimental and control conditions and then to examine the difference between the two conditions on any new charges. As stated previously, this procedure is typically used on a 2 X 2 contingency table (i.e., two variables, each with two levels) with a small sample. Thus, it was determined that this was the appropriate method of analyses for these data.

A Fisher's exact test was performed to examine the relationship between technical violations and condition (See Table 7). The relationship between technical violations and condition was not significant, $(N=32, p>.01$, two tailed $)$. An examination of the relative frequencies was conducted next (see Figure 10). The workbook condition had a lower percentage of participants who experienced a technical violation post-treatment (i.e., $50 \%$ compared to $80 \%$ in the control condition). Furthermore, individuals in the control group were 4.00 times more likely to have a technical violation than those in the experimental group $(\mathrm{OR}=4.00,95 \% \mathrm{CI}$ $[.69,23.26])$.

A Fisher's exact test was performed to examine the relationship between any new charges and condition (See Table 7). The relationship between any new charges and condition 
was not significant, $(N=32, p>.01$, two tailed $)$. An examination of the relative frequencies was conducted next (see Figure 11). The workbook condition had a lower percentage of participants who received a new charge post-treatment (i.e., 5\% compared to $10 \%$ in the control condition). Furthermore, individuals in the control group were 2.33 times more likely to have a new charge than those in the experimental group (OR $=2.33,95 \%$ CI $[.13,41.46])$.

Table 7.

Results of Fisher's exact tests for Technical violations and Any New Charges across Condition

\begin{tabular}{|c|c|c|c|c|c|c|}
\hline \multirow{2}{*}{ Outcome } & \multicolumn{2}{|c|}{ Condition } & \multirow{2}{*}{ Total } & \multirow{2}{*}{$p^{a}$} & \multirow{2}{*}{$O R^{b}$} & \multirow{2}{*}{$95 \% C I$} \\
\hline & Control & Experimental & & & & \\
\hline
\end{tabular}

Technical violation

$\begin{array}{lllllll}\text { Yes } & 80 \%(8) & 50 \%(11) & 59 \%(19) & & & \\ \text { No } & 20 \%(2) & 50 \%(11) & 41 \%(13) & & 4.00 & {[.69,23.26]}\end{array}$

Any new charges

\begin{tabular}{lcccccc} 
Yes & $10 \%(1)$ & $5 \%(1)$ & $6 \%(2)$ & \multirow{2}{*}{5} & 2.33 & {$[.13,41.46]$} \\
No & $90 \%(9)$ & $95 \%(21)$ & $94 \%(30)$ & .5 & & \\
\hline
\end{tabular}

${ }^{a} p$ value for Fisher's exact test. ${ }^{b}$ Odds ratio.

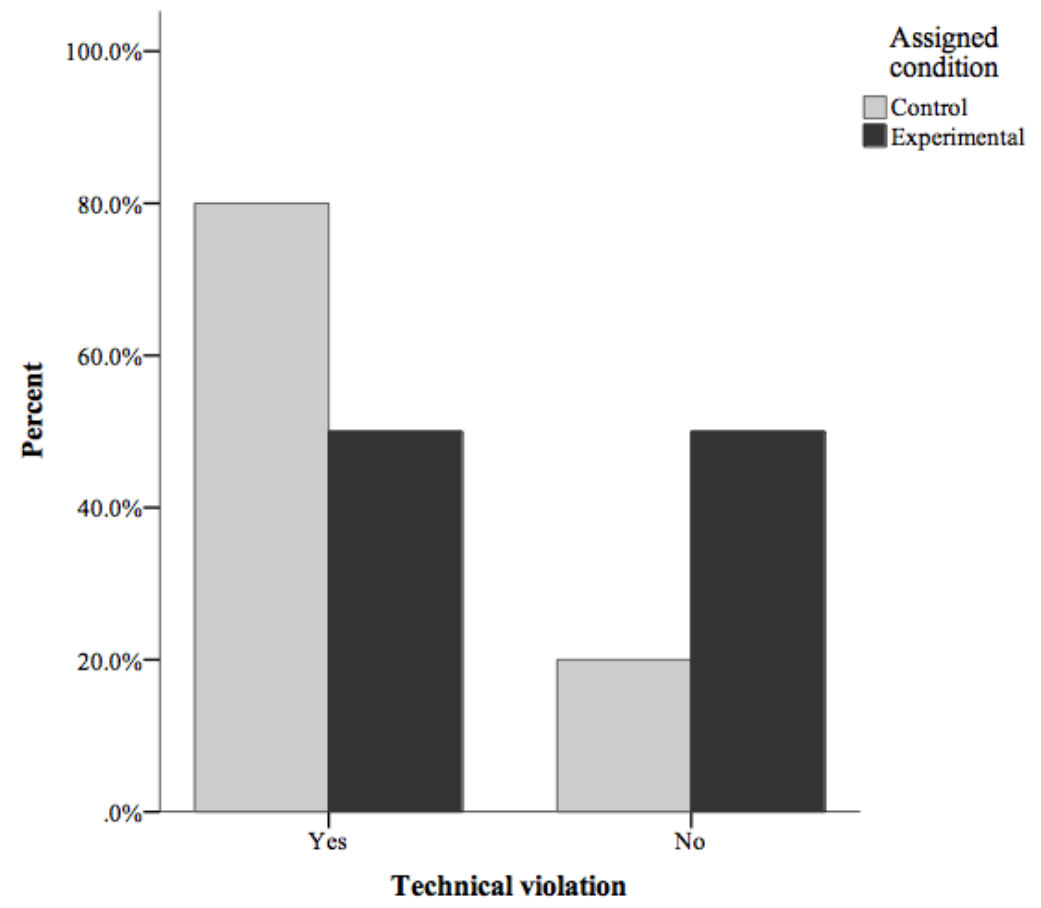

Figure 10. Relative frequencies of Technical Violation Across Condition. 


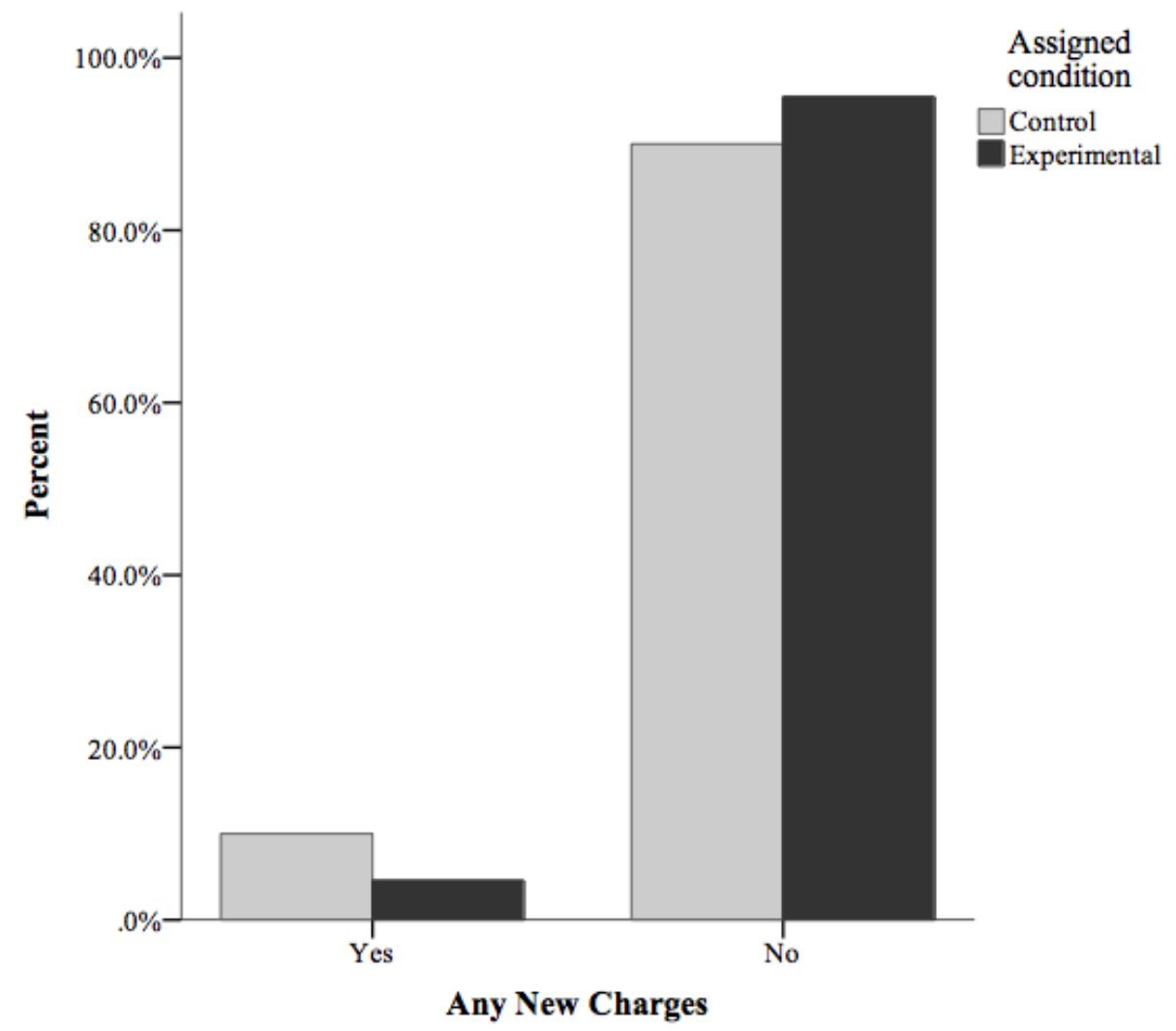

Figure 11. Relative frequencies of Any New Charges Across Condition.

Finally, analyses conducted with $\mathrm{G}^{*}$ Power indicated that all of the previous analyses were underpowered. A total sample of 44 participants would be needed to analyze the data with sufficient power (i.e., $80 \%$ power) for all of the above tests (i.e., $d f$ ranging from 1 to 3 ). Hence, a significantly larger sample would have been necessary to conduct the original planned analyses (e.g., survival analyses). 


\section{Results - Phase Two}

The online client feedback survey response rate was zero and therefore no analyses could be conducted to answer research question three (i.e., What are the general views of the clients in terms of the content and usability of the self-direction workbooks) or research question four (i.e., Did client views differ between the two probation sites). Though unfortunate given the purpose of the responses were to aid in determining the usefulness of these workbooks from the clients point of view, it was an unforeseen barrier in the data collection process. Expected results based on previous research and the implications will be considered in the discussion despite the lack of response, as well as suggestions for future studies in order to prevent a similar scenario. 


\section{Discussion}

The aim of this study was to explore the effectiveness and utility of a set of recently developed self-directed workbooks in a community supervision setting. While similar workbooks have been utilized in a variety of contexts with in-custody offender populations, this is one of the first studies to explore the use of workbooks with a community sample and their effect on recidivism. Thus, the descriptive nature of this study makes it the first step in determining the utility of these workbooks and the results of each research question will be discussed separately. Practical implications and limitations will then be discussed. Suggestions for future research will be discussed more generally at the end.

\section{Summary and Implications of Findings}

Research question one. It was hypothesized that there would be no major demographic differences between the workbook and control conditions given that participation was voluntary and a process was utilized to ensure random assignment to groups. While there were no significant differences on any of the demographic variables across the workbook and control conditions, there was some variation when the relative frequencies between the two conditions and effects sizes were examined. The participants in the workbook condition were more likely to be between the ages of 20-29 and to be male than those individuals in the control condition. The participants in the workbook condition were more likely to have a previous felony conviction than in the control condition. Most notably, men were 4.22 times more likely and those with a previous felony were 1.75 times more likely to be in the experimental group. It appears that the process used to ensure random assignment may not have been effective at ensuring equality between the two conditions (i.e., potentially due to unconscious selection bias), resulting in a potential higher risk experimental group. This is of concern as a higher risk experimental group 
may interfere with the potential to observe treatment effects. In this instance, the control group may be made up of individuals' who are more motivated to change and therefore may perform better (i.e., have less technical violations or new charges), which could act as a confound to any treatment effects that may occur. However, despite the fact that the groups were not equivalent, a small treatment effect was still observed.

It is also important to note that small effect sizes are to be expected given the nature of the sample. More specifically, this is a sample of low-risk clients and based on the RNR principles, it is expected that any observed treatment effects might be small (e.g., 3\% reduction in recidivism compared to $10 \%$ in high risk offenders; Bonta \& Andrews, 2017). Thus, even with a larger sample, observed treatment effects are likely to remain small in comparison to observed effects with higher-risk samples.

Research question two. It was also hypothesized that the individuals in the workbook groups would have lower rates of recidivism (i.e., either technical violations or new charges) and longer time to failure in comparison to the control groups. While there were no statistically significant differences on either outcome variable across the workbook and control conditions, there was some variation when the relative frequencies and effects sizes were examined. The participants in the workbook condition did appear to be less likely to have a technical violation or any new charges post-treatment compared to the control condition. This is further supported as individuals in the control group were 4.00 times more likely to have a technical violation and 2.33 times more likely to have any new charges, despite the fact that individuals in the workbook group were likely higher risk (i.e., younger, male, previous offense is a felony). This difference is also encouraging as some technical violations are related to factors that the workbooks target (e.g., avoiding substance use as a condition or probation). While the results of the current study 
are not enough to fully support the efficacy of the set of workbooks in a community supervision setting, the findings are encouraging.

It is likely that these non-significant results can be attributed to under-powdered analyses due to the small sample size. It is possible that with a larger sample, a significant relationship would have been observed, which would suggest that the self-directed workbooks had a positive impact on client behaviour in the community. One of the goals of these workbooks is to change both the cognitive patterns and resulting behaviour of the clients such that this change will lead to overall improvement in their quality of life. In other words, a client may improve their selfefficacy by remaining crime free through the use of these workbooks, which in turn could lead to more positive outcomes in other areas of their life. More specifically, the client may go on to not only acquire a job, but also find that they are able to succeed at it (i.e., maintain employment, take on more responsibility in their position and even receive a promotion). The development of self-efficacy through the workbook learning process has the potential to impact the clients in many positive ways beyond just the desistance in criminal behaviour.

Furthermore, this reduction in crime would not only would this improve public safety, it would also reduce the spending of government agencies (i.e., would not need to address as many technical violations or new crimes). Determining the effectiveness and usefulness of these workbooks would also give other supervision agencies reason to consider their implementation in the future, especially given the workbooks are public domain resources. In light of the success of similar workbooks with in-custody offender populations (e.g., Proctor, Hoffmann, \& Allison, 2012), it is not unrealistic to suggest that future research with these workbooks may produce favourable results for both probationers and agencies. 
Research questions three and four. Given previous feedback from clients on similar interventions (e.g., Scheck et al., 2013), it was hypothesized that clients would be satisfied with the structure and usefulness of the workbooks. It was also hypothesized that there would be no differences in client views between the two probation sites. Despite the fact that there were planned implementation differences between the two sites (i.e., PO's were to be unaware of who was in which group in the Iowa location), it was not expected that this would have a significant impact on the clients' views of the workbooks. While the data collection process did not go as planned when it came to the client satisfaction survey and the workbook implementation at the Iowa location, and therefore the results cannot be discussed, a brief explanation of expected results based on the responses similar surveys have received will be described.

As previously discussed, Sheck et al. (2013) observed high satisfaction ratings on their program from the offenders. Responses indicated that the most useful sections involved the creation of a change plan and the Interactive Journaling format itself. Overall, the offenders stated that they had learned a great deal, that this new information would be applicable, and that they planned to not only keep the journals, but to share them with others. Most important, these participants reported that the journals aided in their behaviour change.

Given that the workbooks utilised in the current study were based off previous research and similar journals, it is likely that the participants in this study would have responded with similar feedback. There is also no evidence to suggest that there would be any major differences between the two sites regarding feedback. However, if the participants at the Iowa probation site had reported more negative feedback, it could likely be due to the fact that they did not have the support of their PO. As previously discussed, verbalizing certain types of spoken language has been linked with change and, as such, client speech acts as a predictor of outcome. (e.g., 
Kohlenberg \& Tsai, 2007; Brown \& Miller, 1993). While these workbooks have been designed to simulate motivational interviewing in a written format by structuring writing tasks that evoke language to promote change - both thoughts and behaviour, it would make sense that having the PO as a support in the development of self-efficacy by reminding the client of their personal strengths and past successes is likely to improve clients' views on the intervention, as well as their behaviour (Bourgon, Gutierrez, \& Ashton, 2011). Furthermore, POs could assign particular sections of the workbooks for clients to work on at a time, which would potentially increase the interventions effectiveness given that spreading the writing over a longer period of time is associated with larger effect sizes (e.g., Pennebaker, 1997; Smyth, 1998).

\section{Limitations}

Originally, this study was to be implemented at two probation sites in the US. Unfortunately, organizational changes at one probation site lead to implementation delays that ultimately resulted in the study being dropped from the site in Iowa. This impacted both phase one and phase two of the research project, which meant a comparison of the two sites was unable to be conducted. It would have been beneficial to examine both the differences in outcomes and client feedback responses between the two sites, as it would have allowed us to understand whether or not PO involvement was a necessary factor for the efficacy of the treatment.

It is also important to note the lack of response to the client feedback survey. As the survey was conducted online, there is the possibility that clients may have only had access to the survey while at the probation site or in a shared space (i.e., public library). This may have resulted in participants a) deciding that completing the survey would take too much time or effort or b) forgetting that they had a survey to complete. It is also possible that the survey link was not forwarded to all of the participants via the probation site for a variety of reasons (e.g., client's 
supervision term had been completed or their name was missed off the list). Finally, it is also possible that participants just did not want to complete the online survey. While participants received compensation in the form of CSR credits for their involvement in phase one, they did not receive any compensation for their involvement in phase two of this study.

The next limitation was the small sample size and resulting inadequate power, which prohibited the use of most inferential statistical procedures. The observed findings should be considered preliminary at most and further investigation with a larger sample is necessary. Furthermore, this resulted in limiting the generalizability of any findings to the target population of clients under community supervision. While the sample size was barely adequate for the purpose of the current study in its preliminary nature, a significantly larger sample would be necessary for more in-depth analyses, including those regarding subgroups and survival analyses.

The fourth limitation is that information regarding the clients' motivation and readiness to change and perceived self-efficacy prior to workbook implementation, which are important factors to consider, were not examined. Scheck et al. (2013) observed a weak correlation between knowledge and attitude, suggesting that education alone does not infer an adequate level of motivation in order to promote successful behaviour change, at least in the context of substance use behaviours. Data on previous and current programming that clients had received or were currently receiving was also unable to be collected. Controlling for prior experience could be important in understanding the incremental utility of journaling.

It is also important to note that the reading level of clients' was not formally assessed prior to the implementation of the workbooks. Illiteracy could have potentially been identified if the client requested that the PO read the consent form to them during the recruitment process. If a client had requested this change in procedure, this could have presented challenges surrounding 
the integrity of the intervention itself. Given that it is possible that illiterate clients may not have come forward for a variety of reasons, embarrassment for example, a brief literacy check prior to the implementation of intervention materials in future studies may be a suitable solution. Of note, no clients requested that the PO read aloud the consent form during the recruitment process of the current study. All text included in the workbooks is intended for individuals with a reading level between the grades of 4 and six. Furthermore, the text is broken up into short, easy to digest sections and there are a variety of graphics to accompany the key concepts, mitigating the potential challenge of reading ability.

Finally, the location of the probation site that did implement the workbooks has a significantly higher proportion of Hispanic individuals than other areas of both Texas and the US. Thus, one would need to be cautious in extrapolating the findings to settings with a significantly different ethnic breakdown.

\section{Future Research}

Given the aforementioned limitations, several over-arching suggestions for future research on the self-directed workbooks are put forth. First, in order to prevent having such a small sample size, it may be more effective to use a matched sample based on either exact matching or propensity matching instead of a control group, as this will allow for a larger experimental group without significantly compromising the conclusions that could be made.

Second, running a focus group in order to assess the participants' views on the usability of the workbooks may prevent a no-response situation, as well as allow for more detailed responses from the participants. With a higher level of detailed responses in a semi-structured interview setting, a thematic analysis of the responses and suggestions for changes to the 
workbooks could be conducted. It is also possible that just providing participants' with a paper copy of the survey would have increased responses.

Third, once the set of workbooks had been validated as an effective intervention for offenders under community supervision, it would be beneficial to examine whether they are more effective for different subgroups of offenders (e.g., men versus women, sexual offenders, violent offenders, etc.).

Finally, given the high rates of mental health diagnoses in this population (see Prins [2014] for a systematic review), future research should consider the impact of major mental health disorders on the efficacy of this intervention. Studies that evaluate the potential mediators and moderators of efficacy could further refine our understanding of the merits of self-directed workbooks and journaling.

\section{Conclusion}

Despite the limitations, the preliminary results of the current study, in combination with research on similar interventions, do suggest that self-directed workbooks may have potential in reducing both technical violations and recidivism among supervised offenders in the community. Though much more research is necessary to make stronger conclusions that could inform change to policy and practice, this is a sufficient first step or proof of concept to expanding this type of intervention to the offender population under community supervision. When combined with results from similar research, this form of intervention appears to be well received by PO's and clients, requires minimal interaction, is cost effective and time efficient, may have the potential to reduce both technical violations and recidivism, and most importantly, may have the potential to impact the clients lives beyond just the desistance from crime. 


\section{References}

Alexander, M. \& VanBenschoten, S. W. (2008). Motivational interviewing training in criminal justice: Development of a model plan. Federal Probation, 72(2), 61-66.

Andrews, D. A., \& Bonta, J. (2010) Rehabilitating criminal justice policy and practice. Psychology, Public Policy, and Law, 6, 39-55.

Andrews, D. A., Bonta, J., \& Hoge, R. D. (1990). Classification for effective rehabilitation: Rediscovering psychology. Criminal Justice and Behaviour, 17(1), 19-56.

Andrews, D.A., Bonta, J., \& Wormith, J.S. (2004). The Level of Service/Case Management Inventory (LS/CMI). Toronto, Canada: Multi-Health Systems.

Andrews, D. A., Bonta, J., \& Wormith, S. J. (2006). The recent past and near future of risk and/or need assessment. Crime and Delinquency, 52, 7-27. doi: $10.1177 / 0011128705281756$

Andrews, D. A., \& Dowden, C. (2004). Managing correctional treatment for reduced recidivism: A meta-analytic review of programme integrity. Legal and Criminological Psychology, 10, 173-187. doi:10.1348/135532505X36723

Apodaca, T. R., \& Miller, W. R. (2003). A meta-analysis of the effectiveness of bibliotherapy for alcohol problems. Journal of Clinical Psychology, 59, 289-304. doi:10.1002/jclp. 10130

Austin, K. P., Williams, M. W. M., \& Kilgour, G. (2011). The effectiveness of motivational interviewing with offenders: An outcome evaluation. New Zealand Journal of Psychology, 40(1), 55-67.

Bandura, A. (1977). Self-efficacy: Toward a unifying theory of behavioral change. Psychological Review, 84(2), 191-215. 
Bandura, A. (1982). Self-efficacy mechanism in human agency. American Psychologist, 37, 122147.

Baumeister, R. F., \& Vohs, K. D. (2007). Self-regulation, ego depletion and motivation. Social and Personality Psychology Compass, 1(1), 115-128. doi: 10.1111/j.17519004.2007.00001.x

Bem, D. J. (1972). Self-perception Theory. Advances in Experimental Social Psychology, 6(C), $1-62$.

Blenkiron, P. (2001). Coping with depression: A pilot study to assess the efficacy of a self-help audio cassette. British Journal of General Practice, 51, (366-370).

Bonta, J. \& Andrews, D. A. (2017). The psychology of criminal conduct ( $7^{\text {th }}$ ed.), New York, NY: Routledge.

Bower, P., Richards, D., \& Lovell, K. (2001). The clinical and cost-effectiveness of self-help treatments for anxiety and depressive disorders in primary care: A systematic review. British Journal of General Practice, 51 (471), 838-845.

Bourgon, G., Gutierrez, L., \& Ashton, J. (2011). The Evolution of Community Supervision Practice: The Transformation from Case Manager to Change Agent. Irish Probation Journal, 8, 28-48.

Bourgon, G, \& Gutierrez, L. (2012). The general responsivity principle in community supervision: The importance of probation officers using cognitive intervention techniques and its influence on recidivism. Journal of Crime and Justice, 35(2), 149-166. doi: 10.1080/0735648X.2012.674816 
Brennan, T., \& Oliver, W.L. (2000). Evaluation of reliability and validity of COMPAS scales: National aggregate sample. Traverse City, MI: Northpointe Institute for Public Management.

Brown, J. M. \& Miller, W. R. (1993). Impact of motivational interviewing on participation and outcome in residential alcoholism treatment. Psychology of Addictive Behaviours, 7(4), 211-218.

Burrowes, N., \& Needs, A. (2009). Time to contemplate change? A framework for assessing readiness to change in offenders. Aggression and Violent Behaviour, 14(1), 29-49. doi:10.1016/j.avb.2008.08.003

Carter, M. M. \& Sankovitz, R. J. (2014). Dosage probation: Rethinking the structure of probation sentences. Centre for Effective Public Policy, NCJ 245395. Retrieved from: https://www.ncjrs.gov/App/Publications/abstract.aspx?ID=267480

Clancy, J. (1961). Procrastination: A defense against sobriety. Quarterly Journal of Studies on Alcohol, 22, 269-276.

Cochrane, A. L., (1972). Effectiveness and Efficiency: Random Reflections on Health Services, London, England: Royal Society of Medicine Press.

Cohen J. (1988). Statistical Power Analysis for the Behavioral Sciences. New York, NY: Routledge Academic.

Criminal Justice Connections (2015, January/February). The Teas Risk Assessment System: A new direction in supervision planning, 22 (3). Retrieved from: https://www.tdcj.state.tx.us/connections/JanFeb2015/Images/JanFeb2015 agency TRAS $\underline{\text { S.pdf }}$ 
Cuijpers, P. (1997). Bibliotherapy in unipolar depression: A recta-analysis. Journal of Behavior Therapy and Experimental Psychiatry, 28, 139-147. doi:10.1016/S0005-7916(97)000050

Davidson, J. T., Crawford, R., \& Kerwood, E. (2008). Constructing an EBP post-conviction model of supervision in United States Probation, District of Hawaii: A case study. Federal Probation, 72(2), 22-28.

Deci, E. L., \& Ryan, R. M. (1985). Intrinsic motivation and self-determination in human behavior. New York: Plenum.

de Vries Robbé, M., de Vogel, V., Douglas, K. S., \& Nijman, H. L. (2015). Changes in dynamic risk and protective factors for violence during inpatient forensic psychiatric treatment: Predicting reductions in post discharge community recidivism. Law and Human Behavior, 39(1), 53-61. doi:10.1037/lhb0000089

DiCicco, L., Unterberger, H., \& Mack, J. E. (1978). Confronting denial: An alcoholism intervention strategy. Psychiatric Annals, 8, 596-606.

DiClemente, C. C., Schlundt, D., \& Gemmell, L. (2004). Readiness and stages of change in addiction treatment. American Journal on Addictions, 13(2), 103-119. DOI: $10.1080 / 10550490490435777$

Douglas, K. S., \& Skeem, J. L. (2006). Violence risk assessment: Getting specific about being dynamic. Psychology, Public Policy, and Law, 11, 347-383. doi: 10.1037/10768971.11.3.347

Dowden, C., \& Andrews, D. A. (2004). The importance of staff practice in delivering effective correctional treatment: A meta-analytic review of core correctional practices. 
International Journal of Offender Therapy and Comparative Criminology, 48(2), 203214. doi: $10.1177 / 0306624 X 03257765$

Durose, M. R., Cooper, A. D., \& Snyder, H. N. (2014). Recidivism of Prisoners Released in 30 States in 2005: Patterns from 2005 to 2010. Special Report. NCJ 244205. Washington, DC: U.S. Department of Justice, Office of Justice Programs, Bureau of Justice Statistics.

Frattaroli, J. (2006). Experimental disclosure and its moderators: A meta-analysis. Psychological bulletin, 132(6), 823-865. doi: 10.1037/0033-2909.132.6.823

French, S. A. \& Gendreau, P. (2006). Reducing prison misconducts: What works! Criminal Justice and Behaviour, 33(2), 185-218. doi: 10.1177/0093854805284406

Friedmann, P. D., Taxman, F. S., \& Henderson, C. E. (2007). Evidence-based treatment practices for drug-involved adults in the criminal justice system. Journal of Substance Abuse Treatment, 32, 267-277. doi:10.1016/j.jsat.2006.12.020

Folk, J. B., Blasko, B. L., Warden, R., Schaefer, K., Ferssizidis, P., Stuewig, J., \& Tangney, J. P. (2016). Feasibility and acceptability of an impact of crime group intervention with jail inmates. Victims \& Offenders, 11(3), 426-454. doi: 10.1080/15564886.2014.982777

Gendreau, P., \& Andrews, D. A. (2001). Correctional Program Assessment Inventory (CPAI2000). St. John, Canada: University of New Brunswick.

Gendreau, P., Goggin, C., \& Smith, P. (1999). The forgotten issue in effective correctional treatment: Program implementation. International Journal of Offender Therapy and Comparative Criminology, 43(2), 180-187.

Gravetter, F. J., and Wallnau, L. B. (2016). Statistics for the Behavioral Sciences $10^{\text {th }}$ ed. Wadsworth Publishing: Belmont, CA. 
Harris, G. T., \& Rice, M. E. (2003). Actuarial assessment of risk among sex offenders. Annals of New York Academy of Sciences, 989, 198-210. doi: 10.1111/j.1749- 6632.2003.tb07306.x

Harris, G. T., \& Rice, M. E. (2015). Progress in Violence Risk Assessment and Communication: Hypothesis versus evidence. Behavioral Sciences and the Law, 33, 128-145. doi: $10.1002 / \mathrm{bs} 1.2157$

Harris, G. T., Rice, M. E., Quinsey, V. L., \& Cormier, C. A. (2015). Violent offenders: Appraising and managing risk $3^{\text {rd }}$ ed. American Psychological Association: Washington, DC.

Herberman, E. J., \& Bonczar, T. P. (2014) Probation and Parole in the United States, 2013. Bulletin. NCI 248029, Washington, DC: U.S. Department of Justice, Office of Justice Programs, Bureau of Justice Statistics.

Hettema, J., Steele, J., Miller, W. R. (2005). Motivational Interviewing. Annual Review of Clinical Psychology, 1, 91-111. doi: 10.1146/annurev.clinpsy.1.102803.143833

Horney, J., Osgood, D. W., \& Marshall, I. H. (1995). Criminal careers in the short-term: Intraindividual variability in crime and its relation to local life circumstances. American Sociological Review, 60, 655-673. doi: 10.2307/2096316

Howell, D. C. (2012). Statistical Methods for Psychology $8^{\text {th }}$ ed. Wadsworth Publishing: Belmont, CA.

Kaeble, D., and Bonczar, T. P. (2016). Probation and Parole in the United States, 2015. Bulletin. NCI 250230, Washington, DC: U.S. Department of Justice, Office of Justice Programs, Bureau of Justice Statistics.

Kaeble, D., Glaze, L., Tsoutis, A., and Minton, T. (2015). Correctional Populations in the United States, 2014. Bulletin. NCI 249531, Washington, DC: U.S. Department of Justice, Office of Justice Programs, Bureau of Justice Statistics. 
Kazemian, L., \& Maruna, S. (2009). Desistance from crime. In M. D. Khron et al. (Eds.), Handbook on crime and deviance (pp. 277-295). NY: Springer.

Kohlenberg, R. J., \& Tsai, M. (2007). Functional analytic psychotherapy: Creating intense and curative therapeutic relationships. New York, NY: Springer.

Kroner, D. G., \& Yessine, A. K. (2013). Changing risk factors that impact recidivism: in search of mechanisms of change. Law and Human Behavior, 37, 321-336. doi:10.10.7/1hb0000022

Latessa, E. J., \& Lovins, B. (2010). The role of offender risk assessment: A policy maker guide. Victims and Offenders, 5, 203-219. doi: 10.1080/15564886.2010.485900

Latessa, E. J., Smith, P, Lemke, R., Makarios, M., and Lowenkamp, C. (2009). Creation and Validation of the Ohio Risk Assessment System Final Report. University of Cincinnati. Retrieved from: www.uc.edu/ccjr/reports

Lowenkamp, C. T. (2004). Correctional program integrity and treatment effectiveness: A multisite, program level analysis. Unpublished doctoral dissertation, University of Cincinnati, $\mathrm{OH}$.

Lowenkamp, C. T., Latessa, E. J., \& Smith, P. (2006). Does correctional program quality really matter? The importance of adhering to the principles of effective intervention. Criminology and Public Policy, 5, 575-594, http://dx.doi.org/10.1016/j.avb.2012.09.002

Marrs, R. W. (1995). A meta-analysis of bibliotherapy studies. American Journal of Community Psychology, 23, 843-870. doi: 10.1007/BF02507018

Matthews, B., Hubbard, D. J., \& Latessa, E. (2001). Making the next step: Using evaluability assessment to improve correctional programming. The Prison Journal, 81(4), 454-472. doi: $\underline{10.1177 / 0032885501081004003}$ 
McGuire, J. (2002). Criminal sanctions versus psychologically-based interventions with offenders: A comparative empirical analyses. Psychology, Crime \& Law, 8, 183-208. doi: $10.1080 / 10683160208415005$

McMurran, M. (2009). Motivational interviewing with offenders: A systematic review. doi: $10.1348 / 135532508 \times 278326$

Miller, W. R. (1983). Motivational interviewing with problem drinkers. Behavioural Psychotherapy, 11, 147-172.

Miller, W. R., \& Rollnick, S. (2013). Motivational interviewing: Helping people change (3rd ed.). New York, NY: Guilford Press.

Monahan, J., \& Skeem, J. L. (2013). Risk redux: The resurgence of risk assessment in criminal sanctioning. Public Law and Legal Theory Research Paper Series, 2013-36. University of Virginia School of Law.

Mossière, A. Serin, R. (2014). A critique of models and measures of treatment readiness in offenders. Aggression and Violent Behaviour, 19(4), 383-389. doi: 0.1016/j.avb.2014.06.004

National Institute for Health and Clinical Excellence. (2011). Generalized Anxiety Disorder in Adults: Management in primary, secondary and community care. Great Britain: The British Psychological Society and The Royal College of Psychiatrists.

Nesovic, A. (2003). Psychometric evaluation of the correctional program assessment inventory (CPAI) (Order No. NQ83525). Available from Dissertations \& Theses @ Carleton University; ProQuest Dissertations \& Theses Global. (305346242). Retrieved from http://proxy.library.carleton.ca/login?url=https://search-proquestcom.proxy.library.carleton.ca/docview/305346242?accountid=9894 
Olver, M. E., Beggs Christofferson, S. M., Grace, R. C., \& Wong, S. C (2014). Incorporating change information into sexual offender risk assessments using the Violence Risk ScaleSexual Offender Version. Sexual Abuse: A Journal of Research and Treatment, 26, 472499. doi:10.1177/079063213502679

Orbis Partners. (2003). Service Planning Instrument (SPIn). Ottawa, Ontario, Canada: Aut Oreg, S. (2003). Resistance to change: Developing an individual differences measure. Journal of Applied Psychology, 88, 680_693.

Pennebaker, J. W. (1997). Writing about emotional experiences as a therapeutic process. Psychological Science, 8, 162-165. doi: 10.1111/j. 1467-9280.1997.tb00403.x

Pennebaker, J. W., \& Beall, S. K. (1986). Confronting a traumatic event: Toward an understanding of inhibition and disease. Journal of Abnormal Psychology, 95, 274-281.

Pennebaker, J. W., Colder, M., \& Sharp, L. K. (1990). Accelerating the coping process. Journal of Personality and Social Psychology, 58, 528-537.

Pennebaker, J. W., Kiecolt-Glaser, J. K., \& Glaser, R. (1988). Disclosure of traumas and immune function: Health implications for psychotherapy. Journal of Consulting and Clinical Psychology, 56, 239-245.

Porporino, F. J., Robinson, D., Millson, B., \& Weekes, J. R. (2002). An outcome evaluation of prison-based treatment programming for substance users. Substance use \& Misuse, 37(810), 1047-1077. doi:http://dx.doi.org/10.1081/JA-120004165

Prendergast, M. L., Pearson, F. S., Podus, D., Hamilton, Z. K., \& Greenwell, L. (2013). The Andrews' principles of risk, needs, and responsivity as applied in drug treatment programs: meta-analysis of crime and drug use outcomes. Journal of Experimental Criminology, 9, 275-300. doi: 10.1007/s11292-013-9178-z 
Prins, S. J. (2014). The prevalence of mental illnsesses in U.S. state prisons: A systematic review. Psychiatric Services, 65(7), 862-872. doi: 10.1176/appi.ps.201300166

Proschaska, J. O. (1982). Trantheoretical therapy: Toward a more integrative model of change. Psychotherapy: Theory, Research, \& Practice, 19(3), 276-288.

Prochaska, J.O., DiClemente, C.C., \& Norcross, J.C. (1992). In search of how people change: Applications to addictive behaviors. American Psychologist, 47, 1102_1114.

Prochaska, J. O. \& Velicer, W. F. (1997). The transtheoretical model of health behaviour change. American Journal of Health Promotion, 12(1), 38-28.

Proctor, S. L., Hoffmann, N. G., \& Allison, S. (2012). The effectiveness of interactive journaling in reducing recidivism among substance-dependent jail inmates. International Journal of Offender Therapy and Comparative Criminology. 56(2), 317-332. doi:

$10.1177 / 0306624 X 11399274$

Public Safety Canada (2016). Corrections and conditional release statistical overview annual report. Retrieved from: https://www.publicsafety.gc.ca/cnt/rsrcs/pblctns/ccrso2016/index-en.aspx

Richards, J. M., Beal, W. E., Seagal, J. D., \& Pennebaker, J. W. (2000). Effects of disclosure of traumatic events illness on behaviour among psychiatric prison inmates. Journal of Abnormal Psychology 109(1), 156-160.

Rogers, C. R. (1961). The process equation of psychotherapy. American Journal of Psychoptherapy, 15, 27-45.

Ross, E. C., Polaschek, D. L. L., \& Ward, T. (2008). The therapeutic alliance: A theoretical revision for offender rehabilitation. Aggression and Violent Behavior, 13, 462-480, doi:10.1016/j.avb.2008.07.003 
Roth, A. D., \& Pilling, S. (2008). Using an evidence-based methodology to identify the competencies required to deliver effective cognitive and behavioural treatment for depression and anxiety disorders. Bevhaviour and Cognitive Psychology, 36, 129-147. doi:10.1017/S1352465808004141

Scheck, A. M., Hoffmann, N. G., Proctor, S. L., \& Couillou, R. J. (2013). Interactive journaling as a brief intervention for Level-II DUI and DWI offenders. Journal of Alcohol \& Drug Education, 57(3), 66-85.

Scogin, F., Jamison, C., \& Gochneaur, K. (1989). Comparative efficacy of cognitive and behavioral bibliotherapy for mildly and moderately depressed older adults. Journal of Consulting and Clinical Psychology, 57, 403-407. doi:10.1037/0022-006X.57.3.403

Serin, R. C. (2007). The Dynamic Risk Assessment for Offender Re-Entry (DRAOR). Unpublished user manual. Carleton University, Ottawa, Ontario.

Serin, R. C., Lloyd, C. D., \& Hanby, L. J. (2010). Enhancing offender re-entry: An integrated model for enhancing offender re-entry. European Journal of Probation, 2(2), 53-75.

Smith, P., Gendreau, P., \& Swartz, K. (2009). Validating the principles of effective intervention: A systematic review of the contributions of meta-analysis in the field of corrections. Victims \& Offenders, 4(2), 148-169, doi: 10.1080/15564880802612581

Smyth, J. M. (1998). Written emotional expression: Effect sizes, outcome types, and moderating variables. Journal of Consulting and Clinical Psychology, 66, 174-184. doi:10.1037/0022006X.66.1.174

Smyth, J. M., Stone, A. A., Hurewitz, A., \& Kaell, A. (1999). Effects of writing about stressful experiences on symptom reduction in patients with asthma or rheumatoid arthritis. Journal of the American Medical Association, 281, 1304-1309. 
Spera, S. P., Buhrfeind, E. D., \& Pennebaker, J. W. (1994). Expressive writing and coping with job loss. Academy of Management Journal, 37, 722-733.

Stouthamer-Loeber, M., Wei, E., Loeber, R., \& Masten, A. S. (2004). Desistance from persistent serious delinquency in the transition to adulthood. Development and Psychopathology, 16, 897-918. doi: 10.10170S0954579404040064

Substance Abuse and Mental Health Services Administration. (2014). Interactive Journaling. National Registry of Evidenced-based Programs and Practices. Retrieved from: http://www.nrepp.samhsa.gov

Substance Abuse and Mental Health Services Administration. (2013). Results from the 2013 National Survey on Drug Use and Health: Summary of National Findings. Retrieved from: https://www.samhsa.gov/data/sites/default/files/NSDUHresultsPDFWHTML2013/Web/ NSDUHresults2013.pdf

Sutton, L. A. (2001). Back to the drawing board? A review of applications of the transtheoretical model of substance use. Recovery and Relapse, 96, 175-186. doi: $10.1080 / 09652140020017049$

Tabachnick, B. G. \& Fidell, L. S. (2013). Using Multivariate Statisitics (6 ${ }^{\text {th }}$ ed.). Boston: Pearson Education.

Taxman, F. S. (2012). Crime control in the twenty-first century: Science-based supervision. Journal of Crime and Justice, 33(2), 135-144. https://doi.org/10.1080/0735648X.2012.686583 
Taxman, F. S., Shepardson, E., \& Byrne, J. (2004). Tools of the trade: A guide for incorporating science into practice. Washington, D.C.: Community Corrections Division, National Institute of Corrections.

U.S. Courts. Administrative Office of the U.S. Courts (2015). Did you know? Imprisonment costs 8 times more than supervision. Retrieved from: http://www.uscourts.gov/news/2015/06/18/did-you-know-imprisonment-costs-8-times$\underline{\text { more-supervision }}$

Vachon, D. D., Lynam, D. R., \& Johnson, J. A. (2014). The (non)relation between empathy and aggression: Surprising results from a meta-analysis. Psychological Bulletin, 140, 751773. doi:10.1037/a0035236

Ward, T., Day, A., Howells, K., \& Birgden, A. (2004). The multi factor offender readiness model. Aggression \& Violent Behavior, 9, 645-673, doi:10.1016/j.avb.2003.08.001

Weinstein, N. D., Rothman, A. J., \& Sutton, S. R. (1998). Stage theories of health behaviour: Conceptual and methodological issues. Health Psychology, 17(3), 290-299.

Wexler, H. K., Melnick, G., Lowe, L., \& Peters, J. (1999). 3-year reincarceration outcomes for amity in-prison therapeutic community and aftercare in California. The Prison Journal, Vol. 79, pp. 321-336.

Whitelaw, S., Baldwin, S., Bunton, R., \& Flynn, D. (2000). The status of evidence and outcomes in stages of change research. Health Education Research, 15(6), 707-718.

Wright, J. P., Cullen, F. T. (2004). Employment, Peers, and Life-Course Transitions. Justice Quarterly, 21, 183-205. doi: 10.1080/07418820400095781

Yang, M., Wong, S. C. P. \& Coid, J. (2010). The efficacy of violence prediction: A metaanalytic comparison of nine risk assessment tools. Psychological Bulletin, 136(5), 740 767. doi: $10.1037 / \mathrm{a} 0020473$ 
Appendix A

Client Handbook Series

\section{Anger Management}

Client Handbook Series

January 2015

Developed by Carleton University, Criminal Justice Decision Making Laboratory \& Ontario Ministry of Community Safety and Correctional Services

(c) Ralph C. Serin, Sarah McQuaid, \& Angela DeWolf, \& the Ontario Ministry of Community Safety and Correctional Services

This handbook series is public domain and can be copied and used with clients without cost but also without evidence regarding efficacy. 


\section{Types of Violence}

Think about your violent behaviour in the last six months. Read the different types of violence below and pick one that best describes you.

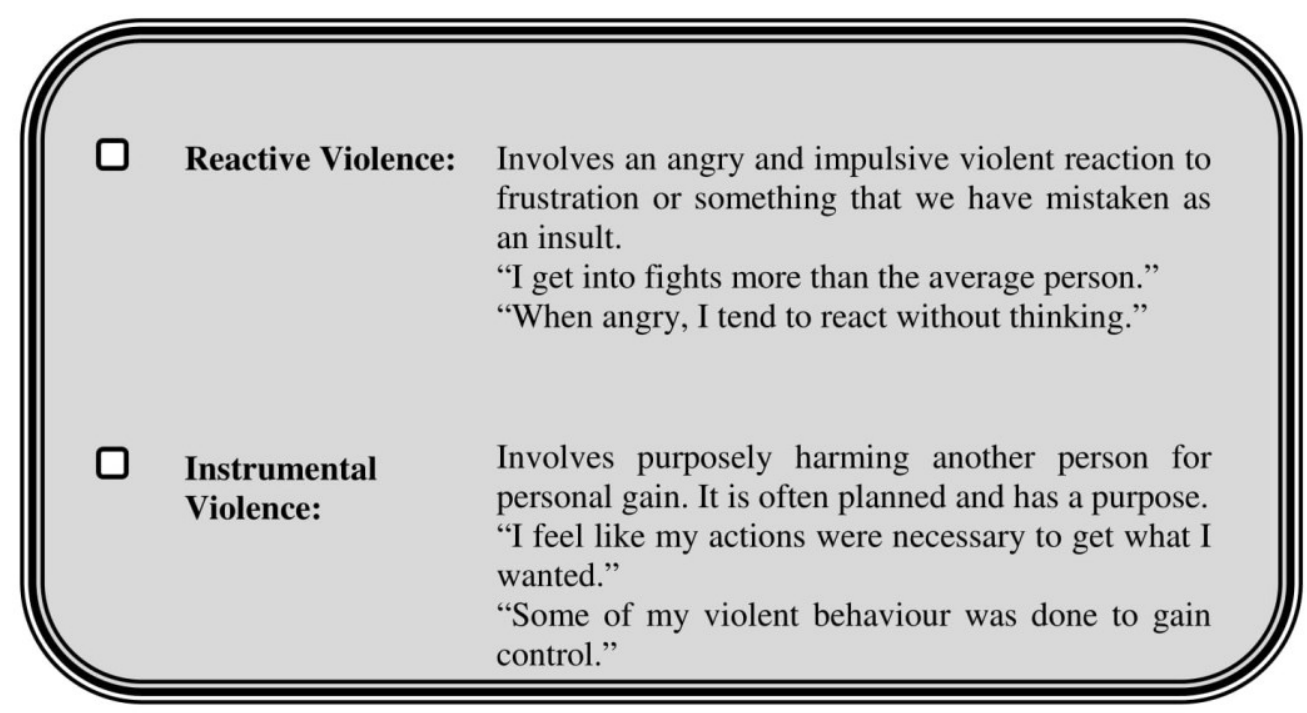

If you picked Instrumental Violence, this workbook is not for you because your violent behaviour is less related to anger and more related to how you think. Please refer to the Criminal Attitudes workbook. The goal of this workbook is to give people anger control skills in order to prevent future violence. If you picked Reactive Violence, please continue with the rest of the workbook. 


\section{Anger}

People often confuse anger, hostility and aggression as the same thing; however, they are separate but related experiences. For instance, the way we think about a situation can affect our feelings and emotions about that situation, which can increase or decrease our risk of violent behaviour.

Thoughts
(Hostility) $\Rightarrow \begin{gathered}\text { Emotions } \\ \text { (Anger) }\end{gathered} \Rightarrow \begin{gathered}\text { Behaviour } \\ \text { (Aggression) }\end{gathered}$

* Hostility is a negative way of thinking about the world that can result in aggressive and violent behaviour.

* Anger is an emotion that can range from mild frustration to full blown rage. It is a natural emotion that can warn us to problems and energize us to act, such as when we feel that someone close to us is being threatened. However, for some people, anger can get out of control and it can lead to problems in work, relationships, and overall quality of life.

* Aggression is a behaviour that is meant to cause harm to another person or damage property. It can be physical (hitting someone), verbal (threats) or emotional (putting someone down). It's important to remember that a person can become angry without acting aggressively and a person can be aggressive without being angry (e.g. committing a robbery). 


\section{Triggers}

Triggers are the different influences in your life that may lead you to become angry. Whether they come from within you (internal triggers) or come from outside sources (external triggers), you still control their impact on your behaviours.

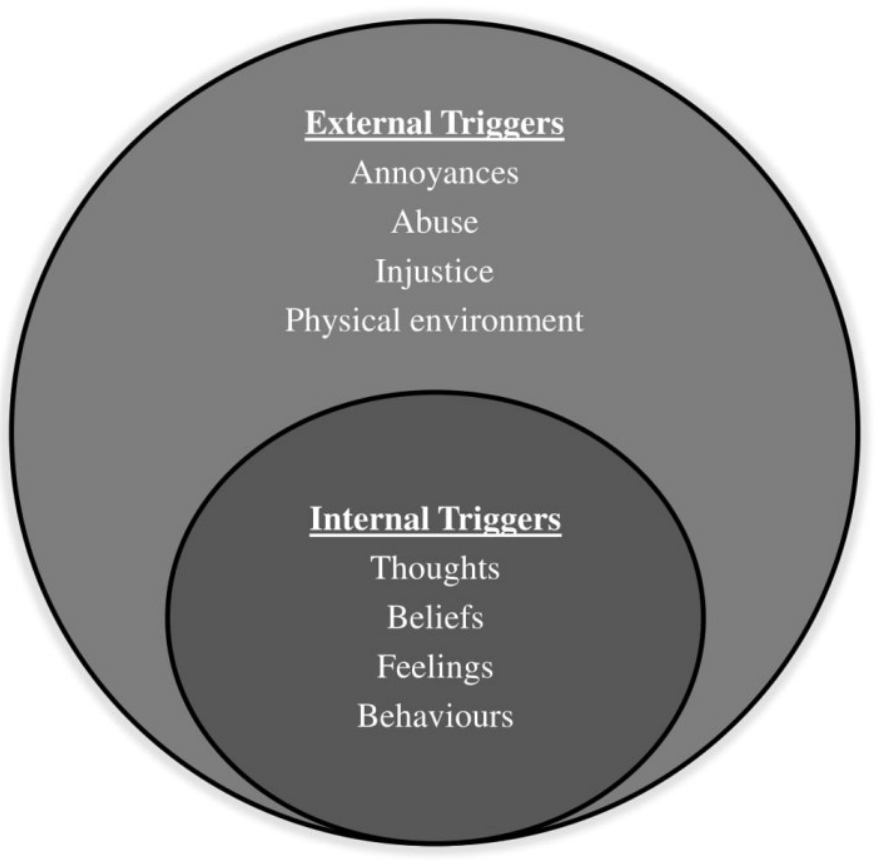

What are some of your triggers? List them in the two boxes below.
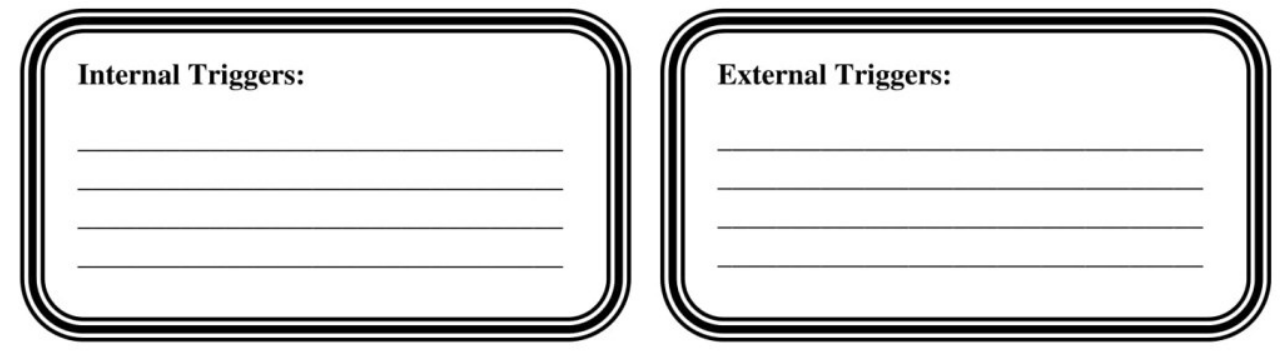


\section{Anger Log}

Keeping an Anger Log can help you keep track of what makes you angry (your triggers) so that you can spot it when it starts to happen again. You can then develop coping strategies to help you deal with your anger in an appropriate way. Below is an example of an Anger Log.

\section{Example Anger Log}

* Where were you?

I was at a bar downtown.

* Who was around you?

Three of my buddies: Mike, Jon, and Dylan.

* What happened?

A guy bumped into me and spilled my drink.

* How angry were you? (On a scale of 0 being not angry at all to 10 being extremely angry)

I was about a 6 .

* How long were you mad for?

A few minutes.

* What physical sensations did you feel? (e.g., rapid heartbeat, muscle tension, adrenaline rush, nausea)

My heart was beating fast, I felt a rush of adrenaline, and I felt kind of lightheaded.

* What emotions did you feel? (e.g., frustrated, embarrassed, anxious, guilty)

Other than angry I felt kind of embarrassed.

* When you noticed you were angry, how did you respond?

As soon as I felt angry I pushed him back and then punched him.

* Do you feel you responded well?

No, I shouldn't have dealt with it in that way.

* How could you have improved your response?

I shouldn't have resorted to violence so quickly and instead ignored him or checked out the situation better. 


\section{Anger Log}

Now it's your turn to fill out an Anger Log. Describe an event in which you felt angry and acted aggressively because of it.

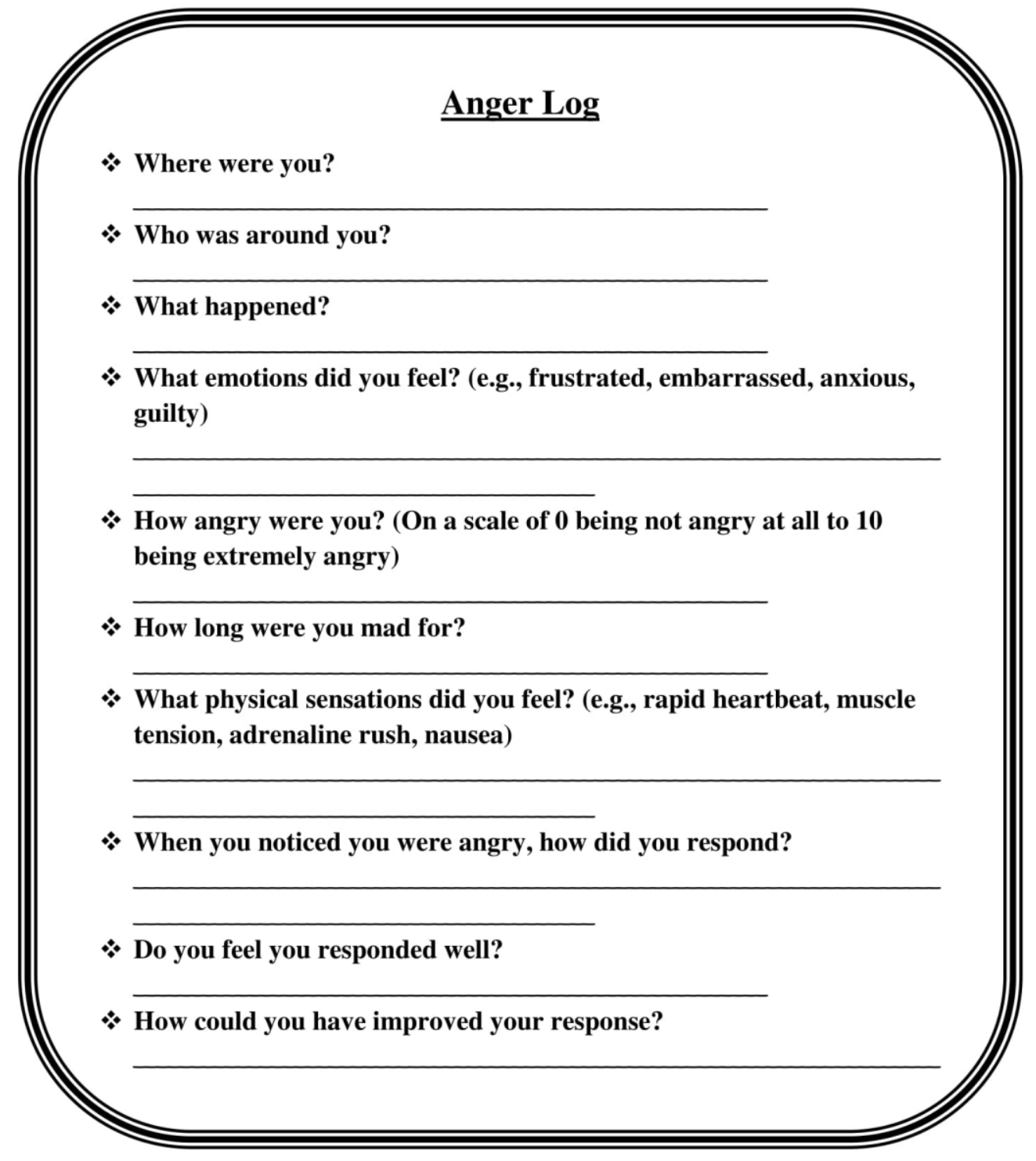




\section{Changing Your Thinking}

Sometimes when we get angry our thinking can spiral out of control, making it difficult to think clearly (e.g. jumping to the wrong conclusions).

In order to change your negative thoughts (e.g. jumping to the wrong conclusions or seeing the worst in everything), you need to be aware of your 'self-talks' that can lead you to become angry. Self-talks are the things you tell yourself about a situation, which can be either positive or negative. As people become angry they often have negative and hostile self-talks, which can be so automatic that they are unaware of them and how they may lead to aggressive behaviour. This means getting angry and then acting aggressively can happen in a few seconds.

Below are some steps that can help you identify your negative self-talks and replace them with more realistic and positive ones.

Step 1: Identify your trigger

- Describe the situation or person that triggered your negative mood.

- E.g. My boss is always giving me a hard time.

Step 2: Identify your automatic thoughts

- Make a list of the automatic thoughts you tell yourself about the situation or your beliefs and expectations of others.

- E.g. "I'm sick and tired of being disrespected all the time. He's obviously out to get me"

Step 3: Identify your emotions

- Describe and rate how you feel about the situation based on your self-talk.

- E.g. angry, upset, frustrated

Step 4: Challenge your thoughts

- Challenge your negative thoughts. Are your thoughts about the situation correct? Is there proof to back up your beliefs?

- E.g. "It seems like my boss gives everyone a hard time, not just me".

- Could the situation be accidental?

- E.g. "The person who pushed me was drunk".

Step 5: Replace and practice positive thoughts

- Create and practice (for mastery) some positive self-talks that you can use to counter similar negative thoughts in the future.

- E.g. "Relax, I shouldn't take things so personally; I know I'm a hard worker." 


\section{Changing Your Thinking}

Try challenging your own thinking. Remember, it's not the event itself that can make you angry but how you think about and view the situation. Learning to challenge your hostile and negative thoughts and replace them with healthy ones takes a lot of practice and effort.

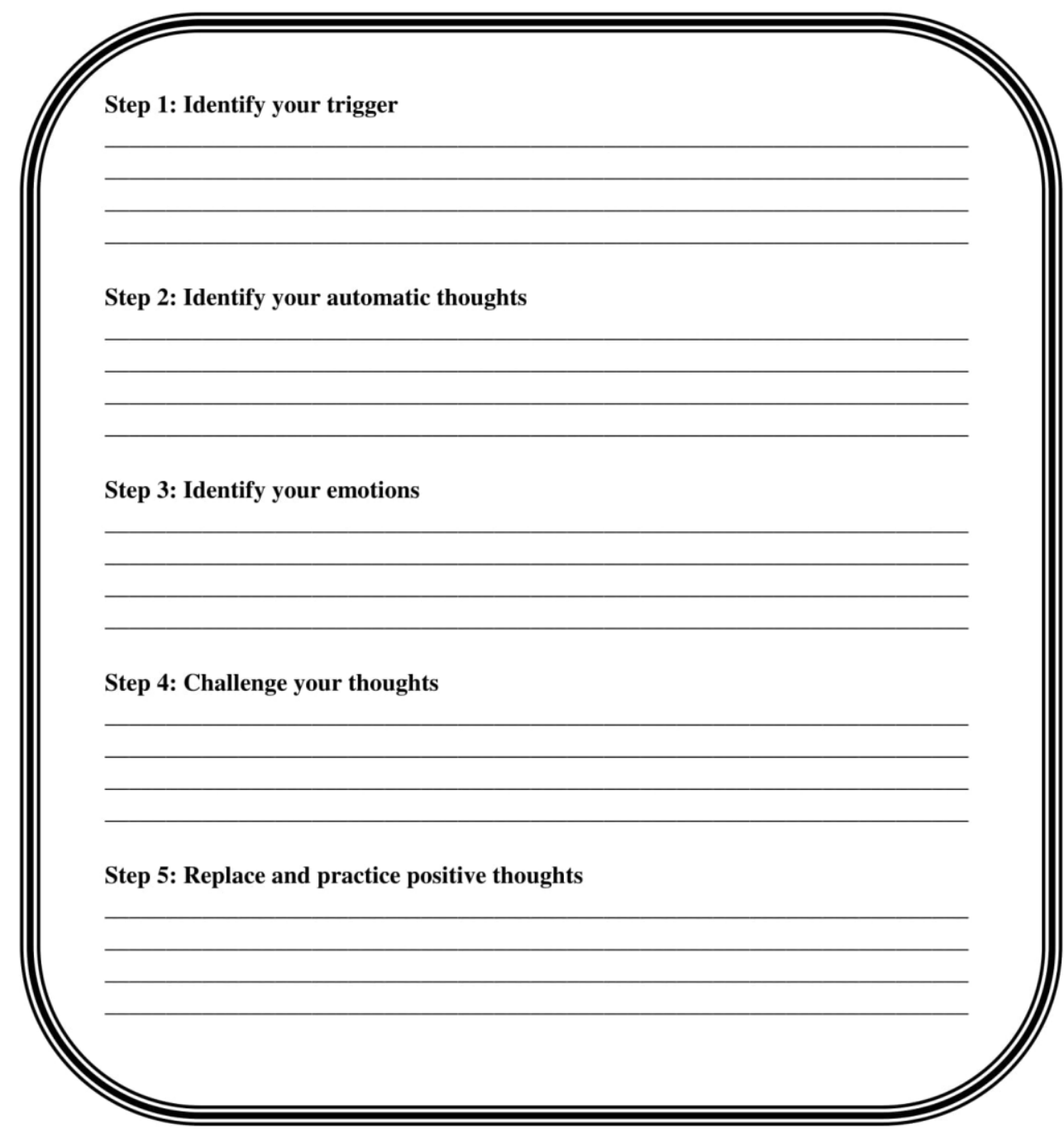




\section{Aggression Management}

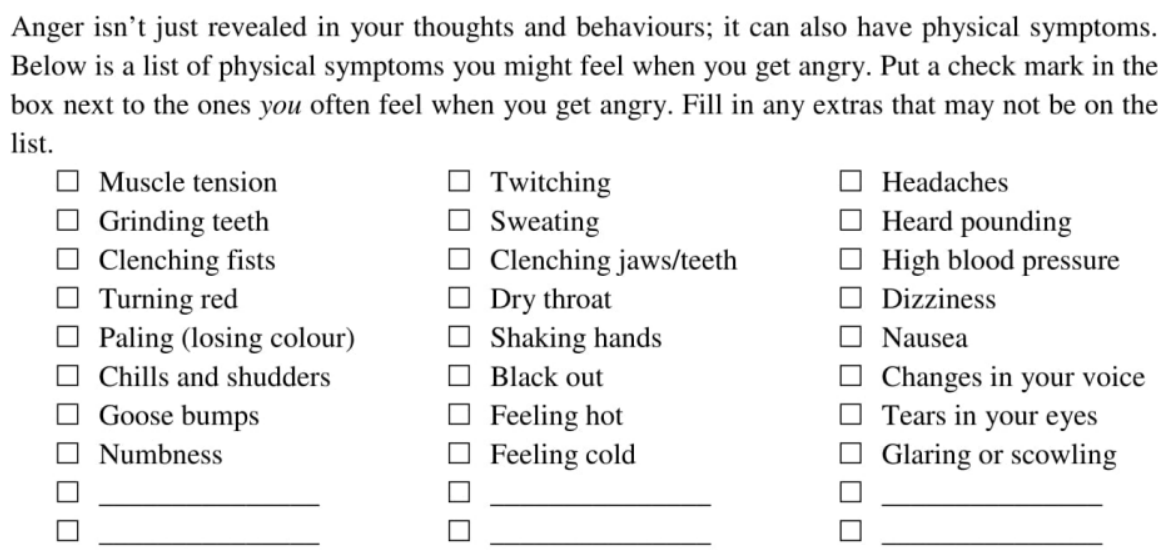

Good! Now you can use these physical cues to help you recognize when you are starting to feel angry. It's good to notice anger (a feeling) and to calm yourself down before it can turn into aggression (your actions). A good first step towards calming down is practicing relaxation. Often when we are angry our muscles will tense up. Taking the time to breathe and to relax your muscles can help your anger subside as well. Try these relaxation steps right now, and remember them the next time you start to feel angry.

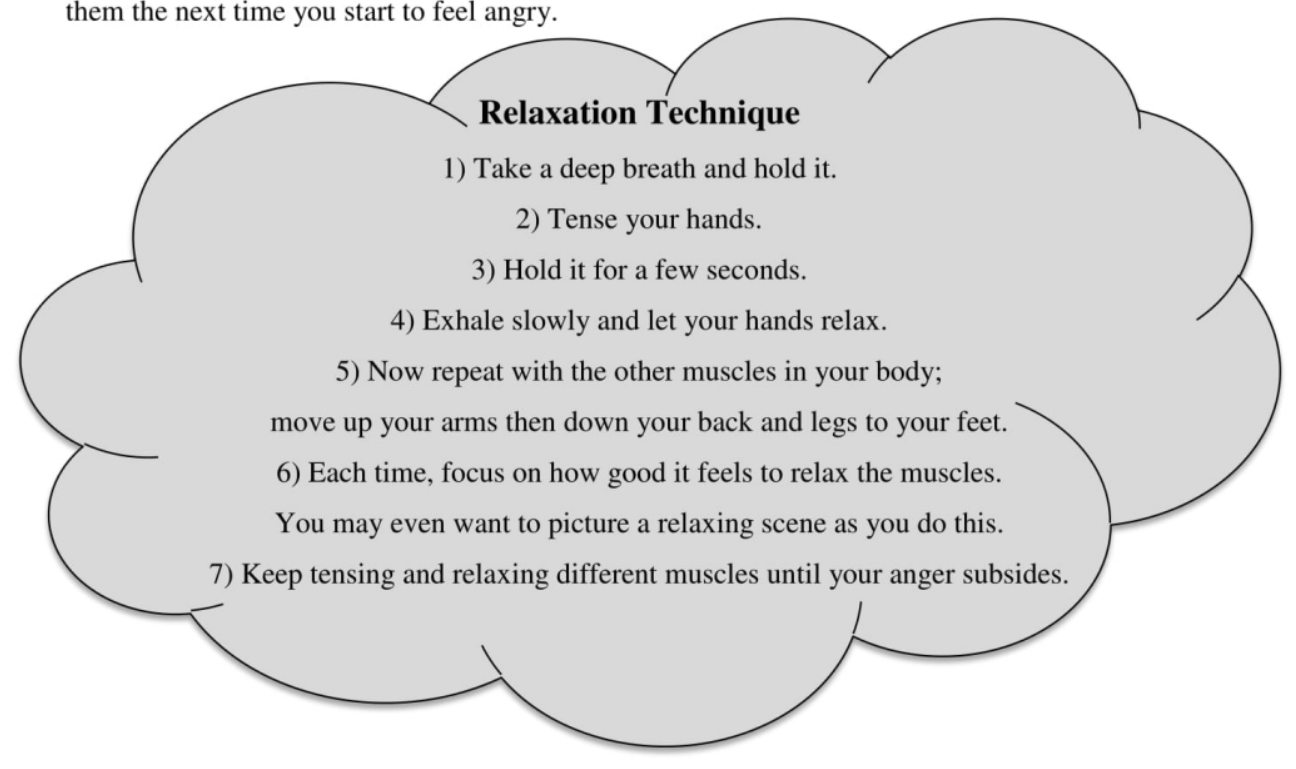




\section{Conflict Resolution}

Many problems happen when you feel that your rights have been violated or when you believe you have been disrespected. Your first reaction may be to fight back because you can't always avoid the things or people that make you angry. Instead, you can learn to control your feelings and behaviour in these situations. Below are some examples of the different ways that a person can deal with conflict.

* Passiveness: Involves holding anger in, backing down or giving in. This is not a helpful way to deal with conflict because it will allow your rights to be violated. This leads you to become resentful and angry at yourself for not standing up for what you wanted or needed. It may avoid conflict, but it will not solve the problem.

* Aggressiveness: Involves exploding and hurting others. This is also not a good way to handle your anger because it can result in being arrested, pushing others away, losing loved ones, and feelings of guilt, shame or regret.

* Assertiveness: Involves listening and expressing your anger in a calm and rational manner. This is the ideal way to deal with conflict or a frustrating situation.

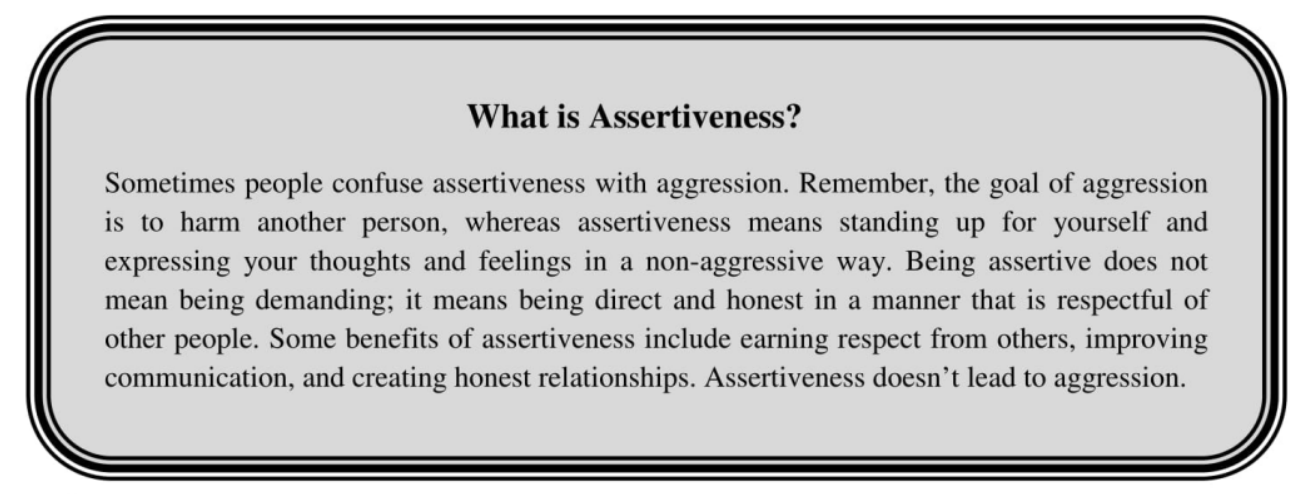

The next page has some helpful skills that you can use the next time you are faced with a conflict or a frustrating situation. 


\section{Skills}

Below are some assertiveness skills that you can use in different situations. It's also important to be aware of your body language, such as keeping eye contact, having an upright posture, not using dramatic gestures and having a positive or neutral facial expression. Scowling and gesturing when trying to be assertive will give mixed messages to the other person.

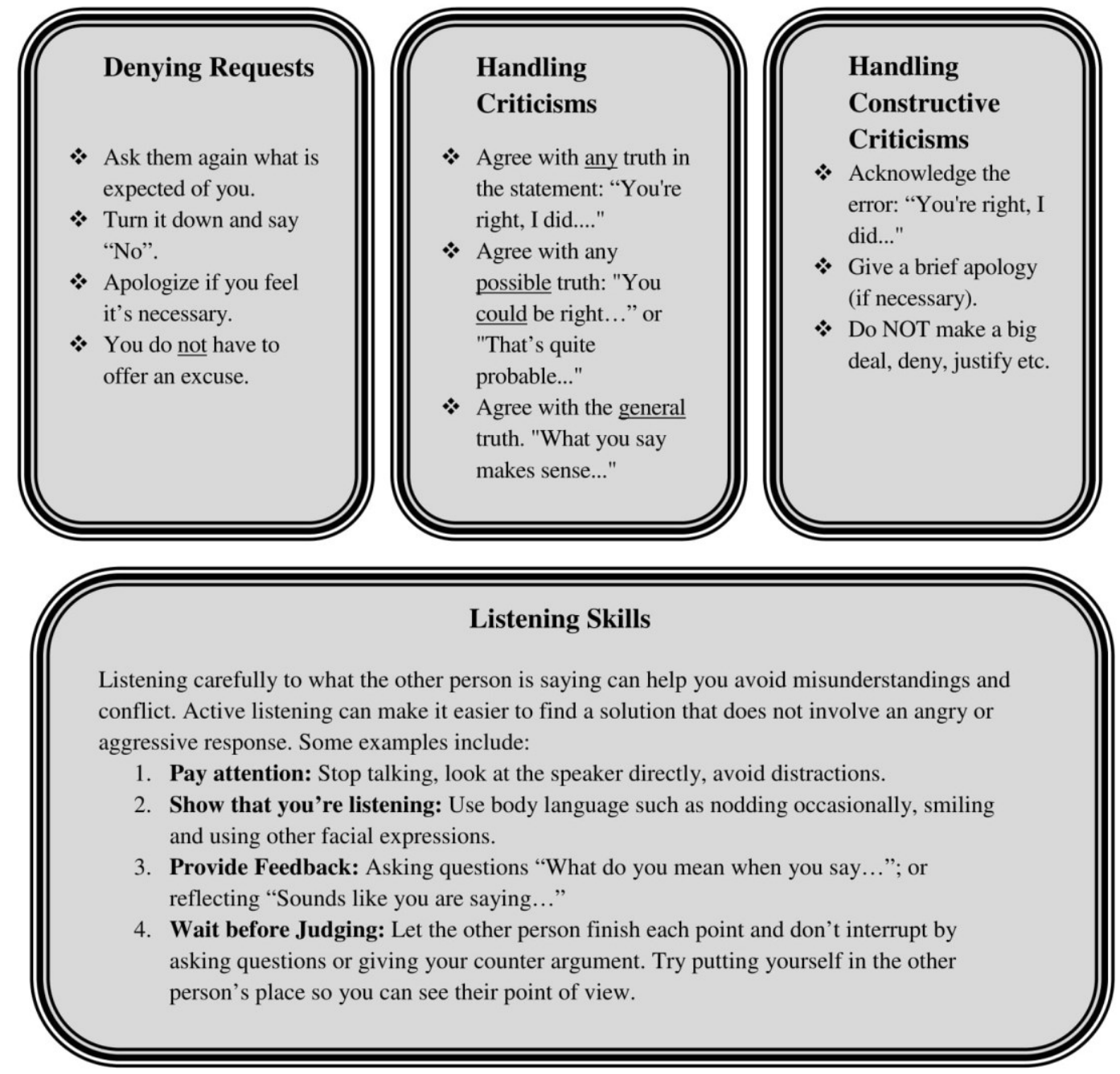




\section{Managing Your Anger}

Step 1. When you know what makes you angry you'll be better able to develop better ways for dealing with those situations when they come up. What events/things trigger your anger?

Step 2. You can't change what you don't acknowledge. Consider whether or not you have an anger problem, and then check one of the boxes below.

"I acknowledge that I have an anger problem."

"I do not have an anger problem."
Step 3. Other people in your life can be a great support network while you are trying to change. They can also be a source of motivation when you are tempted to return to your old ways. Who is in your support network?

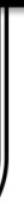

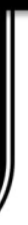

Step 5. Forgive others and have empathy. Holding on to past anger can delay the change process. This is why it's important to forgive others for past wrongs, and also to forgive yourself to start fresh. Having empathy means you put yourself in the other person's shoes to understand how they feel in a situation. This can help you figure out why they acted the way they did, and you might realize that you would have acted the same way.
Step 4. Use the techniques that you've learned to help you calm down and to avoid acting aggressively. List the techniques you've learned; you can go back through the booklet if you have to.

1)

2)

3)

4)

5)

6)

(Trv to master a couple) 


\section{Summary}

\section{Here's a quick summary of what you have learned about anger:}

1) Anger is an emotion; aggression is a behaviour; hostility is a way of thinking.

2) Your triggers are what make you angry. Knowing what your triggers are can help you prepare for any situation.

3) By keeping an Anger Log you can better understand the process you go through when something makes you angry; then you can begin to change your actions.

4) It's important to manage your negative thoughts before they spiral out of control by replacing them with positive self-talks.

5) Recognize what physical sensations you feel when you begin to get angry and then try relaxation techniques to calm yourself down.

6) Conflict is a part of everyday life that is sometimes unavoidable. Knowing how to deal with conflict is not something people are born with but a skill that can be learned.

7) Assertiveness and listening skills can help you manage conflict in a way that does not result in aggressive behaviour.

8) You can always revisit this workbook and use the steps and techniques to help you better manage your anger. Practice is required, in situations of less anger, in order to master the techniques. Not all techniques work equally well for each person. 


\section{Attitudes and Behaviour}

Client Handbook Series

January 2015

Developed by Carleton University, Criminal Justice Decision Making Laboratory

\& Ontario Ministry of Community Safety and Correctional Services

(c) Ralph C. Serin, Angela DeWolf, Sarah McQuaid

$\&$ the Ontario Ministry of Community Safety and Correctional Services

This handbook series is public domain and can be copied and used with clients without cost but also without evidence regarding efficacy. 


\section{Costs and Benefits}

"Criminal attitudes" are our thoughts about criminal actions. People with pro-criminal attitudes think crime is a part of life or out of their control, and tend to make excuses for why they do it. People with non-criminal attitudes understand the problems with crime and choose to live a different lifestyle.

Often, people commit crime because they think that it will help them rather than harm them. In fact, criminal behaviour is learned through getting rewards for crime and expecting that good things will happen from it.

But, as the costs of crime become more than the benefits, people have more to lose. For example, if you commit a crime and get caught, you may go to prison, lose your job or you may hurt or disappoint your family.

In the table below, make a list of the things that you will gain (benefits) if you continue offending and the things that you will lose (costs) if you continue offending.

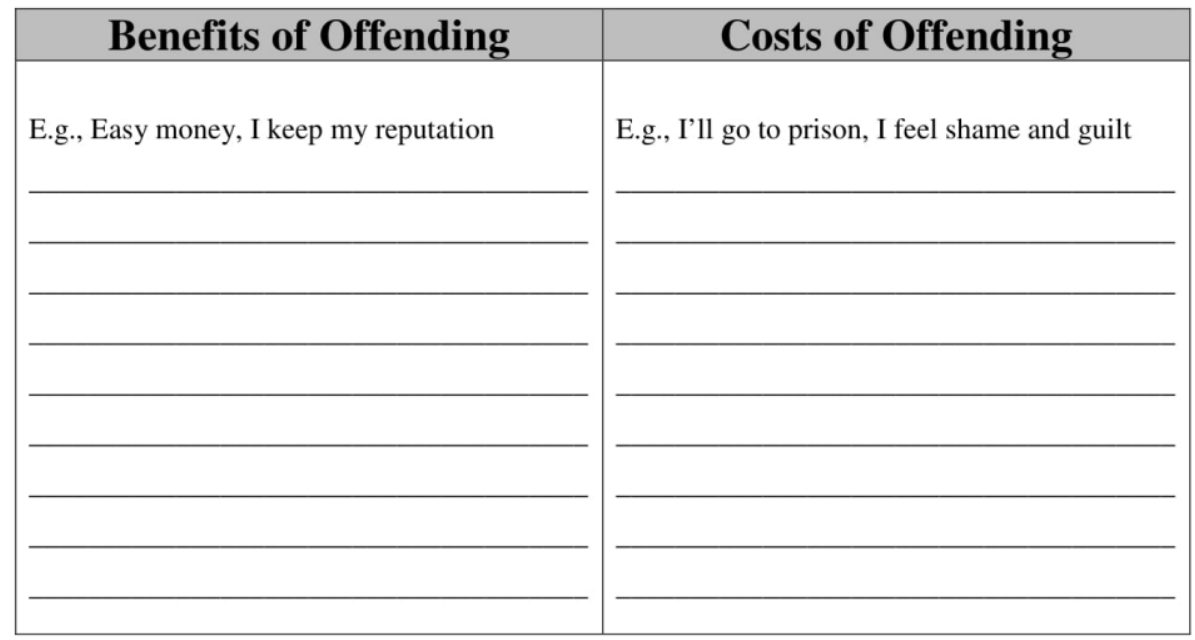

Great! Now that you've thought about the costs and benefits of offending, move on to learn about how the people around us affect our decisions in important ways. 


\section{Peers and Attitudes}

We mainly think like the people who we spend the most time with, whether it is our friends, family, or coworkers. It is those people who affect our thoughts, attitudes, choices, and actions the most. In order to avoid crime it is important to surround yourself with people who are supportive, positive, and most importantly who have non-criminal attitudes.

In the activity boxes below, describe two important relationships that you have and how these people influence your attitudes. Here is an example:

\section{Relationship \#1: Harry (High-School Friend)}

In which category does this person belong?

$\checkmark$ Has pro-criminal attitudes

$\square$ Has non-criminal attitudes

How has this person influenced your criminal attitudes in the past? He thinks that crime is a good way to make money and have fun. He convinced me to steal a car with him. We got caught and I went to jail for it.

How will you let this person influence your criminal attitudes in the future? I will not have any contact with Harry unless he changes his criminal attitudes in the future. 


\section{Peers and Attitudes}

\section{Relationship \#1:}

In which category does this person belong?

$\square$ Has pro-criminal attitudes

$\square$ Has non-criminal attitudes

How has this person influenced your criminal attitudes in the past?

How will you let this person influence your criminal attitudes in the future?

\section{Relationship \#2:}

In which category does this person belong?

$\square$ Has pro-criminal attitudes

$\square$ Has non-criminal attitudes

How has this person influenced your criminal attitudes in the past?

How will you let this person influence your criminal attitudes in the future? 


\section{Common Attitudes}

There are some common thoughts that people often have about their crimes. They influence our decision to act a certain way or not. These actions have consequences, either good or bad.
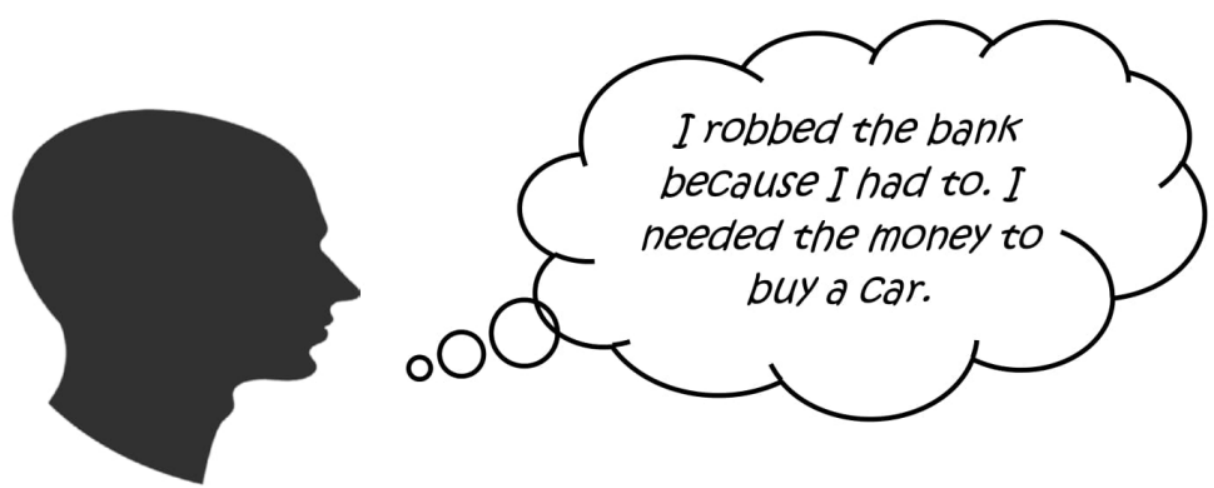

Some thoughts involve making excuses for your actions or for why you did something wrong.
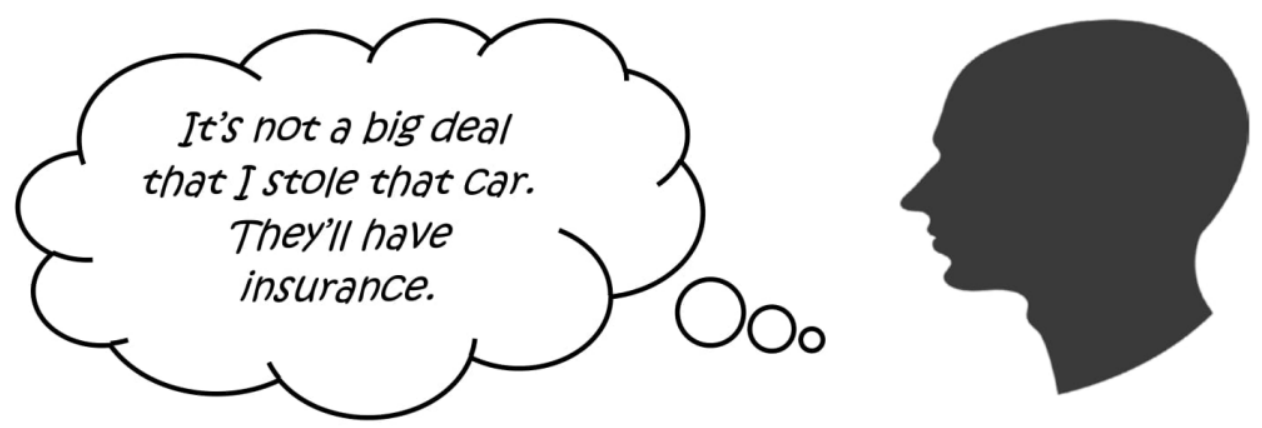

Other thoughts involve downplaying the seriousness of your actions - to make it seem like less of a big deal than it is. 


\section{Changing Our Attitudes}

Sometimes to change negative actions you first have to change some of your attitudes. It's important to know which attitudes make your life better and which ones lead to actions that take you down a bad path.

There are four important steps to follow when trying to change our attitudes. Fill out the form below to begin the process.

\section{Step 1: Identify The Situation}

Describe a time when you had pro-criminal attitudes that lead to a crime. What were those attitudes? Were your expectations reasonable?

\section{Step 2: Identify Your Thoughts}

Write down what you might have said to yourself or to others to rationalize or minimize your crime.

\section{Step 3: Challenge Those Thoughts}

Write down some more alternative thoughts about your crime (e.g., "I really hurt those people when I robbed their house").

\section{Step 4: Monitor Your Success}

In real life situations when you find yourself having pro-criminal attitudes about something, identify them for what they are and practice replacing them with alternative thoughts. Congratulate yourself when you have done this successfully -- eventually it will become habit! 


\section{Identity Change}

One way that can help people move away from crime is something called "identity change". This means starting to view yourself as non-criminal instead of criminal. Is this something you've done?

Part of this involves imagining yourself in the future. For example, you might picture yourself as an ex-offender that is successful and is able to support and take care of your family. Is this realistic for you? If not, why not?

Start the process by picturing your future self. Make a plan towards changing your thoughts and behaviour. Below is an example of how you might imagine yourself in the future and the steps that you can take to make the change possible.

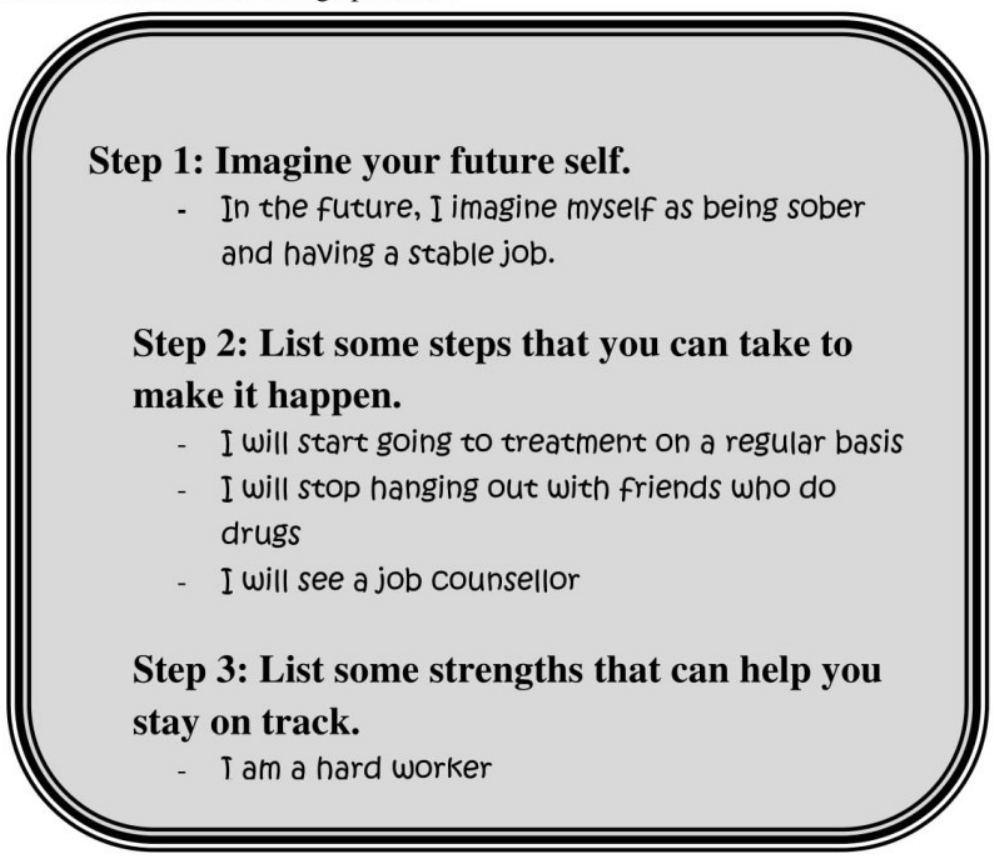

Helpful Tip: Sometimes we need to change our behaviours before changing our attitudes. Good skills to practice are "planning ahead" to avoid high-risk situations from the start, or taking a "time out" to step out of a situation that might affect your life in a negative way. 


\section{Identity Change}

Now it's your turn to imagine yourself in the future. In the table below, write down some steps that you can take to make it possible and some of your strengths that can help you along the way.

Step 1: Imagine your future self.

Step 2: List some steps that you can take to make it happen.

Step 3: List some strengths that can help you stay on track.

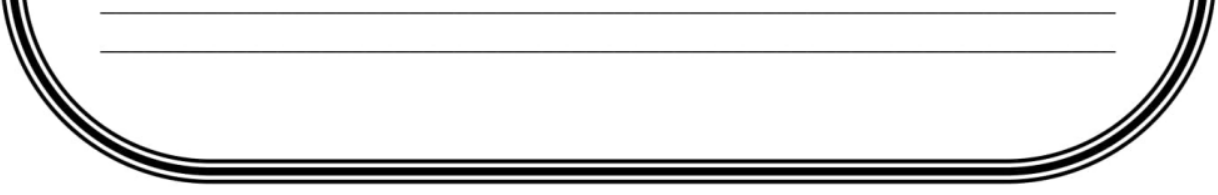




\section{Summary}

\section{Here's a quick summary of what you have learned about criminal attitudes:}

1) Our criminal attitudes are how we feel about committing crimes.

2) Having a pro-criminal attitude means that you see more benefits to committing crime, while having a non-criminal attitude means that you see more costs to committing crime.

3) As the costs of crime begin to outweigh the rewards of crime, people have more to lose. For example, committing a crime may jeopardize a new relationship or job opportunity.

4) The people we spend the most time with will greatly influence our criminal attitudes and also our actions. It's important to build good relationships with non-criminal people.

5) Recognizing our own criminal attitudes and thoughts about crime is important to changing our behaviour.

6) Identity change is when you begin to view yourself as non-criminal. Imagining yourself in the future can help you make a plan to achieve your goals. 


\section{Motivation to Change}

Client Handbook Series

January 2015

Developed by Carleton University, Criminal Justice Decision Making Laboratory \& Ontario Ministry of Community Safety and Correctional Services

(c) Ralph C. Serin, Angela DeWolf, Sarah McQuaid

$\&$ the Ontario Ministry of Community Safety and Correctional Services

This handbook series is public domain and can be copied and used with clients without cost but also without evidence regarding efficacy. 


\section{What is Motivation to Change?}

Motivation to Change is a person's drive to change his or her own beliefs and behaviours.

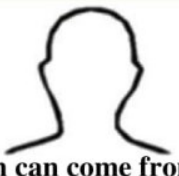

Motivation can come from within:

This is when your reasons for

changing are not for any reward or

outside gain but instead for the sake of

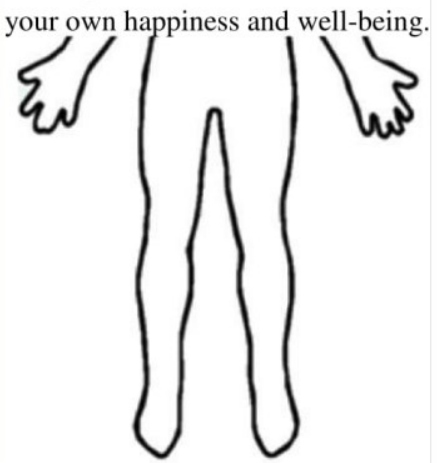

Motivation can come from the outside:

This is when you want to change to get some kind of reward or outcome.

For example, participating in treatment to help you get parole or get off probation. Other people, especially family and loved ones, can also affect your desire to change, for example, when your reasons for changing are to make other people happy.

\section{What Helps and Hurts Motivation to Change?}

Things that help motivation:

- Staying out of jail

- Feeling like a success

- Having supportive friends and family
Things that hurt motivation:

- Not having support

- Feeling like a failure

- Fear

- Doubt

- Negative thinking

Draw a line anywhere on the scale below to indicate how motivated you are to change right now.

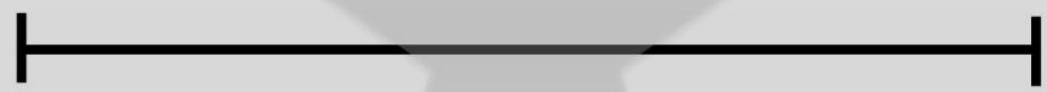




\section{What Change Means for You}

Start thinking about what you might want to change about yourself or your life. Sometimes we make personal changes for ourselves, and sometimes we feel pressured to make changes for other people. Think about why you want to change. Is it for you, or for someone else?

In this box, list some things you think (or know) other people in your life would like you to change about yourself. For example: "My girlfriend wants me to get a better paying job."

Good, now in this box list some things that you want to change about yourself. Try to start with small changes that you can easily make, but make sure that they are things you want to change. For example: "I would like to try and stop drinking for a week"

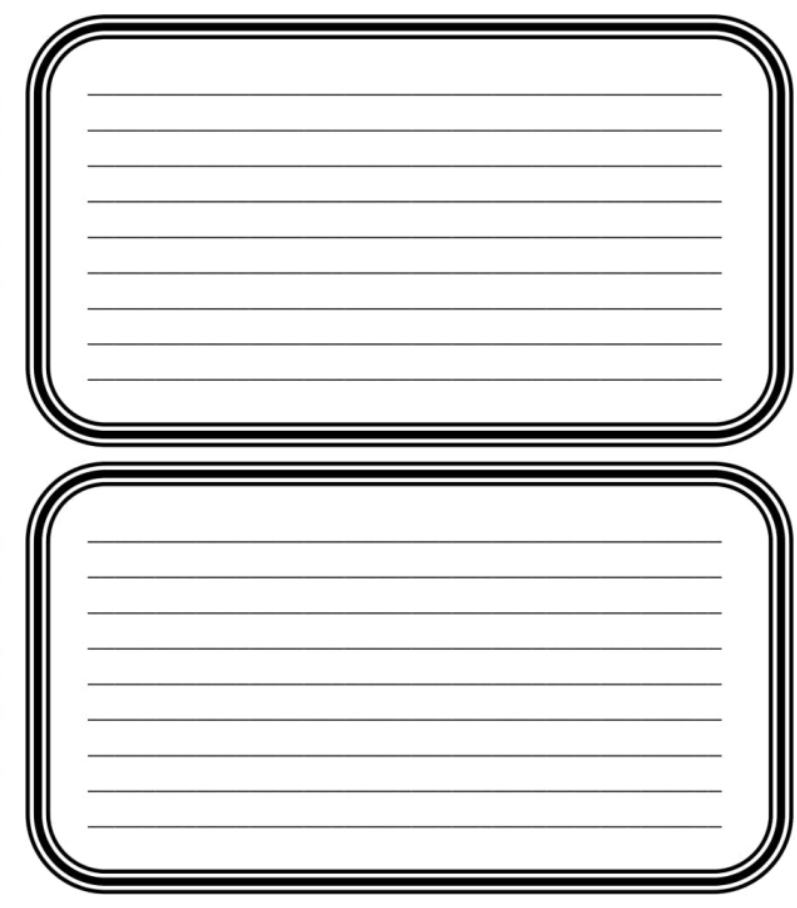

Remember, while making positive changes about yourself often also changes the lives of the people around you in a positive way, the goal of this workbook is to help you better yourself for you. 


\section{Stages of Change}

There are several stages a person must go through before they can change their behaviour. These stages of change are a cycle, where people may go through them a few times before lasting change happens.

Remember, relapses or falling back into old patterns and behaviours can sometimes happen, but the important thing is to learn from your set backs.

1. No problem: Unaware of a problem and no thoughts of change.

2. On the fence: Thinking about changing, but still on the fence.

3. Preparation: Intending to change and planning what it would take to make the change happen. e.g. "I want to stop drinking, so I should go to treatment."

4. Action: Taking first steps toward changing behaviour. e.g. "I have started treatment and I have stopped drinking for 3 days."

5. Maintaining change: There is a commitment to change and is practicing new skills and behaviour to maintain change. 


\section{Expectancy about Change}

Changing your behaviour is a long term process that won't happen overnight. It will be hard at times, and you may doubt yourself and think: "I've tried this before and failed, so I doubt I can do it this time". However, if you are committed to changing your behaviour, change is possible.

List what you expect to happen throughout the change process (e.g. it will be hard, I might fail):

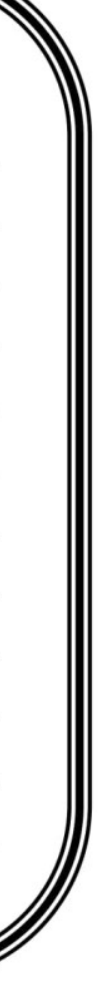

Nice job! Now that you have thought about what to expect during the change process, it's time to start thinking about what things might slow down or stop your change process. 


\section{Barriers to Change}

Sometimes you might face roadblocks that can make changing harder, such as hanging out with criminal friends, doing drugs, and having harmful thoughts.

Sometimes you might try to justify or explain why you did something wrong. These thoughts can get in the way of being honest about your problems. Some of these thoughts include:

* Minimizing Actions: Downplaying the seriousness of your actions.

* Justifying Actions: Making up excuses for why you did something wrong.

* Shifting Responsibility: Moving the blame onto something or someone else.

* Denial: Denying anything happened or that you did anything wrong.

Below are some examples of thoughts that might be used for different types of crimes:

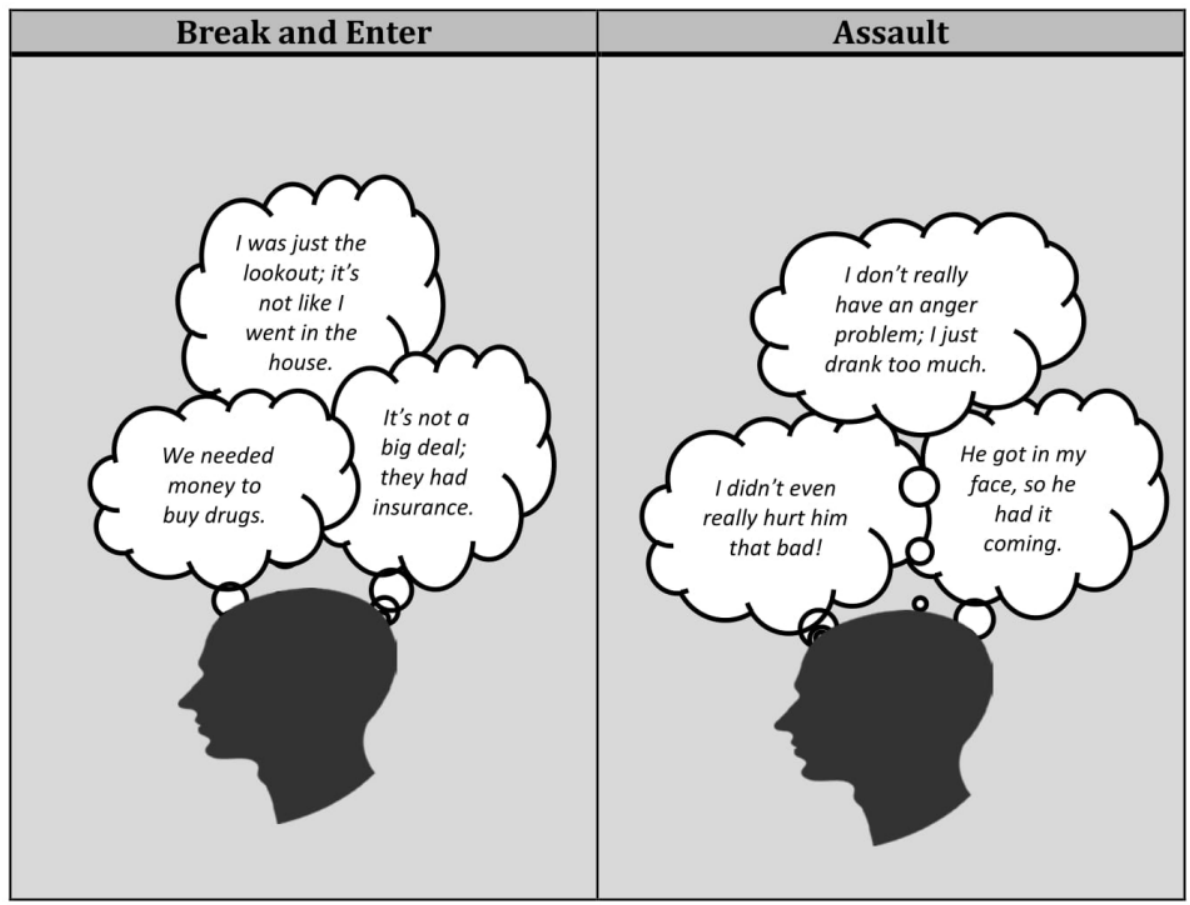




\section{Barriers to Change}

* Now it's your turn. Write down some of your own thoughts that you might use when committing a crime.

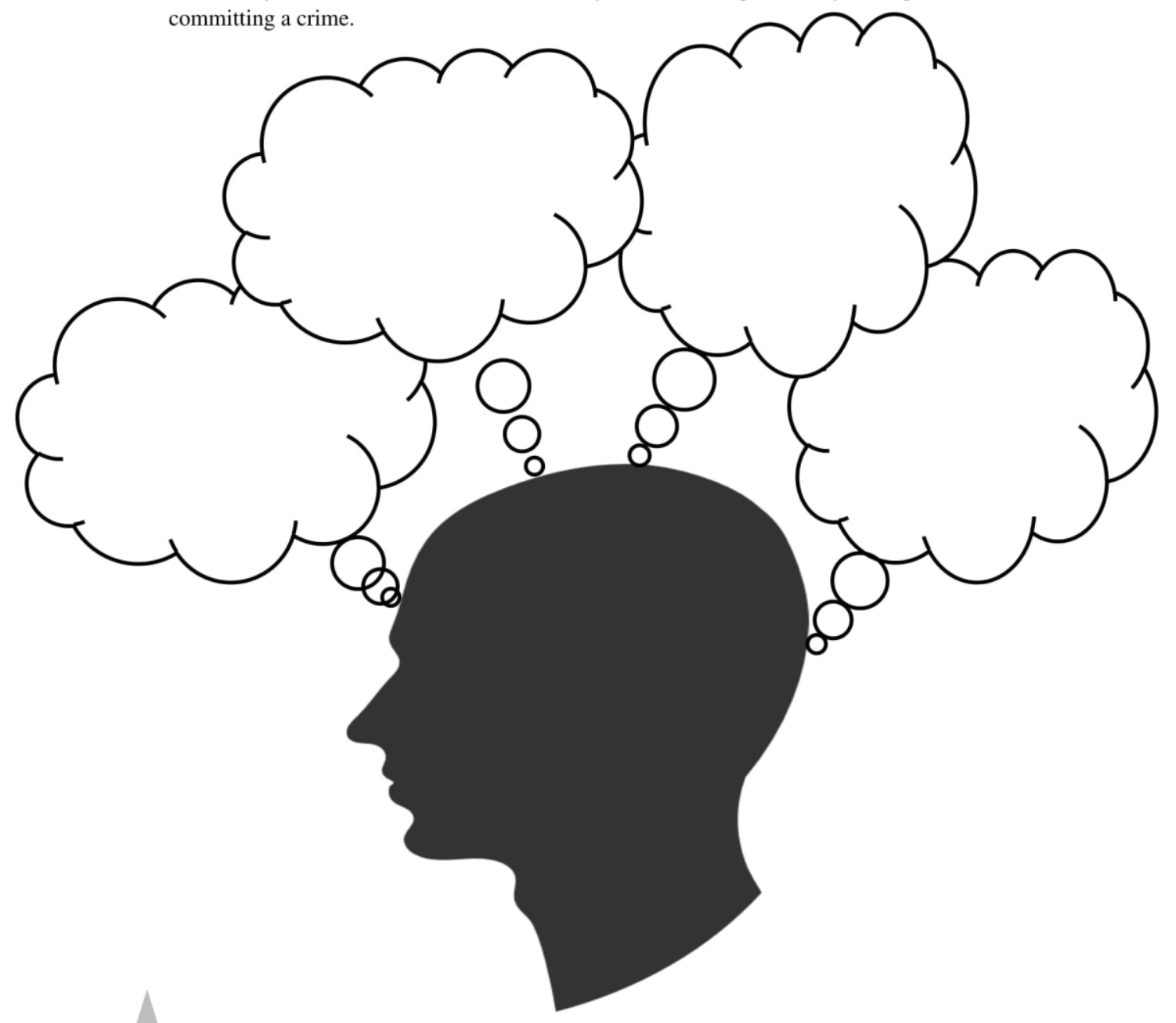

Well done! Now that you have written down some of your harmful thoughts, it's time to look at some of the events that contributed to your offending. 


\section{Offense Chain}

* Making an offense chain means looking back at what happened before, during, and after you committed a crime. This will help you understand everything that happened and how events link together.

* Consider the people, places, situations, and feelings that may increase your risk of getting into trouble. For example:

Who else was there? (e.g. friends, by yourself)

What did you do? (e.g. steal, hit someone)

Where were you? (e.g. at home, at the bar)

When did it happen? (e.g. during the day or night)

Why did you do it? (e.g. revenge, money problems)

How did you feel/what did you think before, during, and after? (e.g. anger, stress, relief, justifications)

Below is an example of an offense chain of someone who was arrested for assault

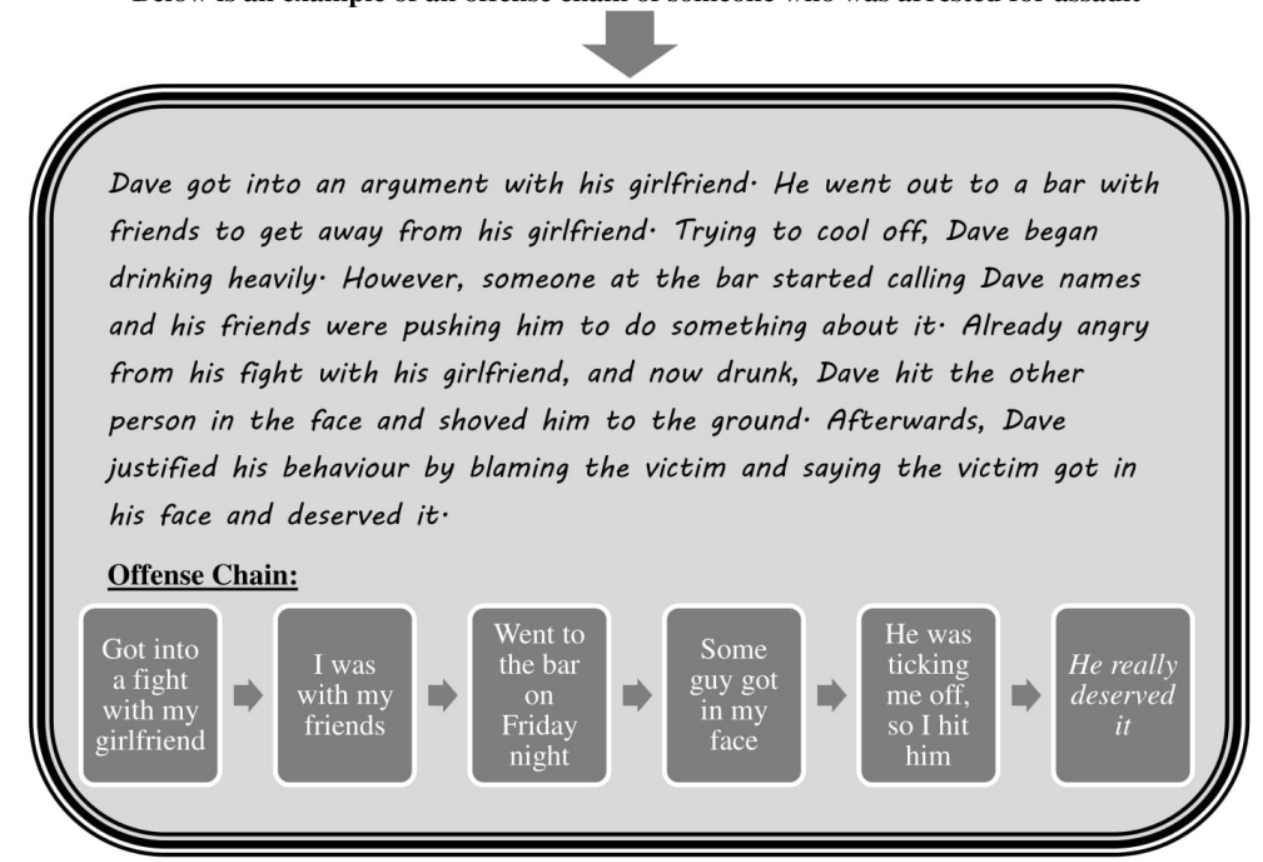




\section{Offense Chain}

* Using the example above, it's now your turn to create your own offense chain.

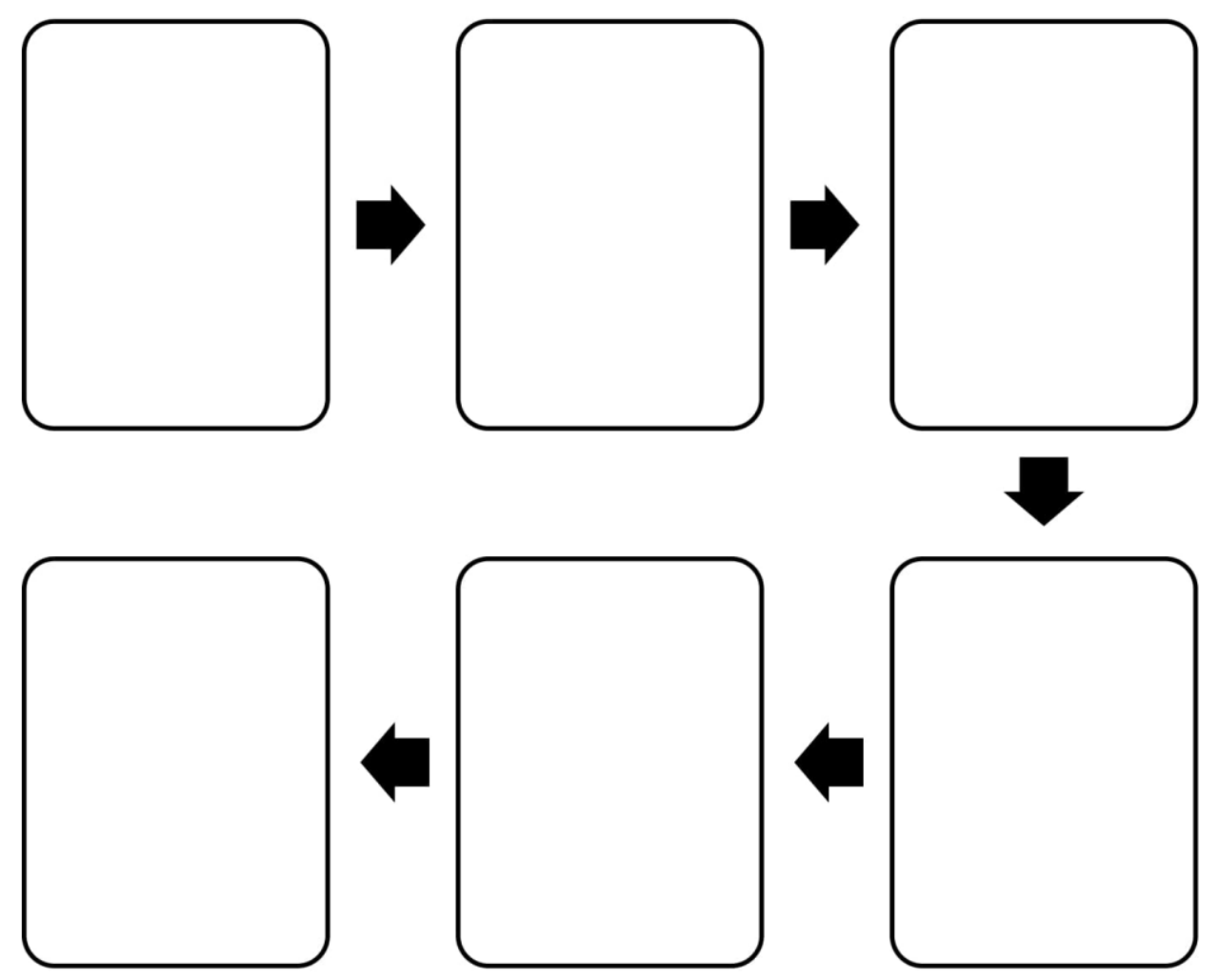

Great work in writing down some of the factors that led up to your crime. It's now time to look at the pros and cons of offending. 


\section{Costs and Benefits}

Often, people have clashing thoughts and feelings, and even fears, about change. For example, someone might want to change his behaviours to stay out of jail but also doesn't want to change because he feels like he will lose friends and money. When someone doesn't want to change, it may be because he sees more good things about offending than bad things.

These feelings are normal, but they can decrease motivation to change. It helps to be aware of what you believe are the costs and the benefits of offending.

In the table below, make a list of the things that you will gain (benefits) if you continue offending and the things that you will lose (costs) if you continue offending.

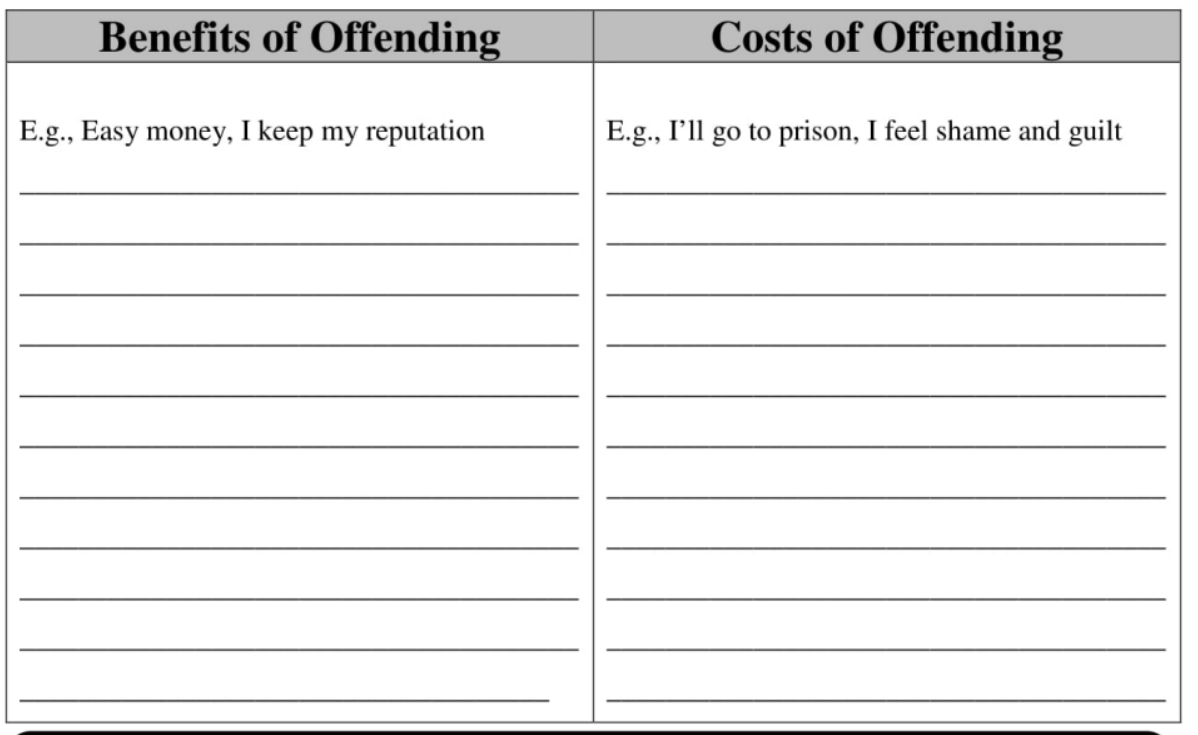

Think About... - How do the costs outweigh the benefits?

- Why might change be a good idea?

Good! Now that you have weighed the costs and benefits of offending, you are ready to start thinking about what your most important reasons for changing are. 


\section{Reasons to Change}

You have just thought about the costs and benefits of offending and seen that the costs of offending are greater than the benefits of offending. Now it's time to take it a step further and think about what your reasons are for changing and what your reasons are for not changing.

\section{Examples}

Reason for not changing: "I don't want to stop stealing because I can't make money any other way."

Reason for changing: "I want to stop stealing because being in jail takes me away from my family, and I want to be there while my kids grow up."

Now it's your turn:

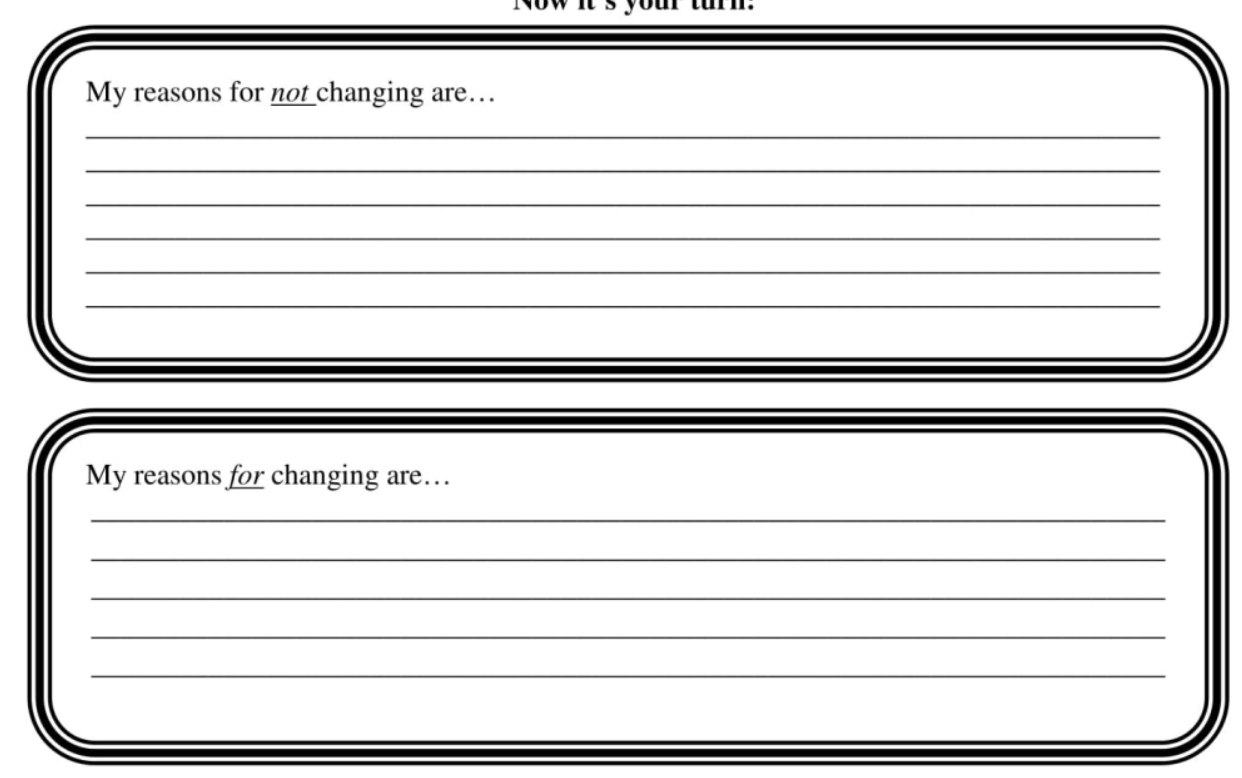

Nice work! You have expressed why you want to change and what some of your fears about changing are. Now, move on to the next activity to determine what your strengths and challenges are and what steps you can take to start making a change. 


\section{Steps to Follow}

Now that you have a better understanding of your expectancies about change, it's time to move toward creating goals.

First, it's important to decide what you think are your strengths (things you are good at or qualities in yourself that you like) and what things about yourself you feel you need to work on.

Making a list of your own strengths and challenges can help increase your motivation to change and can help you to create strategies for making real changes. Your challenges are things that you will work toward changing, and your strengths are qualities that you already have that you can build-upon to help you reach your goals.

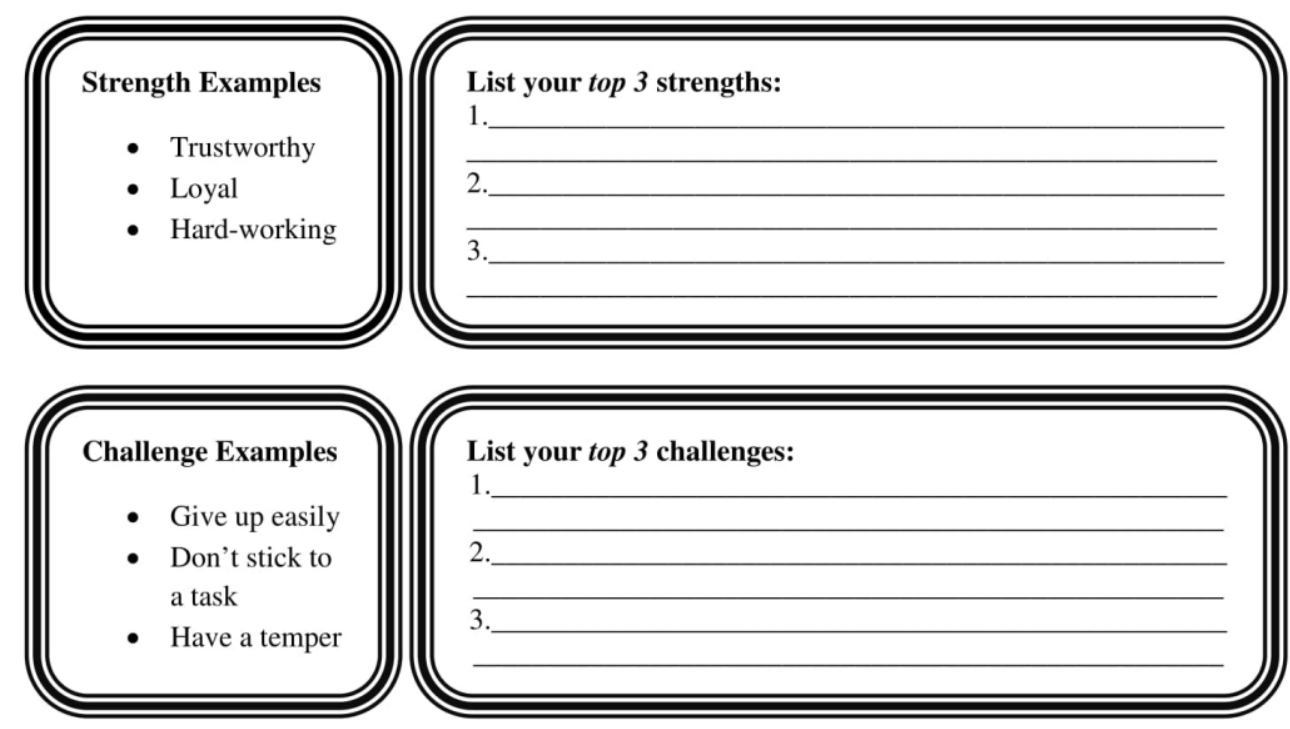

Well done! Now that you see what your strengths are and what things you would like to change, you can move on to creating goals to make those changes. 


\section{Steps to Follow}

\section{Step 1. Setting Goals}

Writing down your goals is an important step toward making changes. Having goals can help keep you on track, but there are a few important things to remember:

$\checkmark$ Goals should be something you can easily measure and track. For example, having the goal of "becoming a better person" is good but too hard to measure or track. A better goal would be to "attend AA meetings twice per week."

$\checkmark$ Goals should be realistic and achievable. While it's great to have big life goals, you are much more likely to reach your goals if they are smaller. For example, setting a goal to not drink any alcohol for one month is much more reachable than having the goal to not drink any alcohol for one year. You can then build up from there. Everyone is different so find goals that are right for you.

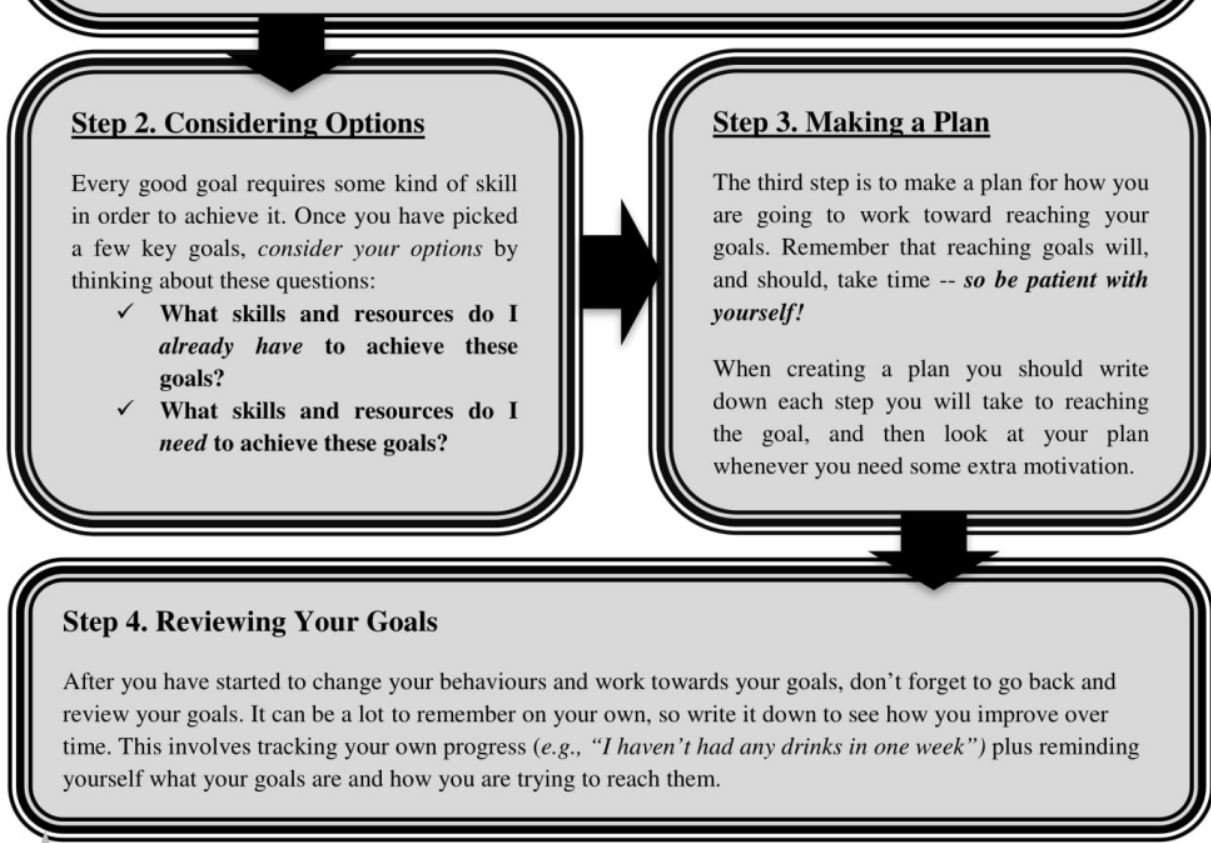

Now that you have reviewed the steps involved in setting goals, check out the next page for an example of a Goals Sheet. Then, you will fill one out for yourself. 


\section{Goals Sheet Example}

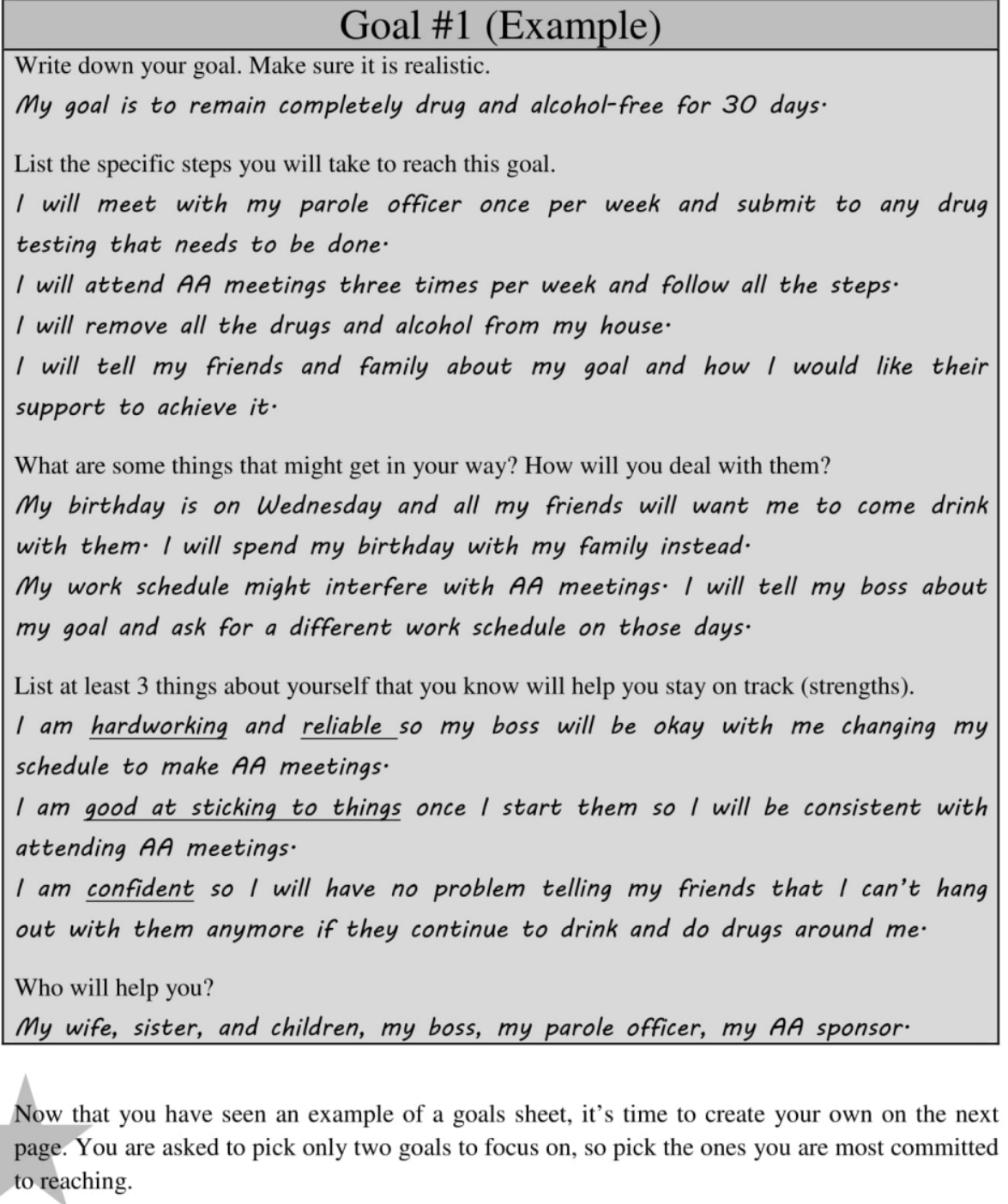

Now that you have seen an example of a goals sheet, it's time to create your own on the next page. You are asked to pick only two goals to focus on, so pick the ones you are most committed to reaching. 


\section{Goals Sheet}

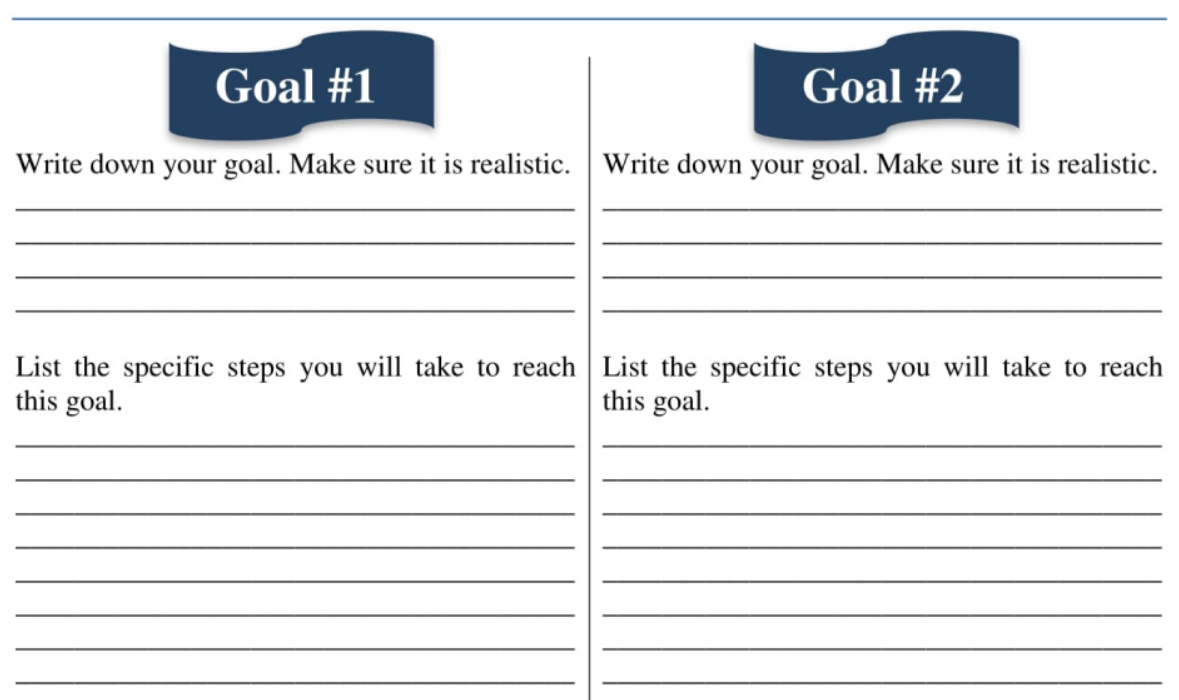

What are some things that might get in your way? How will you deal with them?

What are some things that might get in your way? How will you deal with them?

List at least 3 things about yourself that you know will help you stay on track (strengths).

List at least 3 things about yourself that you know will help you stay on track (strengths).

Who will help you?

Who will help you? 


\section{Summary}

\section{Here's a quick summary of what you have learned about motivation:}

7) Motivation to change is a person's drive to change his or her own beliefs and behaviours.

2) The stages of change are a cycle, where people often don't get change right the first time. It's important to be realistic in your expectations about how and when the change will happen.

3) There will always be roadblocks during the change process; if you can plan for it beforehand, you will have a better chance of overcoming it.

4) If you get stuck during the change process you can always look back to your offense chain or make a new one to help you see where the problem starts.

5) It's important to know, and keep track of, your reasons for changing and why you may or may not want to change.

6) Your strengths will keep you on track while your challenges might hold you back. While working through your challenges, don't forget to build up your strengths.

7) The steps to follow are: 1) Set realistic goals, 2) Consider your options, and 3) Make a concrete plan for how you are going to make the changes.

Now that you know more about motivation, rate yourself again on the scale below to indicate how motivated you are to change right now.

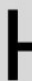




\section{Peers \& \\ Relationships}

Client Handbook Series

January 2015

Developed by Carleton University, Criminal Justice Decision Making Laboratory \& Ontario Ministry of Community Safety and Correctional Services

(C) Ralph C. Serin, Angela DeWolf, \& Sarah McQuaid , \& the Ontario Ministry of Community Safety and Correctional Services

This handbook series is public domain and can be copied and used with clients without cost but also without evidence regarding efficacy. 


\section{What Leads to Crime?}

There are many things that can lead to criminal behaviours, but there are four big risk areas that are most important when thinking about your own actions.

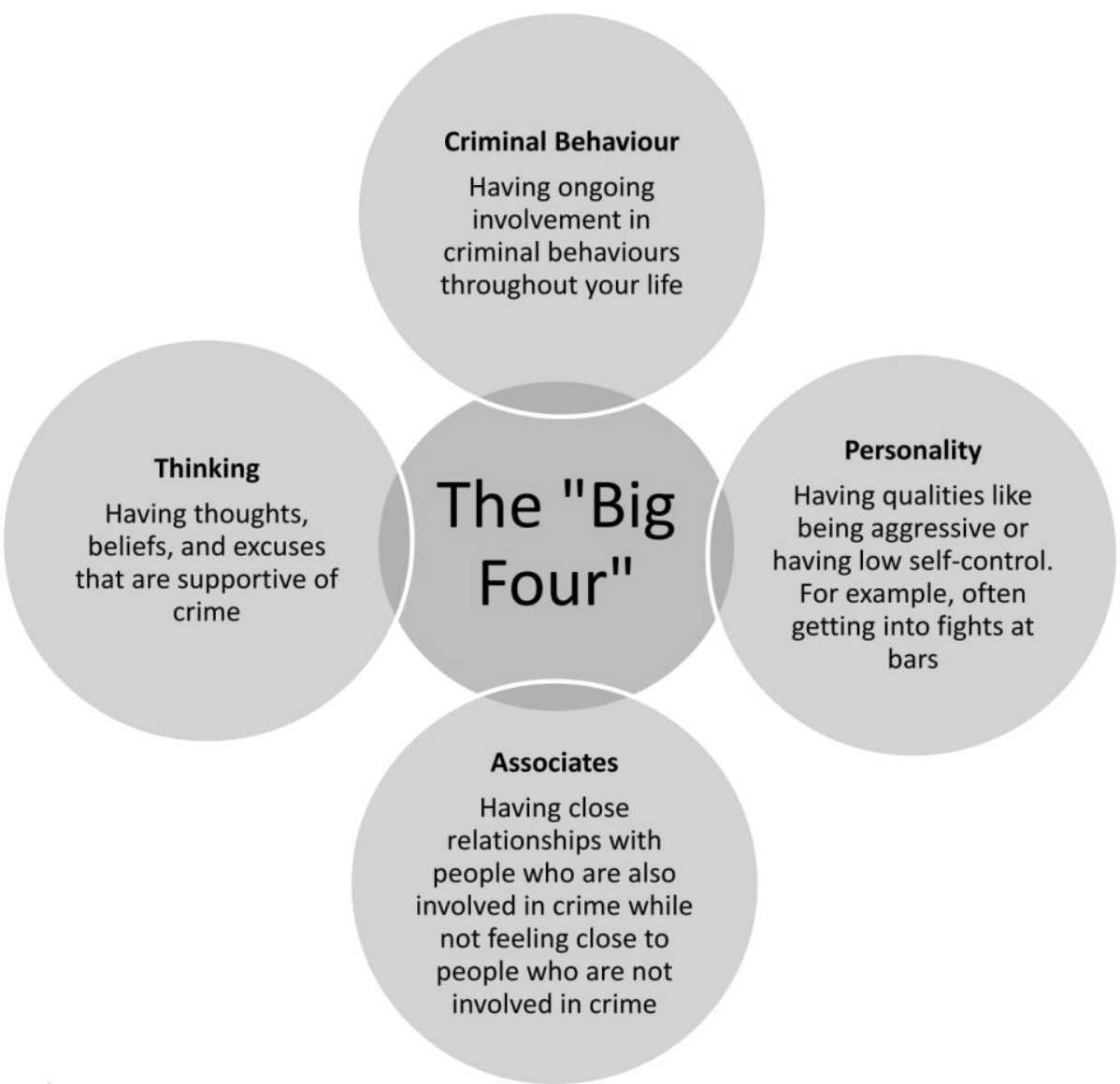

Now that you have learned about the "Big Four" risk areas, think briefly about what traits or qualities you have that might fit into any of these categories. 


\section{Offense Chain}

Building an offense chain can help you understand the events that happened before, during, and after you committed a crime and how these events link together.

It means looking back at the people, places, situations, and feelings that may have placed you at risk for committing a crime.

An offense chain means looking at:

Who else was there? (e.g. friends)

What did we do? (e.g. we got into a fight)

Where were we? (e.g. we were at the bar)

When did it happen? (e.g. during the day or night)

Why did we do it? (e.g. we did it for revenge, money problems)

How did you feel/what did you think before, during, and after? (e.g. anger, stress, relief, justifications)

* Who did you get into trouble with? (e.g. my best friend Alex)

* What did you do with them? (e.g. we broke into a house)

* Where were you and when did it happen? (e.g. we were downtown around 2:00 am)

* Why did you do it? (e.g. we needed money to score some drugs)

* How did you feel? (e.g. I felt excited) 


\section{Let's Think About Who}

Think of your peers as the people who belong to the same social group that you do; they can be your family, your friends, your co-workers, or people you admire, among others. Your relationships with your peers likely play a big part in your offending behaviours. Some of your relationships may be positive and healthy while others may be problematic and unhealthy.

Healthy relationships are based on honesty, respect, and mutual support. These relationships can add to personal improvement and growth. Here are some qualities of positive peer relationships:

Positive Relationship Qualities

- Peers are non-criminal

- Peers are supportive and helpful when you want to make a change

- Peers make you feel good about yourself

- Peers are stable forces in your life

- You have good, effective communication with these people

- Each person is willing to support the other

- You are able to express your feelings to each other

- You are able to successfully resolve conflicts with each other

- You respect one another

Describe a healthy relationship you have experienced. How has this relationship impacted your criminal behaviours? 


\section{Let's Think About Who}

Unhealthy relationships are often based on conflict and manipulation. These relationships contribute to negative emotions and unhealthy or criminal behaviours. These negative emotions often lead to stress and more negative emotions. Here are some qualities of negative peer relationships:

Negative Relationship Qualities

- Peers have pro-criminal lifestyles or attitudes

- Peers do not want you to change

- Peers pressure you to do crimes

- Peers make you feel bad about yourself

- Peers are not supportive

- Peers are not there for you when you ask for help

- The relationship contributes to substance use, violence, or other bad habits and criminal behaviours

- The relationship has frequent conflicts

- The relationship is based on manipulation and control

- Conflicts are not resolved

- Feelings are not expressed

Describe an unhealthy relationship you have experienced.

How has this relationship impacted your criminal behaviours? 


\section{Pro-Social or Criminal?}

We often behave like those around us. Even if we are interested in changing our behaviour, having criminal friends or family can make it difficult. Therefore, it is important to take a good look at your current set of friends or family to see if those around you have a negative influence or a positive influence.

Write down the names of 3 people with whom you spend most of your time in the community. Then for each person, answer the following the set of questions. If you answer yes to most of the questions, then they might not be a positive influence in your life.

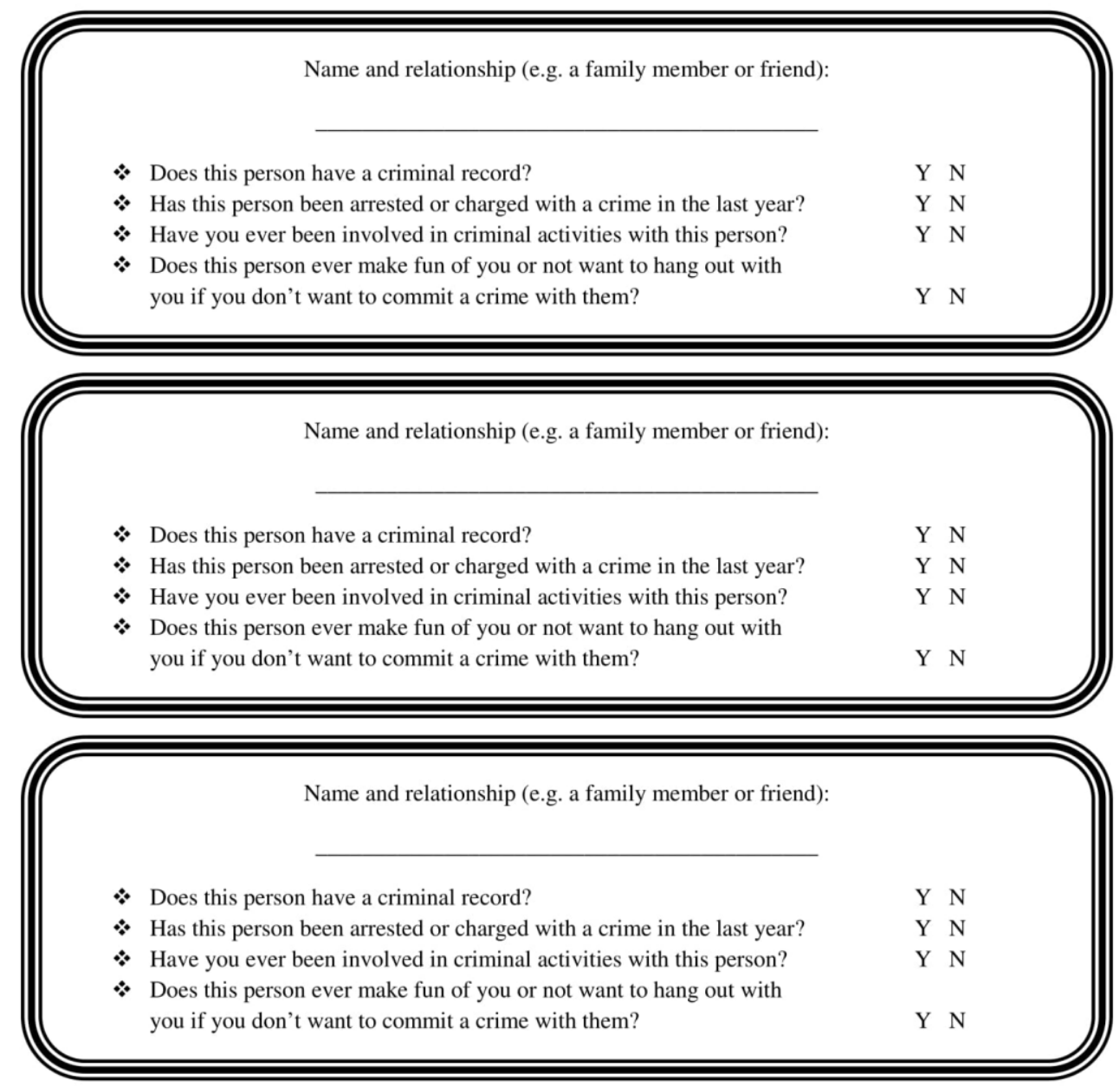




\section{Resolving Conflicts}

Even friends don't always get along. Some conflict is normal in both good and bad relationships, but it is important to know how to properly manage conflict. Otherwise, leftover feelings may affect you, the relationship, or the other person, in a negative and ongoing way. Learning the skills needed to resolve conflict in a healthy way will make it easier to handle.

Knowing which situations might involve conflict and imagining yourself dealing with it in an appropriate way will help you to prepare for the real thing. Here are examples of some effective responses to conflict:

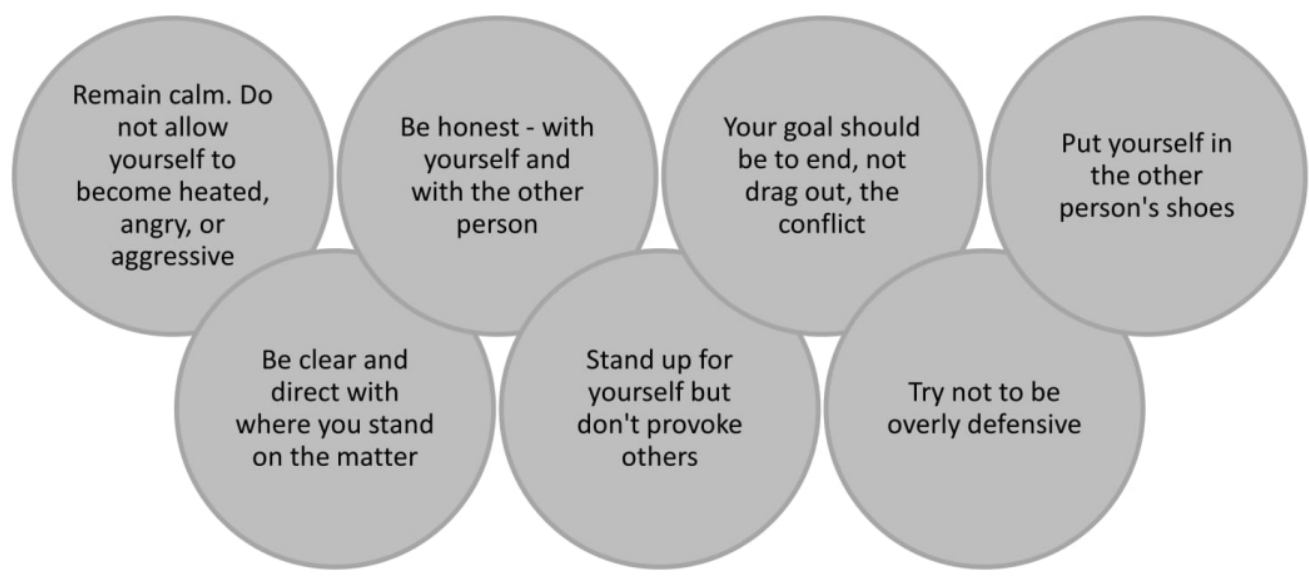

Now that you know some good ways to deal with conflict, complete the activity on the next page

to practice how you would now handle a situation you have experienced in a past. 


\section{Resolving Conflicts}

Being prepared for conflicts will help you deal with them and keep your relationships positive and healthy. Practicing effective responses to conflict will help you learn, and feel confident in, how to respond.

Describe a time when you experienced a conflict with one of your peers.

How did you handle the situation then?

How would you handle the same situation now? What has changed? 


\section{Setting Limits}

If you have criminal friends or family, it is usually a good idea to stop hanging out with them because they can have a negative influence in your life and can put you at risk of getting into trouble. However, sometimes it is not possible to avoid or cut all ties with criminal friends or family. Instead, you can learn to manage criminal friends or family by setting limits, such as when and where you will see them.

\section{When setting limits, it might be helpful to think about:}

1. When and where you typically get into trouble and with whom. For instance, you may get into trouble with your best friend while hanging out at a bar late at night (e.g. after midnight).

2. Some pro-social activities that you like to do. For example, playing basketball, working on your car, or going to the movies.

It is also helpful to plan ahead of time what you might say and do. Below are two examples of how you might create healthy boundaries with a family member or a friend and some things you can say to them.

\section{Your brother is a drug dealer:}

If your brother deals out of his home, then instead of going to his place where he has drugs, you can meet at a neutral place such as a coffee shop or movie theatre.

Things you can say:

1. You're my brother and I care about you, but I can't be around you if you're using or selling drugs.

2. I can't hang out at your place because it's too risky. How about we go grab a coffee instead.

\section{Your best friend is an active criminal:}

If you know that you usually get into trouble with your friend late at night, then you can meet your friend at an organized facility, such as at a sports complex during the day or early evening.

\section{Things you can say:}

1. You're my best friend and I still want to hang out with you, but not if it will put me at risk of going back to prison.

2. We can hang out but lets go shoot some hoops instead of going out for drinks. 


\section{Setting Limits}

Now it's your turn. In the box below, write down when and where you get into trouble and with whom. Also, write down some pro-social activities you can do instead and some things you can say.

When and where do you usually get into trouble? (e.g. late at night when I'm at the bar)

Who are you with? (e.g. friends, family)

What are some pro-social activities that you like to do? (e.g. playing sports, working on my car)

Write down some things you can say:

1 


\section{The Key to Healthy Relationships}

Behaviour is often greatly influenced by the relationships you have with others. Allowing negative relationships to take over and control your life will be reflected in your decisions and actions. The same will happen if you develop positive and supportive relationships - your life choice will reflect this positivity and you will be more successful.

The key to having stable, healthy relationships with people who will help you live a non-criminal lifestyle, is to get involved in non-criminal leisure activities (you can build healthy relationships with the people you meet while doing these activities). Here are some examples:

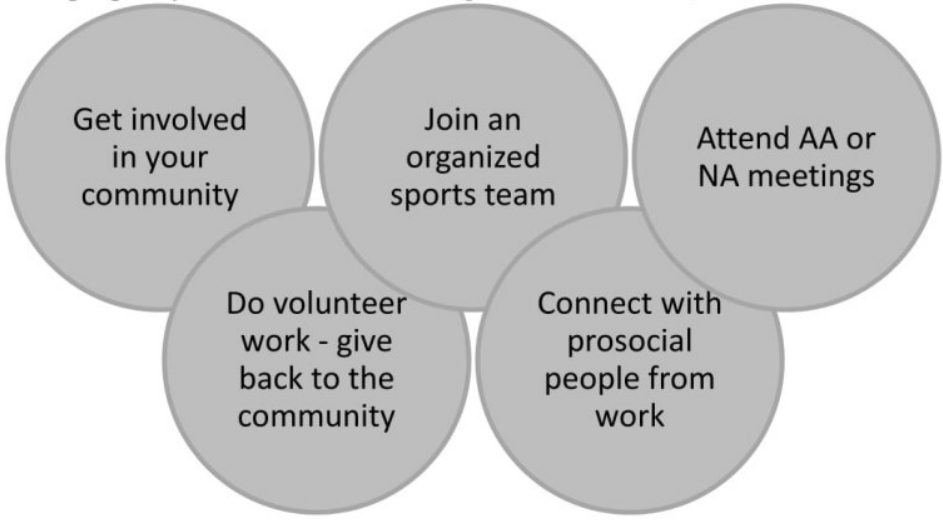

Your turn! What non-criminal activities will you get involved with? What do you hope to gain from doing these activities? 


\section{Summary}

\section{Here's a quick summary of what you have learned about peers and relationships:}

7) Our peers and relationships play a big role in our behaviours.

2) Making an offense chain can help you identify the thoughts, feelings, and actions that led you to committing a crime.

3) Keeping relationships healthy and positive is important for living a non-criminal lifestyle.

4) It is important to take a good look at the people with whom you spend most of your time. This can help you determine whether your friends or family have a positive or negative influence in your life.

5) All relationships have conflict, but learning how to deal with it appropriately can help keep your relationships healthy and positive.

6) Setting limits with criminal friends or family can help you manage these relationships without having to cut all ties.

7) The key to developing and maintaining healthy relationships is to participate in non-criminal leisure activities. It is at these places that you can spend time with people who can be a positive force in your life. 


\section{Substance Abuse}

Client Handbook Series

January 2015

Developed by Carleton University, Criminal Justice Decision Making Laboratory \& Ontario Ministry of Community Safety and Correctional Services

(C) Ralph C. Serin, Angela DeWolf, Sarah McQuaid

$\&$ the Ontario Ministry of Community Safety and Correctional Services

This handbook series is public domain and can be copied and used with clients without cost but also without evidence regarding efficacy. 


\section{The Issue of Addiction}

Addiction is very complicated and the reason people become addicted to drugs and alcohol is not well understood. Addiction creates intense and uncontrollable cravings that don't stop, even when the effects are very bad. Addiction can threaten so many aspects of your life and can affect both you and the people around you forever. Thankfully, treatment for addiction can work. It may be challenging but it is entirely possible to live an alcohol and drug-free lifestyle. If you think you have a problem with substance use or if addiction might be a problem for you, keep reading.

\section{Something To Think About...}

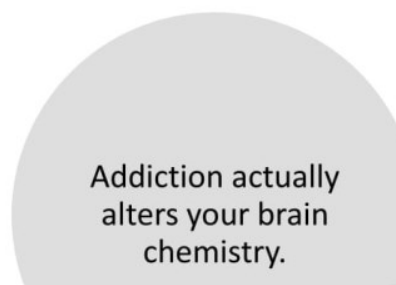

People can become addicts for many reasons, like their environment, brain development, or a combination of things.

\section{It is estimated that roughly half of all prisoners in the US have a substance abuse problem.}

\section{Without substance use, you are much less likely to be reincarcerated.}

This workbook is not meant to replace treatment. It is designed to help you reflect on your substance use behaviour and to help you plan for a better future.

Draw a line on the scale below to show your need to change your substance use behaviour.

\section{I}

No change needed.
Though challenging, treatment for substance abuse is entirely possible and can be very successful. 


\section{Motivation for Substance Use}

People use drugs and alcohol for different reasons, and using them can affect us in many ways, both good and bad. For example, some people might feel that getting drunk makes it easier to talk to people. Others might find that they tend to treat others poorly when they drink.

Think about how your own substance use has affected different parts of your life. Check the box if it has affected that particular area positively or negatively, or both.

\section{Substance abuse has impacted my...}

General living

Mental abilities (e.g., concentration, ability to learn)

Physical health

Physical dependence (e.g., feeling uncomfortable without it)

Ability to cope with problems

Work or school performance

Social life

Relationships

Self-esteem

Family

Good! Now, think about your substance use behaviour.

What have been the top three consequences? List them here:

\section{Positively Negatively}

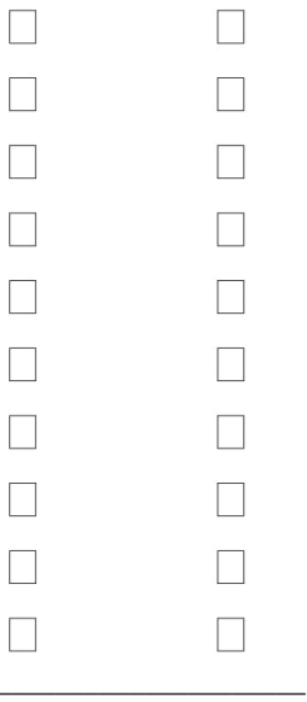

1.

$$
2 \text {. }
$$

3.

Well done! Now that you've started to think about the impacts that substance abuse has had on your life, move on to learn about why substance abuse has become part of your life. 


\section{Motivation for Substance Use}

The path to drug addiction most often begins with choosing to take drugs, which people have many reasons for doing. Over time, though, your ability to choose not to do drugs goes away and the drug use becomes more and more needed. Often the reasons why people started using are different from the reasons why they keep using. It's important to see the differences between why you started and why you continue, in order to understand what you can do to stop.

Start by describing the reasons why you started using. It may be one reason or it may be many. For example, "I was very stressed out about losing my job" or "I wanted to be cool."
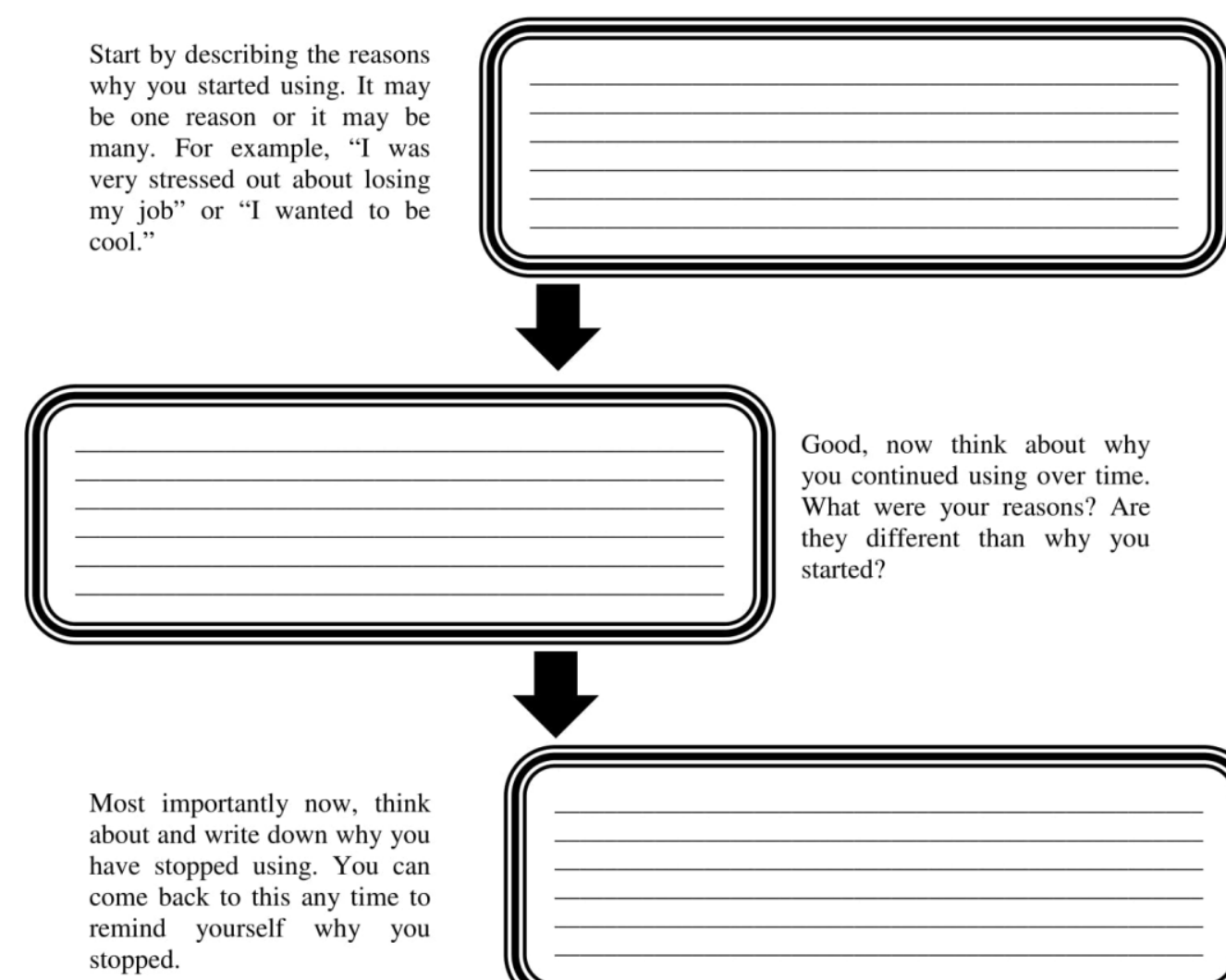

Good, now think about why you continued using over time. What were your reasons? Are they different than why you started? 


\section{Substance Abuse and Crime}

While it's not the only reason for it, there is a clear link between alcohol, drugs and crime. In fact, many people arrested for crimes were high or drunk when they did it. Also, the type of substance abuse is often related to different types of crime.

* Alcohol and Crime: Alcohol is an important part of many violent crimes. For instance, people that abuse alcohol are at a higher risk for violent behaviour, such as fights and domestic assaults. Important note: although they may be related, fixing a substance abuse problem cannot totally fix domestic abuse because there are often other problems involved that also need to be dealt with.

* Drugs and Crime: Drugs are often a key factor in many property crimes. For example, breaking and entering, or robbery are often committed in order to get money to buy drugs.

Below are some questions that can help you start making the link between substance abuse and your criminal behaviour. Circle the answers that best describe you.

1. Do you typically abuse:
a) Alcohol
b) Drugs
c) Both

2. What type of crime are you currently charged with:
a) Assault
b) Domestic Violence
c) Break and Enter
d) Theft
e) Drug possession
f) Other
If other, list:

3. The day you were arrested for your current charge, were you:
a) Drunk
b) High
c) Both 


\section{Issues with Problem Solving}

Addictions affect the way we think about and solve problems in our daily lives. Substance use lowers our self-control and blocks our ability to think about the consequences of our actions. This also means that drinking or using one drug can lead to using other drugs. While you are using you will not see the consequences of your actions as clearly as if you were sober or straight. This can, and often does, lead to making poor decisions. You might get into trouble because of it, or do impulsive things you later regret like stealing or getting into fights. Can you think of a time when this has happened?

In the spaces below, describe a time when you were faced with a problem that you solved poorly because of your substance use.
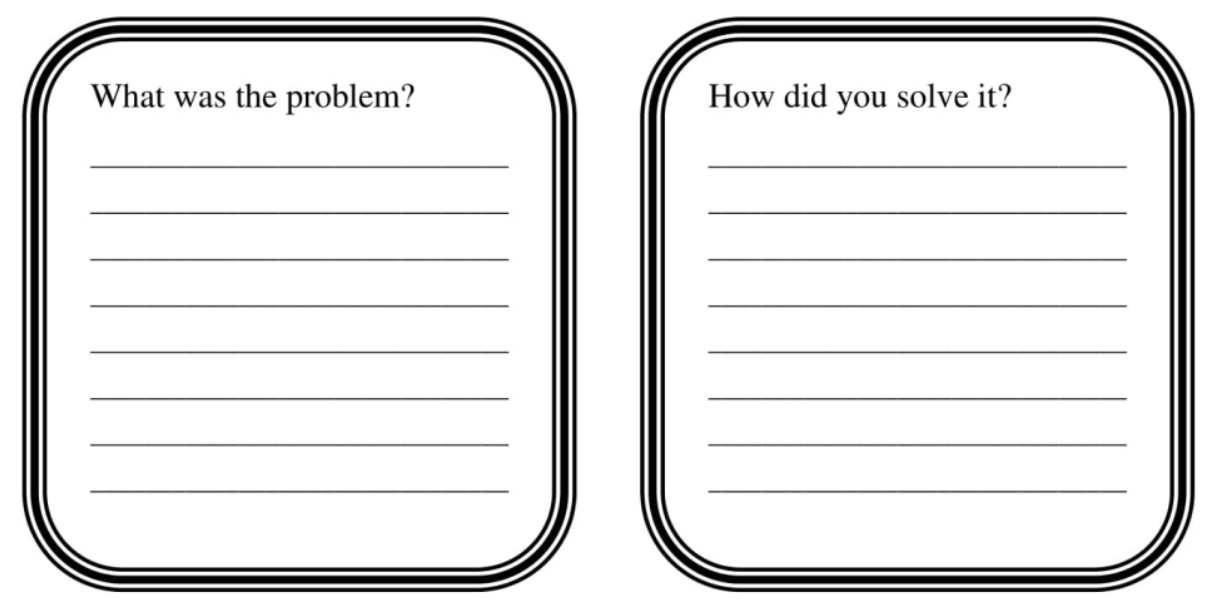

Good! Now, think about if you were faced with the same problem now. How would you try to solve it?

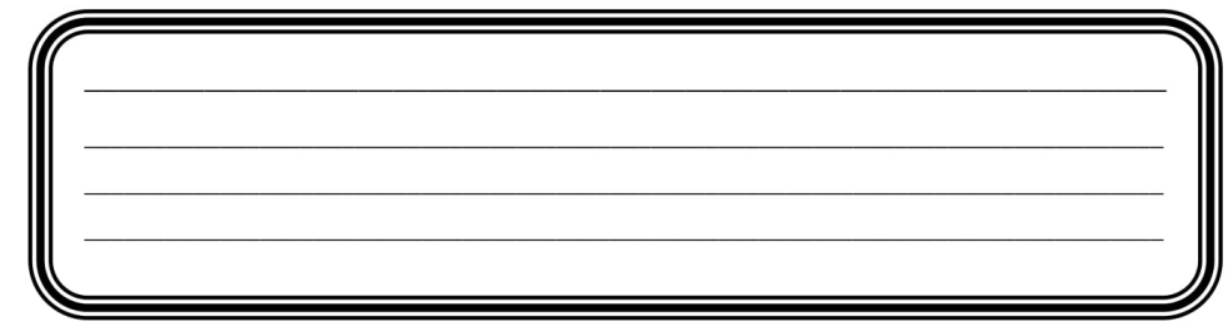




\section{Relapse Prevention}

A "Relapse Prevention Plan" can help change your addictive behaviour by first finding the things that cause the biggest risk for you and then making a plan to deal with or avoid those risk factors.

The figure below shows the pathways that a person may go through when they are faced with a high-risk situation.
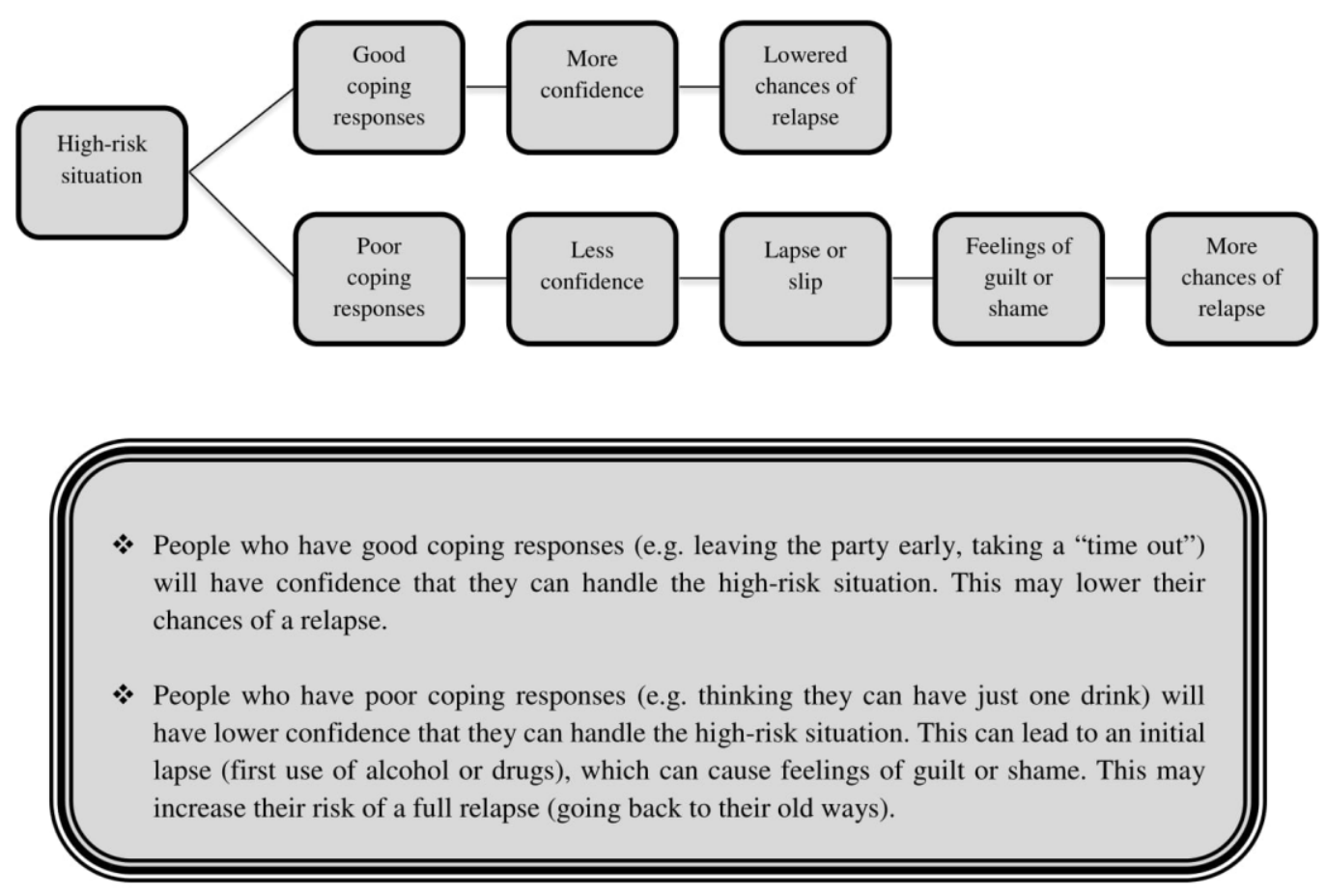

Good work! Remember: Avoiding high-risk situations in the first place is one of the best ways to prevent relapse. The next section will outline the different steps in making a relapse prevention plan. 


\section{Relapse Prevention}

\section{Step 1: Identifying high-risk factors}

There may be times when you are faced with situations or have feelings that can put you at greater risk for a relapse. Some examples include:

1. Negative (e.g., stress, anger, boredom) emotions that lead to using substances to feel better, or positive (e.g., excitement, happiness) emotions that lead to using substances to celebrate.

2. Thinking: thoughts that make using or drinking seem ok. (e.g. "I can handle just one drink")

3. Conflict with others: this can lead to negative emotions (e.g. having an argument with your partner can leave you angry).

4. Hanging out with friends or family when alcohol or drugs are there.

Remember, it is not always possible to avoid these high-risk situations. However, once you are aware of the people, feelings, and situations that can put you at risk for a relapse, you can handle them better.

Step 2: Making a Plan

Once you have identified your high-risk situations, it is important to make a plan or a way to cope (or deal) with these situations. This can help you be prepared so that you are less likely to be caught off guard. Having a plan may also give you a bigger sense of control and confidence in these situations. This involves planning what you will say or do in these situations.

For example, you are invited to celebrate a friend's birthday at a restaurant. You could:

Plan 1: Order a non-alcoholic drink before sitting down.

Plan 2: Plan to leave early if you begin to feel uncomfortable.

Plan 3: Have an answer ready if they offer you a drink. e.g. "No thanks, I'm driving" or "No thanks, I don't drink anymore."

Plan 4: Go with a non-drinking friend. 


\section{Relapse Prevention}

Using the information from the previous section and the example below, think of some possible risk factors and how you plan to handle them in the future.

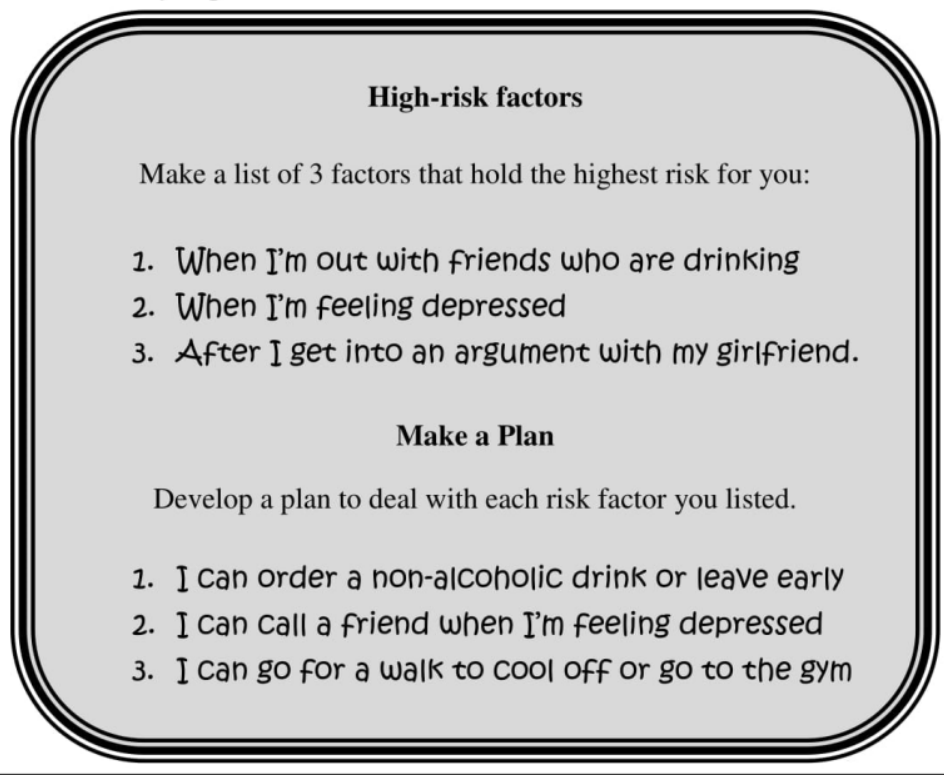

1.

Make a list of 3 factors that hold the highest risk for you:

2.

3. 


\section{Planning for Failure}

Changing your addictive behaviour is a process that can be very hard at times. Some people will have several lapses (i.e. slips) before they stop for good. After a slip occurs, you may feel guilt or shame, which may lead you to start drinking or using drugs again in order to avoid these negative feelings.

$B u t$, if you do have a slip it does not mean you are a failure or you lack will power. By viewing these slips as a learning opportunity, you can learn to deal with them so they do not turn into a full-blown relapse (i.e. when you go back to your old ways, such as uncontrolled drinking or drug use).

Below are some ways that can help you manage a lapse before it turns into a relapse.

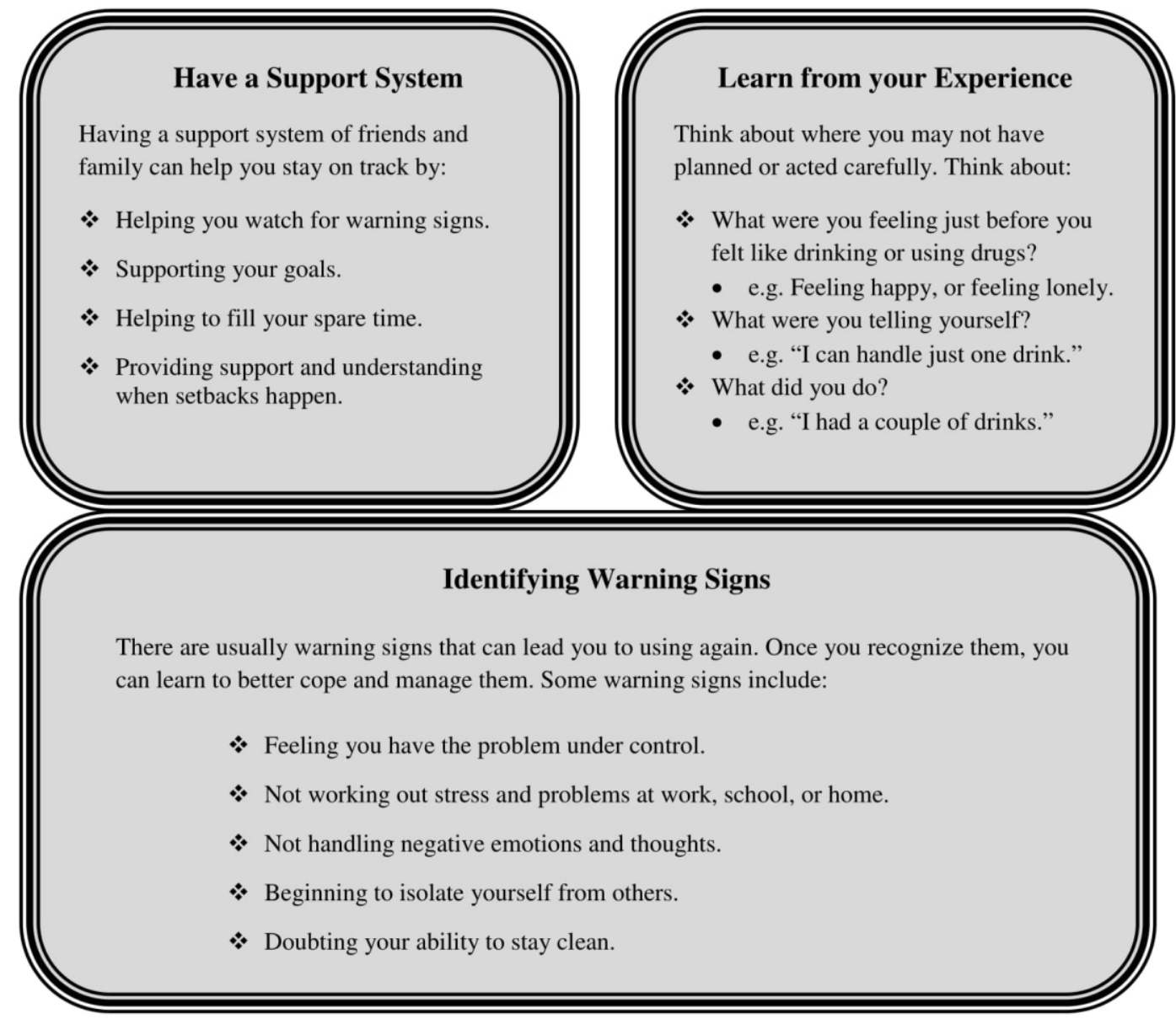




\section{Realistic Goals}

Setting realistic and reachable goals is an important part of really changing your behaviour. It is also a huge part of setting yourself up for successful recovery.

When setting goals, some recovering addicts feel like they won't be successful unless they give up absolutely all substances, even ones they didn't have a problem with. For example, a heroin user might also stop using alcohol or even tobacco.

Others feel like it's not realistic for them to give up all substances. For example, a cocaine user may stop using cocaine but continue using alcohol because they find it doesn't make them want to use other drugs or do crime.

It's important to think about this very carefully and to be honest with yourself about what is realistic for you, and what is the best decision for you in terms of the success of your recovery.
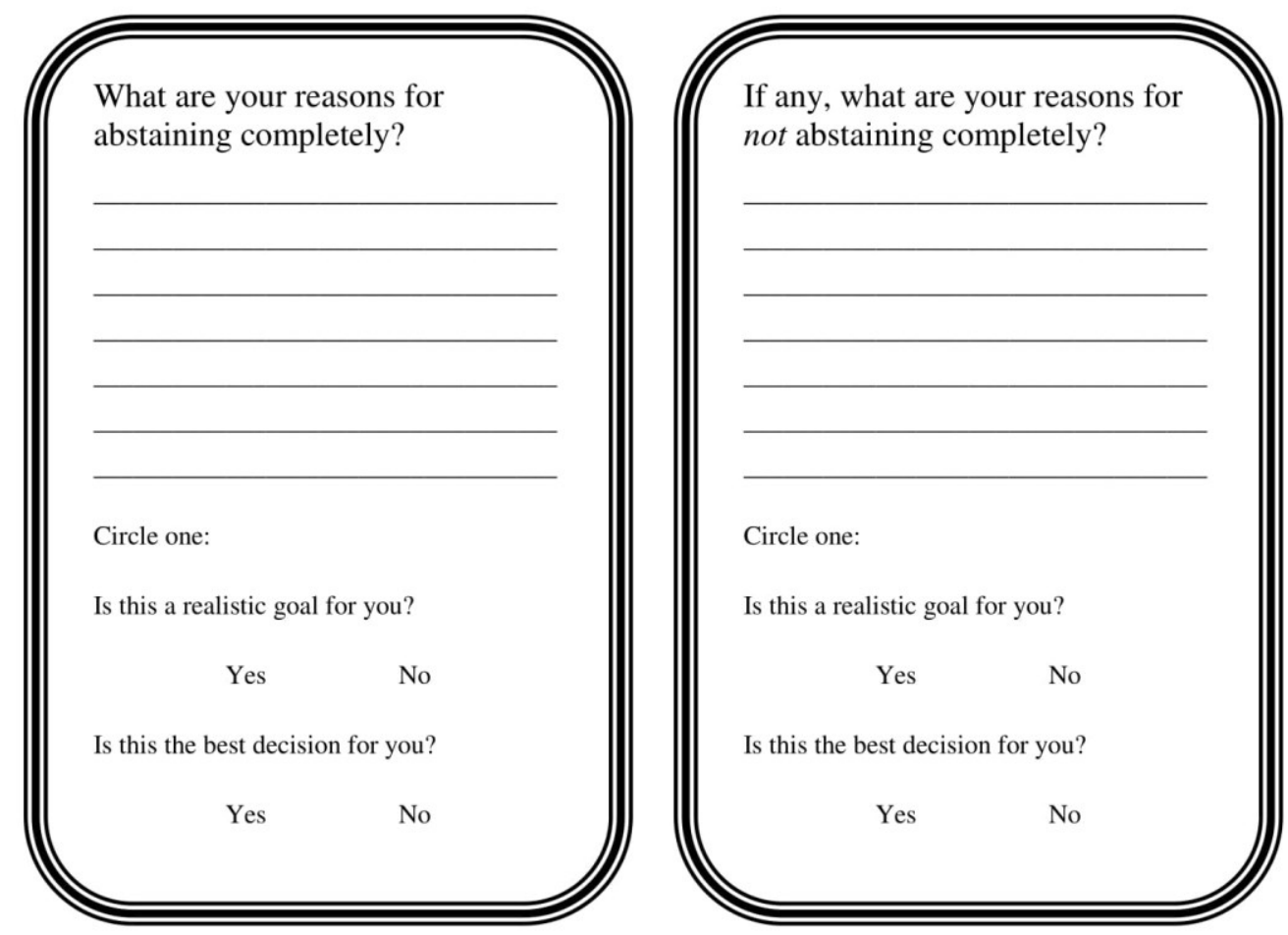


\section{Summary}

\section{Here's a quick summary of what you have learned about substance use:}

7) Addiction is a complex illness that can affect your life and the lives of those around you.

2) Treatment and recovery can be challenging but very successful.

3) On the road to recovery, it's important to figure out why you started using, and also what made you continue using.

4) It's also important to remember why you have stopped using. You can come back to this and remind yourself of your motivation during challenging times.

5) Substance use lowers our self-control and leads to poor decision-making when we try to solve daily problems.

6) There is a link between substance abuse and crime. People who abuse alcohol are more likely to be involved in violent crimes and hurting others. People who abuse drugs are more likely to be involved in robberies and potentially hurting others.

7) Having a relapse prevention plan can help you be prepared when you are faced with a highrisk situation.

8) It's important to be realistic and honest with ourselves when we are making goals. 


\section{Appendix B}

(Online) Client Satisfaction Survey: Evaluating the Self-Directed Workbooks

\section{Part 1 - Demographics and Background}

1. Please indicate your gender.
a. Female
b. Male
c. Prefer not to answer

2. Please indicate the range that includes your age.
a. $18-24$
b. $25-34$
c. $35-44$
d. $45-54$
e. $55-64$
f. 65 or older
g. Prefer not to answer

3. Please indicate your level of education.
a. Below grade 8
b. Grade 8
c. Grade 9
d. Grade 10
e. Grade 11
f. Grade 12
g. Technical/vocational training
h. Post-secondary education

\section{Part 2 - Self-Directed Workbooks}

1. Did you complete all of the workbooks?
a. Yes
b. No

2. If you answered no for the previous question, why did you not complete them all?

- Open-ended response option

3. Is there anything that we missed or that we should change on in any of the five workbooks?

- Open-ended response option

4. My PO was able to answer any questions I had about the workbooks.
a. Yes
b. No
c. My PO was not involved in my use of the workbooks 
Thinking about the interactive workbook that focused on anger that you have previously completed, please indicate how you feel about each of the statements below.

\begin{tabular}{|c|l|l|l|l|l|l|}
\hline & & & & & & \\
\hline $\begin{array}{c}\text { I feel that the workbook material was easy } \\
\text { to understand. }\end{array}$ & & & & & & \\
\hline $\begin{array}{c}\text { The workbook material prepared me to be } \\
\text { more successful in the community. }\end{array}$ & & & & & & \\
\hline $\begin{array}{c}\text { I feel that the workbook material provided } \\
\text { me with knowledge and skills that will be } \\
\text { useful in the community. }\end{array}$ & & & & & & \\
\hline $\begin{array}{c}\text { The workbook is well structured. } \\
\text { I feel that the workbook activities were } \\
\text { relevant to the topic it was covering. }\end{array}$ & & & & & & \\
\hline $\begin{array}{c}\text { I feel that the reading level of this } \\
\text { workbook was appropriate. }\end{array}$ & & & & & & \\
\hline $\begin{array}{c}\text { I feel that activities in this workbook } \\
\text { complimented previous programs that I } \\
\text { have completed. }\end{array}$ & & & & & & \\
\hline $\begin{array}{c}\text { I feel that the workbook used language } \\
\text { that is easy to understand. }\end{array}$ & & & & & & \\
\hline $\begin{array}{c}\text { I feel that the instructions in the } \\
\text { workbook were clear enough. }\end{array}$ & & & & & & \\
\hline $\begin{array}{c}\text { I feel that the workbook took a reasonable } \\
\text { amount of time to complete. }\end{array}$ & & & & & & \\
\hline
\end{tabular}

Thinking about the interactive workbook that focused on criminal attitudes that you have previously completed, please indicate how you feel about each of the statements below.

\begin{tabular}{|c|c|c|c|c|c|c|}
\hline & 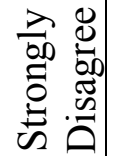 & 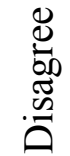 & $\begin{array}{l}\overline{\bar{g}} \\
\stackrel{\overline{0}}{0} \\
z\end{array}$ & 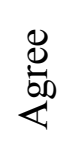 & 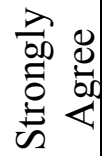 & 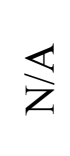 \\
\hline $\begin{array}{l}\text { I feel that the workbook material was easy } \\
\text { to understand. }\end{array}$ & & & & & & \\
\hline
\end{tabular}




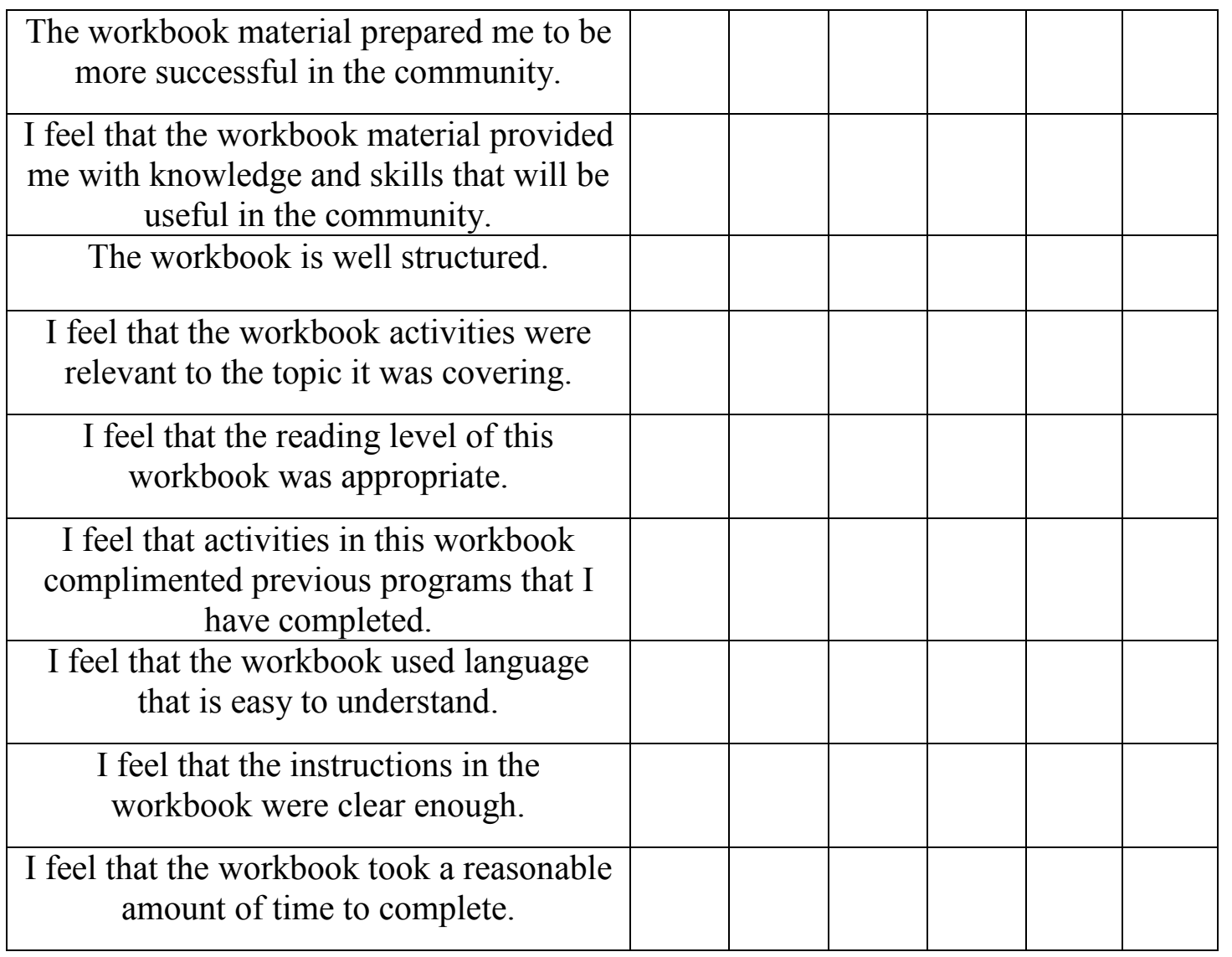

Thinking about the interactive workbook that focused on motivation to change that you have previously completed, please indicate how you feel about each of the statements below.

\begin{tabular}{|c|c|c|c|c|c|c|}
\hline & 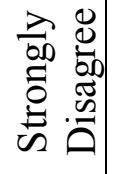 & 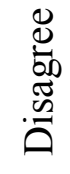 & 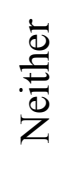 & 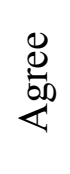 & 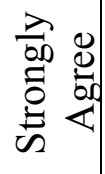 & 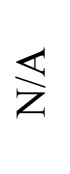 \\
\hline \multicolumn{7}{|l|}{$\begin{array}{l}\text { I feel that the workbook material was easy } \\
\text { to understand. }\end{array}$} \\
\hline \multicolumn{7}{|l|}{$\begin{array}{l}\text { The workbook material prepared me to be } \\
\text { more successful in the community. }\end{array}$} \\
\hline \multicolumn{7}{|l|}{$\begin{array}{l}\text { I feel that the workbook material provided } \\
\text { me with knowledge and skills that will be } \\
\text { useful in the community. }\end{array}$} \\
\hline \multicolumn{7}{|l|}{ The workbook is well structured. } \\
\hline $\begin{array}{l}\text { I feel that the workbook activities were } \\
\text { relevant to the topic it was covering. }\end{array}$ & & & & & & \\
\hline
\end{tabular}




\begin{tabular}{|c|l|l|l|l|l|l|}
\hline $\begin{array}{c}\text { I feel that the reading level of this } \\
\text { workbook was appropriate. }\end{array}$ & & & & & & \\
\hline $\begin{array}{c}\text { I feel that activities in this workbook } \\
\text { complimented previous programs that I } \\
\text { have completed. }\end{array}$ & & & & & & \\
\hline $\begin{array}{c}\text { I feel that the workbook used language } \\
\text { that is easy to understand. }\end{array}$ & & & & & & \\
\hline $\begin{array}{c}\text { I feel that the instructions in the } \\
\text { workbook were clear enough. }\end{array}$ & & & & & & \\
\hline $\begin{array}{c}\text { I feel that the workbook took a reasonable } \\
\text { amount of time to complete. }\end{array}$ & & & & & & \\
\hline
\end{tabular}

Thinking about the interactive workbook that focused on substance use that you have previously completed, please indicate how you feel about each of the statements below.

\begin{tabular}{|c|c|c|c|c|c|c|}
\hline & 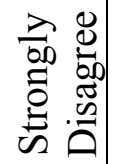 & 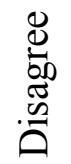 & 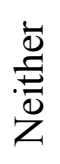 & 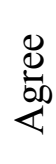 & 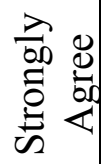 & $\frac{\nwarrow}{Z}$ \\
\hline \multicolumn{7}{|l|}{$\begin{array}{l}\text { I feel that the workbook material was easy } \\
\text { to understand. }\end{array}$} \\
\hline \multicolumn{7}{|l|}{$\begin{array}{l}\text { The workbook material prepared me to be } \\
\text { more successful in the community. }\end{array}$} \\
\hline \multicolumn{7}{|l|}{$\begin{array}{l}\text { I feel that the workbook material provided } \\
\text { me with knowledge and skills that will be } \\
\text { useful in the community. }\end{array}$} \\
\hline \multicolumn{7}{|l|}{ The workbook is well structured. } \\
\hline \multicolumn{7}{|l|}{$\begin{array}{l}\text { I feel that the workbook activities were } \\
\text { relevant to the topic it was covering. }\end{array}$} \\
\hline \multicolumn{7}{|l|}{$\begin{array}{l}\text { I feel that the reading level of this } \\
\text { workbook was appropriate. }\end{array}$} \\
\hline \multicolumn{7}{|l|}{$\begin{array}{l}\text { I feel that activities in this workbook } \\
\text { complimented previous programs that I } \\
\text { have completed. }\end{array}$} \\
\hline \multicolumn{7}{|l|}{$\begin{array}{l}\text { I feel that the workbook used language } \\
\text { that is easy to understand. }\end{array}$} \\
\hline $\begin{array}{l}\text { I feel that the instructions in the } \\
\text { workbook were clear enough. }\end{array}$ & & & & & & \\
\hline
\end{tabular}


I feel that the workbook took a reasonable amount of time to complete.

Thinking about the interactive workbook that focused on peer relationships that you have previously completed, please indicate how you feel about each of the statements below.

\begin{tabular}{|c|c|c|c|c|c|c|}
\hline & 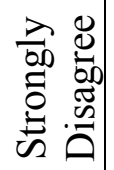 & 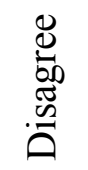 & 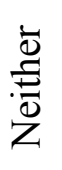 & 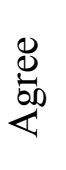 & 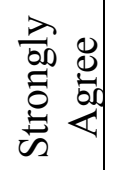 & $\overleftrightarrow{\measuredangle}$ \\
\hline $\begin{array}{l}\text { I feel that the workbook material was easy } \\
\text { to understand. }\end{array}$ & & & & & & \\
\hline $\begin{array}{l}\text { The workbook material prepared me to be } \\
\text { more successful in the community. }\end{array}$ & & & & & & \\
\hline $\begin{array}{l}\text { I feel that the workbook material provided } \\
\text { me with knowledge and skills that will be } \\
\text { useful in the community. }\end{array}$ & & & & & & \\
\hline The workbook is well structured. & & & & & & \\
\hline $\begin{array}{l}\text { I feel that the workbook activities were } \\
\text { relevant to the topic it was covering. }\end{array}$ & & & & & & \\
\hline $\begin{array}{l}\text { I feel that the reading level of this } \\
\text { workbook was appropriate. }\end{array}$ & & & & & & \\
\hline $\begin{array}{l}\text { I feel that activities in this workbook } \\
\text { complimented previous programs that I } \\
\text { have completed. }\end{array}$ & & & & & & \\
\hline $\begin{array}{l}\text { I feel that the workbook used language } \\
\text { that is easy to understand. }\end{array}$ & & & & & & \\
\hline $\begin{array}{l}\text { I feel that the instructions in the } \\
\text { workbook were clear enough. }\end{array}$ & & & & & & \\
\hline $\begin{array}{l}\text { I feel that the workbook took a reasonable } \\
\text { amount of time to complete. }\end{array}$ & & & & & & \\
\hline
\end{tabular}


Appendix C

\section{Text for Email to Texas PO's}

Attached to this email is a recruitment notice from external researchers at Carleton University who invite you to participate in their research study involving self-directed offender workbooks. Please note that this research is completely voluntary. Thank you. 


\section{Appendix D}

\section{Texas Probation Officer Informed Consent}

This informed consent form is designed to explain to you the study's purpose, the required tasks and additional information to allow you to decide whether or not you wish to participate in the study. Please take the time to read this information carefully.

Project Title: Self-directed workbooks: Evaluating their efficacy in a US Probation setting

\section{Research personnel:}

Stephanie Biro

Department of Psychology Graduate Student, Carleton University

stephaniebiro@.cmail.carleton.ca Telephone: 613-520-2600 x 1595

Ralph Serin

Ph.D., C. Psych., Department of Psychology Faculty, Carleton University ralph.serin@,carleton.ca Telephone: 613-520-2600 x 1557

Date of ethics clearance: To be determined to CUREB (as indicated on the clearance form)

Ethics clearance for the collection of data expires: To be determined to CUREB (as indicated on the clearance form)

Purpose: The purpose of this study is to implement recently developed self-directed workbooks at various probation sites in order to begin to evaluate their effectiveness. We also plan to survey your clients on their use of the workbooks at a later date in order to evaluate their usefulness and appropriateness.

Task requirements: If you choose to participate in the study, you will be asked to incorporate the workbooks into your current probation practices for some of your clients. More specifically, you will have clients who chose not to participate (i.e., no workbooks during their probation), clients who have chosen to participate and have been assigned to the control group (i.e., no workbooks) during their probation) and those who have chosen to participate and have been assigned to the experimental group (i.e., will have workbooks to include into your practices). For the clients who consent to participate, they will be randomly assigned into either the control group (i.e., current probation practices only) or the experimental group (i.e., self-directed workbooks alongside current probation practices). We will provide you with a Participant Log where each participant ID number has been randomly assigned to one of the two groups. For example, the first participant to consent to the study may be placed into the control group and will thus be given no 
workbooks. As well, all clients who choose to participate will receive 10 hours of Community Service Restitution (CSR) credits, whether they are assigned to the control or the experimental group.

You will be asked to incorporate the self-directed offender workbooks into your current probation practices for the clients who are in the experimental group. These workbooks target anger, criminal attitudes, peer relationships, substance abuse and motivation to change. For example, the anger workbook includes descriptions of key terms relating to that area (e.g., reactive violence versus instrumental violence, anger versus hostility or aggression), a page to log feelings of anger, the necessary steps in order for the client to change their thinking and a section on anger management and conflict resolution. Each workbook has activities that can be incorporated during your client sessions or be assigned as homework. You will continue your regular probation practice over the course of the next few months - with the only difference being that some of your clients will also be working through these five workbooks. How you choose to incorporate these workbooks into your practice is up to your discretion. You may choose to have your clients do the activities as homework before their next session or you may choose to have them complete them during your face-to-face. In approximately four months, we will ask that you forward a survey link to your clients in the experimental group. The survey will contain questions that assess the client's views on the content and usability of the workbooks.

Time required: While the entire study will take approximately four months, the implementation of these workbooks are not expected to significantly impact your workload. We hope that these workbooks will align with your current practices and be a helpful case management tool.

Remuneration: Your participation in this study is completely voluntary and you will not be paid for your participation.

Right to withdraw: You have the right to withdraw from this study at any point, without penalty. If you choose to withdraw, please email Stephanie Biro, whose contact information can be found at the top of this form and you will be withdrawn from the research study. Please also email Stephanie Biro if any of your clients choose to withdraw from the study at any point.

Potential risk and discomfort: The level of potential risk and discomfort is expected to be very low. However, if you should feel discomfort at any point during this study, please be reminded that your participation is entirely voluntary, and that you may withdraw from the study at any time without penalty.

Anonymity/confidentiality: Your participation in this study and all responses will be kept confidential. All identifying information provided during the study will not be disclosed to any third party individual or group. This data will be used for research publications, conference presentations and/or teaching material. 
This study has received clearance by the Carleton University Research Ethics Board-B (Research Ethics Approval \#16-097).

If you have any questions or concerns regarding your involvement in this study, please contact:

Carleton University Research Ethics Board-B Chair: Dr. Shelley Brown

(613) 520-2600 ext. 1505

shelley.brown@,carleton.ca

Carleton University Research Ethics Board

(613) 520-2517

ethics@,carleton.ca

Consent. I have read the above form and hereby consent to continue participating in this study. The data in this study will be used for research publications and/or teaching purposes. I am aware that the data collected in this study will be kept strictly confidential and anonymous. By clicking yes I consent to participate in this study.
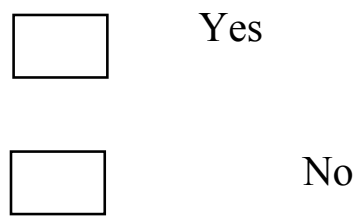


\title{
Appendix E
}

\section{Instruction Manual and Script to Recruit Participants from Texas Correctional}

Sites

\author{
Inclusion Criteria \\ - Low-moderate risk clients \\ - Recently released probationers \\ - Can speak and read English at a grade 6 level \\ - 18 years old or older \\ - Male or Female

\section{Exclusion Criteria} \\ - None
}

\section{Summary of the Current Study}

We are interested in examining the effectiveness (i.e., reducing the likelihood a client will reoffend or have a technical violation) of recently developed interactive workbooks through their implementation at two different correctional sites. These workbooks target anger, criminal attitudes, peer relationships, substance abuse and motivation to change. In the interest of public safety, new techniques to increase the reduction of reoffending and technical violations in offenders are consistently being examined. If current correctional practices are found to be more successful with the implementation of these added workbooks than that of the current practices alone, a larger scale implementation should be considered. Finally, we are interested in getting feedback regarding the workbooks from the clients in the experimental group. A user satisfaction survey will be implemented at a later date and these responses will help to highlight any potential changes that may need to be made to the workbooks.

As we are located in Canada, we are asking you to recruit participants on our behalf. These individuals will be recently released and will be just beginning their probation in the community. Thus, they will be given the option of participating in our study where they may or may not get the chance to use these workbooks. The workbooks themselves include material to read, instructions and questions for the client to work through on their own. However, it is up to you to decide how to specifically incorporate the workbooks into your sessions.

\section{Overview}

\section{Random assignment}

As we are interested in evaluating the effectiveness of a new treatment technique, participants will be randomly assigned (i.e., they will not get to choose) to either the 
control group (i.e., they will only experience your sites current correctional practices) or the experimental group (i.e., they will experience your sites current correctional practices plus they will receive all five of our workbooks). To make this process easier, we have used an online randomizer to select which group each participant will fall into. The Participant Log lists which of the groups each participant will be assigned to $(1=$ control and 2 = experimental). For example, the first client to agree to participate may be placed into the control group, while the second may be placed into the experimental group. Once a client has agreed to participate, please enter their full name and client number into the Participant Log, as well as the testing location (e.g., TX for Texas), your initials, and the current date (e.g., 2016-05-25) for May 25, 2016). Please fill out all of the necessary forms carefully.

\section{Introduction and Consent Form}

When the client arrives for their appointment, briefly outline what will happen. Introduce the study, ask him/her to read and sign the consent form if they are interested in participating.

\section{Script}

I'm working with a professor in psychology at a Canadian University in Canada doing a research study. The purpose of the study is to evaluate the effectiveness of recently developed client workbooks. These workbooks examine topics such as anger, criminal attitudes, peer relationships, substance abuse and motivation to change.

For this study, you would be randomly assigned to one of two conditions. In one condition, you will experience the current probation practices (e.g., meet with PO). In the other condition, you will experience the current probation practices and you will be given a set of five workbooks to complete over the course of your probation. These workbooks are for your personal use and information in these workbooks will not be shared with anyone other than your PO.

The researchers would also ask your permission to look at your files to check your offence history and risk assessment information, as well as collecting follow-up re-offence information. It is important to keep in mind that some people may feel upset by working through the workbooks. It is completely up to you whether or not you participate in this study and you will not be penalized for either choice. Your choice to participate or not participate will not affect how this office treats you. If you decide to participate, the information you provide will be used only for research and teaching purposes and will not be put on any of your institutional files. Your privacy will be respected and protected.

Finally, this study involves reading documents written in English. If you choose to participate, you will receive 10 hours of Community Service Restitution (CSR) credits. You will receive these credits whether you are randomly assigned to the control group (i.e., no workbooks) or the experimental group (i.e., workbooks). However, your participation in this study is completely voluntary. If you choose not to participate, you will be able to earn CSR credits in other ways that are not related to this research. Would you be willing to participate in this study? 
If the client does not wish to participate, please thank them for their time and then you may continue with their session.

\section{If the client agrees, please hand them a consent form:}

Great! I'll ask you to please read the consent form and, if you still wish to participate, please sign both copies.

If the client reads the consent form and then decides not to participate, please thank them for their time and then you may continue with their session.

If the client reads the consent form and still wishes to participate, please continue.

As the experimenter, you will need to sign both copies of the consent form. Give the participant one copy and keep the copy that both you and the participant signed for our records. Once the consent form is signed, describe the procedure and then let the client know whether or not they will receive a set of workbooks. If the participant is in the control group, please proceed with Script 1. If the participant is in the experimental group, please proceed with Script 2.

\section{Script 1}

Okay, thank you. You have been randomly assigned to the control group. This means that you will not be receiving a set of workbooks. However, you will still proceed with our normal probation practices. Thank you for participating in this research study. Let's begin our session.

\section{Script 2}

Okay, thank you. You have been randomly assigned to the experimental group. This means that you will be receiving a set of workbooks. Inside each workbook you will find material to read on that topic and questions to work through. I will be providing some oversight and support in completing these workbooks while also proceeding with our normal probation practices. As mentioned in the consent form you read, there will be more information about this study posted on the internal bulletin board at a later date. Let's begin our session.

Note: How you choose to incorporate these workbooks into your practice is up to your discretion and therefore you may adjust Script 2 to meet your needs. For example, you may choose to have your clients do the activities as homework before their next session or you may choose to have them complete them during your face-to-face. 
In order to put participants at ease and make them feel safer revealing potentially sensitive personal information, please maintain a level of professionalism. This can be conveyed by your appearance, behaviour and body language.

Participation in research is always voluntary. Please make sure you do not coerce any participants. In the case of coercion, they may assume that refusal to participate means they will be in trouble with correctional management or probation staff. In the case of undue influence, a decision to participate could mean they will not be in trouble with correctional management or probation staff.

Thank you again for your assistance in this research.

Please email us if any questions arise.

Stephanie Biro:

stephaniebiro@cmail.carleton.ca

Ralph Serin:

ralph.serin@carleton.ca 


\section{Appendix F}

\section{Texas Client Informed Consent}

This informed consent form is designed to explain to you the study's purpose, the required tasks and additional information to allow you to decide whether or not you wish to participate in the study. Please take the time to read this information carefully.

Project Title: Self-directed workbooks: Evaluating their efficacy in a US Probation setting

\section{Research personnel:}

Stephanie Biro

Department of Psychology Graduate Student, Carleton University

stephaniebiro@.cmail.carleton.ca Telephone: 613-520-2600x x 1595

Ralph Serin

Ph.D., C. Psych., Department of Psychology Faculty, Carleton University

ralph.serin@carleton.ca Telephone: 613-520-2600 x 1557

Date of ethics clearance: To be determined to CUREB (as indicated on the clearance form)

Ethics clearance for the collection of data expires: To be determined to CUREB (as indicated on the clearance form)

Purpose: The purpose of this study is to try out new client workbooks at different probation sites to see how effective and useful they are. These workbooks focus on anger, criminal attitudes, peer relationships, substance abuse and motivation to change, which are areas that have been found to be difficult for many clients during probation. For example, the anger workbook includes descriptions of key terms relating to that topic, a page to log feelings of anger, the necessary steps in order for the client to change their thinking and a section on anger management and conflict resolution. Each workbook has activities to work through which can be done at your own pace. However, it is suggested that all five of the workbooks are completed within six months.

Task requirements: If you choose to participate, you will be randomly assigned to either the control group or the experimental group. If you are randomly assigned to the control group, you will not receive the workbooks. You will continue with the normal probation practices. If you are randomly assigned to the experimental group, you will receive the five workbooks. These books will be for your own personal use and to work through at your own pace. However, your PO will act as a support in your completion of these 
books. They will help you to incorporate the workbooks into the normal probation practice. If you choose to participate, we are also asking your permission to look at your files for information such as your age, race, education level, offence history and risk assessment information, as well as follow-up re-offense information.

Time required: There is no specific time frame as to when you need to have these workbooks completed. These books were developed in order to help clients remain successful during probation. However, your PO may have some suggestions as to how to incorporate the books into your sessions.

Remuneration: If you choose to participate, you will receive 10 hours of Community Service Restitution (CSR) credits. You will receive these credits whether you are randomly assigned to the control group (i.e., no workbooks) or the experimental group (i.e., workbooks). However, your participation in this study is completely voluntary. If you choose not to participate, you will be able to earn CSR credits in other ways that are not related to our research.

Right to withdraw: You have the right to withdraw from this study at any point, without penalty. If you choose to withdraw, please let your PO know and they will contact the researchers to have you withdrawn from the research study.

Potential risk and discomfort: While the level of potential risk and discomfort is expected to be very low, it is important to keep in mind that some people may feel upset by working through the workbooks. However, if you should feel discomfort at any point during this study, please be reminded that your participation is entirely voluntary, and that you may withdraw from the study at any time without penalty. If you find that after participating in this study you feel any sort of emotional, mental, or physical stress or anxiety, please contact your PO or case management staff. You may also contact your nearest crisis centre, Austin Travis County Integral Care: 515-472-4357, 56 East Ave, Austin, TX.

Anonymity/confidentiality: Your participation in this study and all responses will be kept confidential. Your information will be used for research and teaching purposes only and your confidentiality will be respected and protected. We will not mention your name in any publication or presentation. All identifying information provided during the study will not be disclosed to any third party individual or group. The information collected will be securely stored in a locked cabinet at the probation site and then at Carleton University in a locked filing cabinet and password-protected computer. This information will be accessible only to the researchers working on this project. Five years after publication of the final report for this project, we will destroy the personal information we gathered about you.

The information collected will be securely stored at Carleton University in a locked filing cabinet and password-protected computer and will be accessible only to the researchers working on this project. Five years after publication of the final report for this project, we will destroy the personal information we gathered about you. 
Debriefing: Please be aware that we will be posting more information about this study posted on the internal bulletin board in the near future.

This study has received clearance by the Carleton University Research Ethics Board-B (Research Ethics Approval \#\#16-097).

If you have any questions or concerns regarding your involvement in this study, please contact:

Carleton University Research Ethics Board-B Chair: Dr. Shelley Brown (613) 520-2600 ext. 1505

shelley.brown@,carleton.ca

Carleton University Research Ethics Board

(613) 520-2517

ethics@carleton.ca

Consent. I have read the above form and hereby consent to continue participating in this study. The data in this study will be used for research publications and/or teaching purposes. I am aware that the data collected in this study will be kept strictly confidential and anonymous. My signature indicates that I agree to participate in this study. There are two copies of the consent form, one of which I may keep.

Participant Signature:

Date:

Experimenter Signature:

Date: 


\section{Appendix G}

Example Participant Log for Interactive Client Workbook Study with Carleton University - Texas

\begin{tabular}{|c|c|c|c|c|c|c|}
\hline $\begin{array}{c}\text { Participant } \\
\text { Number }\end{array}$ & $\begin{array}{l}\text { Offender } \\
\text { Number }\end{array}$ & Full Name & $\begin{array}{l}\text { Testing } \\
\text { Location } \\
I A \text { or } T X\end{array}$ & Date & $\begin{array}{c}\text { Group } \\
1=\text { Control } \\
2=\text { Experimental }\end{array}$ & Initials \\
\hline 1 & & & & & 1 & \\
\hline 2 & & & & & 2 & \\
\hline 3 & & & & & 2 & \\
\hline 4 & & & & & 2 & \\
\hline 5 & & & & & 2 & \\
\hline 6 & & & & & 2 & \\
\hline 7 & & & & & 2 & \\
\hline 8 & & & & & 1 & \\
\hline
\end{tabular}




\section{Appendix H \\ Debriefing Form for Texas Probation Clients}

\section{What are we trying to learn in this research?}

Our ultimate goal is to improve current probation practices. The purpose of the current study is to examine how effective these self-directed workbooks are at helping to reduce technical violations and reoffending during probation by focusing on topics that are typical problem areas for probation clients, such as anger or substance use.

\section{Why is this important to psychologists or the general public?}

In the interest of the clients, research is always interested in finding new ways to improve client success on probation. If these workbooks are found to be more successful (i.e., reducing reoffending and technical violations) than current practices alone, a larger scale implementation should be considered. As well, the user satisfaction survey responses will help to highlight any potential changes that may need to be made to the workbooks.

\section{How can I learn more?}

We hope to have a summary of the findings for this study prepared by August 2017. Please contact Ralph Serin if you would like a copy. We will also list any articles and post any presentations related to this study on Ralph Serin's lab website:

https://carleton.ca/cjdml/

\section{What if I have questions later?}

If you wish to discuss this research further feel free to contact Stephanie Biro by email: stephaniebiro@cmail.carleton.ca and/or Ralph Serin by email: ralph.serin@,carleton.ca; If you have any questions or concerns about this study please contact Dr. Shelley Brown (Chair of the Carleton University Research Ethics Board-B, 613-520-2600 ext. 1505, shelley.brown@carleton.ca), or contact the Carleton University Research Ethics Board-B (613-520-2517, ethics@,carleton.ca).

\section{What can I do if I experience discomfort or distress after participating in this study?}

If you find that after participating in this study you feel any sort of emotional, mental, or physical stress or anxiety, please contact your PO or case management staff. You may also contact your nearest crisis centre, Austin Travis County Integral Care: 515-472-4357, 56 East Ave, Austin, TX.

This study has received clearance by the Carleton University Research Ethics Board-B (Research Ethics Approval \#16-097). 
Thank you for taking the time to participate in this study! Your participation is greatly appreciated! 


\section{Appendix I}

\section{Research Assistant Confidentiality Agreement}

This study, titled: Self-directed workbooks: Evaluating their efficacy in a US Probation setting, is being undertaken by Dr. Ralph Serin and Stephanie Biro at Carleton University.

The study has 2 objectives:

1. To implement recently developed interactive workbooks with probationers at two federal probation sites.

2. To examine their effectiveness at reducing the likelihood a client will reoffend or have a technical violation.

Data from this study will be used for research publications, conference presentations and/or teaching material.

I, , agree to:

1. Keep all the research information shared with me confidential by not discussing or sharing the research information in any form or format (e.g. disks, tapes, transcripts) with anyone other than the Principal Investigator(s);

2. Keep all research information in any form or format secure while it is in my possession;

3. Return all research information in any form or format to the Principal Investigator(s) when I have completed the research tasks;

4. After consulting with the Principal Investigator(s), erase or destroy all research information in any form or format regarding this research project that is not returnable to the Principal Investigator(s) (e.g. information sorted on computer hard drive).

Research Assistant:

(print name)

(signature)

(date)

If you have any questions or concerns about this study, please contact:

Stephanie Biro

Department of Psychology Graduate Student, Carleton University

stephaniebiro@cmail.carleton.ca Telephone: 613-520-2600 x 1595 
Ralph Serin

Ph.D., C. Psych., Department of Psychology Faculty, Carleton University ralph.serin@carleton.ca Telephone: 613-520 


\title{
Appendix J
}

\section{Instruction Manual and Script to Recruit Participants from Iowa Correctional Sites}

\author{
Inclusion Criteria \\ - Low-moderate risk clients \\ - Recently released probationers \\ - Can speak and read English at a grade 6 level \\ - 18 years old or older \\ - Male or Female

\section{Exclusion Criteria} \\ - None
}

\section{Summary of the Current Study}

We are interested in examining the effectiveness (i.e., by reducing the likelihood a client will reoffend or have a technical violation) of recently developed interactive workbooks through their implementation at two different correctional sites. These workbooks target anger, criminal attitudes, peer relationships, substance abuse and motivation to change. In the interest of public safety, new techniques to increase the reduction of reoffending and technical violations in offenders are consistently being examined. If current correctional practices are found to be more successful with the implementation of these added workbooks than that of the current practices alone, a larger scale implementation should be considered. Finally, we are interested in getting feedback regarding the workbooks from the clients in the experimental group. A user satisfaction survey will be implemented at a later date and these responses will help to highlight any potential changes that may need to be made to the workbooks.

As we are located in Canada, we are asking you to recruit participants on our behalf. These individuals will be recently released and will be just beginning their probation in the community. Thus, they will be given the option of participating in our study where they may or may not get the chance to use these workbooks. It is important to note that, in order to maintain confidentiality, the case management and probation staff should not be aware of which clients have consented to participate or not. The workbooks themselves include material to read, instructions and questions for the client to work through on their own. Please direct any questions that come up from clients to the researchers and not to the case management or probation staff.

\section{Overview}

\section{Random assignment}


As we are interested in evaluating the effectiveness of a new treatment technique, participants will be randomly assigned (i.e., they will not get to choose) to either the control group (i.e., they will only experience your sites current correctional practices) or the experimental group (i.e., they will experience your sites current correctional practices plus they will receive all five of our workbooks). To make this process easier, we have used an online randomizer to select which group each participant will fall into. The Participant Log lists which of the groups each participant will be assigned to $(1=$ control and 2 = experimental). For example, the first client to agree to participate may be placed into the control group, while the second may be placed into the experimental group. Once a client has agreed to participate, please enter their full name and client number into the Participant Log, as well as the testing location (e.g., IA for Iowa), your initials, and the current date (e.g., 2016-05-25) for May 25, 2016). Please fill out all of the necessary forms carefully.

\section{Introduction and Consent Form}

When the client arrives for their appointment, confirm that they meet the criteria listed above (e.g., low-moderate risk offender, can read English) and then briefly outline the study, ask him/her to read and sign the consent form if they are interested in participating.

\section{Script}

Hello, what is your name? [Check participant criteria] you very much for meeting with me today. My name is . I'm working with a professor in psychology at a Canadian University in Canada doing a research study. The purpose of the study is to evaluate the effectiveness of recently developed client workbooks. These workbooks examine topics such as anger, criminal attitudes, peer relationships, substance abuse and motivation to change.

For this study, you would be randomly assigned to one of two conditions. In one condition, you will experience the current probation practices (e.g., meet with PO). In the other condition, you will experience the current probation practices and you will be given a set of five workbooks to complete over the course of your probation. The information in these workbooks will not be shared with anyone and are for your personal use only. Your PO will not have any knowledge of whether or not you are participating in this study.

The researchers would also ask your permission to look at your files to check your offence history and risk assessment information, as well as collecting follow-up re-offence information. It is important to keep in mind that some people may feel upset by working through the workbooks. It is completely up to you whether or not you participate in this study and you will not be penalized for either choice. Your choice to participate or not participate will not affect how this office treats you. If you decide to participate, the information you provide will be used only for research and teaching purposes and will not be put on any of your institutional files. Your privacy will be respected and protected.

Finally, this study involves reading documents written in English. Would you be willing to participate in this study? 
If the client does not wish to participate, please thank them for their time and then you may direct them to their appointment or to a waiting area.

\section{If the client agrees, please hand them a consent form:}

Great! I'll ask you to please read the consent form and, if you still wish to participate, please sign both copies.

If the client reads the consent form and then decides not to participate, please thank them for their time and then you may direct them to their appointment or to a waiting area.

\section{If the client reads the consent form and still wishes to participate, please continue.}

As the experimenter, you will need to sign both copies of the consent form. Give the participant one copy and keep the copy that both you and the participant signed for our records. Once the consent form is signed, describe the procedure and then let the client know whether or not they will receive a set of workbooks. If the participant is in the control group, please proceed with Script 1. If the participant is in the experimental group, please proceed with Script 2.

\section{Script 1}

Okay, thank you. You have been randomly assigned to the control group. This means that you will not be receiving a set of workbooks. However, you will still proceed with our normal probation practices. Thank you for participating in this research study. As mentioned in the consent form you read, there will be more information about this study posted on the internal bulletin board at a later date. You may now proceed to your meeting with

\section{Script 2}

Okay, thank you. You have been randomly assigned to the experimental group. This means that you will be receiving a set of workbooks. Here is each of the five workbooks. As I said previously, each one discusses a different topic. The workbooks are designed so that you may work through them at your own pace, on your own time. Inside each workbook you will find material to read on that topic and questions to work through. Should you have any questions, please direct them to me. If there is a question I can't answer, I will get an answer for you from the researchers. We ask that you work through them at your own pace while also proceeding with our normal probation practices. As mentioned in the consent form you read, there will be more information about this study posted on the internal bulletin board at a later date. You may now proceed to your meeting with 
In order to put participants at ease and make them feel safer revealing potentially sensitive personal information, please maintain a level of professionalism. This can be conveyed by your appearance, behaviour and body language.

Participation in research is always voluntary. Please make sure you do not coerce any participants. In the case of coercion, they may assume that refusal to participate means they will be in trouble with correctional management or probation staff. In the case of undue influence, a decision to participate could mean they will not be in trouble with correctional management or probation staff.

\section{Thank you again for your assistance in this research.}

Please email us if any questions arise.

Stephanie Biro:

stephaniebiro@cmail.carleton.ca

Ralph Serin:

Ralph.serin@carleton.ca 


\section{Appendix K}

\section{Iowa Client Informed Consent}

This informed consent form is designed to explain to you the study's purpose, the required tasks and additional information to allow you to decide whether or not you wish to participate in the study. Please take the time to read this information carefully.

Project Title: Self-directed workbooks: Evaluating their efficacy in a US Probation setting

\section{Research personnel:}

Stephanie Biro

Department of Psychology Graduate Student, Carleton University

stephaniebiro@.cmail.carleton.ca Telephone: 613-520-2600 x 1595

Ralph Serin

Ph.D., C. Psych., Department of Psychology Faculty, Carleton University

ralph.serin@carleton.ca Telephone: 613-520-2600 x 1557

Date of ethics clearance: To be determined to CUREB (as indicated on the clearance form)

Ethics clearance for the collection of data expires: To be determined to CUREB (as indicated on the clearance form)

Purpose: The purpose of this study is to try out new client workbooks at different probation sites to see how effective and useful they are. These workbooks focus on anger, criminal attitudes, peer relationships, substance abuse and motivation to change, which are areas that have been found to be difficult for many clients during probation. For example, the anger workbook includes descriptions of key terms relating to that topic, a page to log feelings of anger, the necessary steps in order for the client to change their thinking and a section on anger management and conflict resolution. Each workbook has activities to work through which can be done at your own pace. However, it is suggested that all five of the workbooks are completed within six months.

Task requirements: If you choose to participate, you will be randomly assigned to either the control group or the experimental group. If you are randomly assigned to the control group, you will not receive the workbooks. You will continue with the normal probation practices. If you are randomly assigned to the experimental group, you will receive the five workbooks. These books will be for your own personal use and it is completely up to you 
how you decide to make use of them. For example, you may choose to begin with the workbook that discusses the topic you're struggling with most right now. Case management staff and your PO will not be aware as to whether or not you decided to participate in this study and you will not be penalized for either choice. As well, your PO will not have access to what you write in your workbooks. If you choose to participate, we are also asking your permission to look at your files for information such as your age, race, education level, offence history and risk assessment information, as well as follow-up reoffense information.

Time required: There is no specific time frame as to when you need to have these workbooks completed. These books were developed in order to help clients remain successful during probation.

Remuneration: Your participation in this study is completely voluntary and you will not be paid for your participation.

Right to withdraw: You have the right to withdraw from this study at any point, without penalty. If you choose to withdraw, please let the research assistant who recruited you know (Name and contact information will be inserted here) and they will contact the researchers to have you withdrawn from the research study.

Potential risk and discomfort: While the level of potential risk and discomfort is expected to be very low, it is important to keep in mind that some people may feel upset by working through the workbooks. If you should feel discomfort at any point during this study, please be reminded that your participation is entirely voluntary, and that you may withdraw from the study at any time without penalty. If you find that after participating in this study you feel any sort of emotional, mental, or physical stress or anxiety, please contact your PO or case management staff. You may also contact your nearest crisis centre, Everly Ball Community Mental Health Services:

515-564-5742, 1420 Mulberry St, Des Moines, IA.

Anonymity/confidentiality: Your participation in this study and all responses will be kept confidential. Your information will be used for research and teaching purposes only and your confidentiality will be respected and protected. We will not mention your name in any publication or presentation. All identifying information provided during the study will not be disclosed to any third party individual or group. The information collected will be securely stored in a locked cabinet at the probation site and then at Carleton University in a locked filing cabinet and password-protected computer. This information will be accessible only to the researchers working on this project. Five years after publication of the final report for this project, we will destroy the personal information we gathered about you.

Debriefing: Please be aware that we will be posting more information about this study on the internal bulletin board in the lobby in the near future. 
This study has received clearance by the Carleton University Research Ethics Board-B (Research Ethics Approval \#16-097).

If you have any questions or concerns regarding your involvement in this study, please contact:

Carleton University Research Ethics Board-B Chair: Dr. Shelley Brown

(613) 520-2600 ext. 1505

shelley.brown@,carleton.ca

Carleton University Research Ethics Board

(613) 520-2517

ethics@carleton.ca

Consent. I have read the above form and hereby consent to continue participating in this study. The data in this study will be used for research publications and/or teaching purposes. I am aware that the data collected in this study will be kept strictly confidential and anonymous. My signature indicates that I agree to participate in this study. There are two copies of the consent form, one of which I may keep.

Participant Signature:

Date:

Experimenter Signature:

Date: 


\section{Appendix L}

Example Participant Log for Interactive Client Workbook Study with Carleton University - Iowa

\begin{tabular}{|c|c|c|c|c|c|c|}
\hline $\begin{array}{c}\text { Participant } \\
\text { Number }\end{array}$ & $\begin{array}{l}\text { Offender } \\
\text { Number }\end{array}$ & Full Name & $\begin{array}{l}\text { Testing } \\
\text { Location } \\
\text { IA or } T X\end{array}$ & Date & $\begin{array}{c}\text { Group } \\
1=\text { Control } \\
2=\text { Experimental }\end{array}$ & Initials \\
\hline 1 & & & & & 1 & \\
\hline 2 & & & & & 2 & \\
\hline 3 & & & & & 2 & \\
\hline 4 & & & & & 2 & \\
\hline 5 & & & & & 2 & \\
\hline 6 & & & & & 2 & \\
\hline 7 & & & & & 2 & \\
\hline 8 & & & & & 1 & \\
\hline
\end{tabular}




\section{Appendix M}

\section{Debriefing Form for Iowa Probation Clients}

\section{What are we trying to learn in this research?}

Our ultimate goal is to improve current probation practices. The purpose of the current study is to examine how effective these self-directed workbooks are at helping to reduce technical violations and reoffending during probation by focusing on topics that are typical problem areas for probation clients, such as anger or substance use.

\section{Why is this important to psychologists or the general public?}

In the interest of the clients, research is always interested in finding new ways to improve client success on probation. If these workbooks are found to be more successful (i.e., reducing reoffending and technical violations) than current practices alone, a larger scale implementation should be considered. As well, the user satisfaction survey responses will help to highlight any potential changes that may need to be made to the workbooks.

\section{How can I learn more?}

We hope to have a summary of the findings for this study prepared by August 2017. Please contact Ralph Serin if you would like a copy. We will also list any articles and post any presentations related to this study on Ralph Serin's lab website:

https://carleton.ca/cjdml/

\section{What if I have questions later?}

If you wish to discuss this research further feel free to contact Stephanie Biro by email: stephaniebiro@,cmail.carleton.ca and/or Ralph Serin by email: ralph.serin@,carleton.ca; If you have any questions or concerns about this study please contact Dr. Shelley Brown (Chair of the Carleton University Research Ethics Board-B, 613-520-2600 ext. 1505, shelley.brown@carleton.ca), or contact the Carleton University Research Ethics Board-B (613-520-2517, ethics@,carleton.ca).

\section{What can I do if I experience discomfort or distress after participating in this study?}

If you find that after participating in this study you feel any sort of emotional, mental, or physical stress or anxiety, please contact your PO or case management staff. You may also contact your nearest crisis centre, Everly Ball Community Mental Health Services: 515-564-5742, 1420 Mulberry St, Des Moines, IA.

This study has received clearance by the Carleton University Research Ethics Board-B (Research Ethics Approval \#16-097). 
Thank you for taking the time to participate in this study! Your participation is greatly appreciated! 


\section{Appendix N}

\section{Client Recruitment Letter}

Dear Sir/Madam,

I am a graduate student in the Department of Psychology at Carleton University and I am contacting you because of your current use of the self-directed workbooks during your probation. I would like to invite you to participate in giving anonymous feedback regarding the content and use of these workbooks. All responses will be strictly anonymous and no identifying information will be collected. This data will be used for research publications, conference presentations and/or teaching material. The survey is to be completed online and will take you approximately 20 minutes to complete.

If you would like to know more information about this survey or you would like to participate, you can access the survey from the following link:

If you have any questions, please contact me at stephaniebiro@cmail.carleton.ca or my supervisor, Ralph Serin, at ralph.serin@,carleton.ca

Thank you for your consideration,

Stephanie Biro

Department of Psychology Graduate Student, Carleton University

Telephone: 613-520-2600 x 1595

Ralph Serin

Department of Psychology Faculty, Carleton University

Telephone: 613-520-2600 × 1557

This study has received clearance by the Carleton University Research Ethics Board-B (Research Ethics Approval \#16-097). 


\section{Appendix O}

\section{(Online) Informed Consent}

This informed consent form is designed to explain to you the study's purpose, the required tasks and additional information to allow you to decide whether or not you wish to participate in the study. Please take the time to read this information carefully.

Project Title: Self-directed workbooks: Evaluating their efficacy in a US Probation setting

\section{Research personnel:}

Stephanie Biro

Department of Psychology Graduate Student, Carleton University

stephaniebiro@,cmail.carleton.ca Telephone: 613-520-2600 x 1595

Ralph Serin

Ph.D., C. Psych., Department of Psychology Faculty, Carleton University

ralph.serin@carleton.ca Telephone: 613-520-2600 x 1557

Date of ethics clearance: December 15, 2016

Ethics clearance for the collection of data expires: October 31, 2017

Purpose: The purpose of this study is to survey probation clients on their current use of recently developed interactive workbooks in order to evaluate the effectiveness and usefulness of the workbooks.

Task requirements: You will be directed to an online survey platform where you will be asked to complete a series of questions regarding the interactive workbooks that you have been using. The questions will assess your views on the content and usefulness of these workbooks. You will also be asked to complete a brief demographic questionnaire.

Time required: This study will take approximately 20 minutes to complete.

Remuneration: Your participation in this study is completely voluntary and you will not be paid for your participation.

Right to withdraw: You have the right to withdraw from this study at any point, without penalty. If you choose to withdraw before the end of the survey, you simply need to click the withdraw button located on each page and leading to the debriefing form. 
Potential risk and discomfort: If you regularly experience test anxiety, this research may cause slight discomfort. If you should feel discomfort at any point during this study, please be reminded that your participation is entirely voluntary, that you may choose not to answer any question, and that you may withdraw from the study at any time without penalty.

Anonymity/confidentiality: Your participation in this study and all responses will be strictly anonymous. All identifying information provided during the study will not be disclosed to any third party individual or group. This data will be used for research publications, conference presentations and/or teaching material. All answers will be coded in such a way that participants cannot be identified. IP addresses will not be collected during this study.

We will collect data through the software Qualtrics, which uses servers with multiple layers of security to protect the privacy of the data (e.g., encrypted websites and password protected storage). Please note that Qualtrics is hosted by a server located in the USA. The United States Patriot Act permits U.S. law enforcement officials, for the purpose of an anti-terrorism investigation, to seek a court order that allows access to the personal records of any person without that person's knowledge. In view of this we cannot absolutely guarantee the full confidentiality and anonymity of your data. With your consent to participate in this study you acknowledge this.

This study has received clearance by the Carleton University Research Ethics Board-B (Research Ethics Approval \#16-097).

If you have any questions or concerns regarding your involvement in this study, please contact:

Carleton University Research Ethics Board-B Chair: Dr. Shelley Brown

(613) 520-2600 ext. 1505

shelley.brown@,carleton.ca

Carleton University Research Ethics Board

(613) 520-2517

ethics@carleton.ca

Consent. I have read the above form and hereby consent to continue participating in this study. The data in this study will be used for research publications and/or teaching purposes. I am aware that the data collected in this study will be kept strictly confidential and anonymous. By clicking yes I consent to participate in this study.
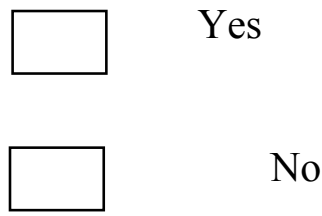


\section{Appendix P}

\section{Online Debriefing Form for Texas Survey}

\section{What are we trying to learn in this research?}

Our ultimate goal is to improve current probation practices. The purpose of the current study is to examine how effective these self-directed workbooks are at helping to reduce technical violations and reoffending during probation by focusing on topics that are typical problem areas for probation clients, such as anger or substance use. We hope that your feedback can help us to improve the workbooks for future use.

\section{Why is this important to psychologists or the general public?}

In the interest of the clients, research is always interested in finding new ways to improve client success on probation. If these workbooks are found to be more successful (i.e., reducing reoffending and technical violations) than current practices alone, a larger scale implementation should be considered. As well, the user satisfaction survey responses will help to highlight any potential changes that may need to be made to the workbooks.

\section{How can I learn more?}

We hope to have a summary of the findings for this study prepared by August 2017. Please contact Ralph Serin if you would like a copy. We will also list any articles and post any presentations related to this study on Ralph Serin's lab website: https://carleton.ca/cjdml/

\section{What if I have questions later?}

If you wish to discuss this research further feel free to contact Stephanie Biro by email: stephaniebiro@cmail.carleton.ca and/or Ralph Serin by email: ralph.serin@carleton.ca; If you have any questions or concerns about this study please contact Dr. Shelley Brown (Chair of the Carleton University Research Ethics Board-B, 613-520-2600 ext. 1505, shelley.brown@carleton.ca), or contact the Carleton University Research Ethics Board-B (613-520-2517, ethics@,carleton.ca).

\section{What can I do if I experience discomfort or distress after participating in this study?}

If you find that after participating in this study you feel any sort of emotional, mental, or physical stress or anxiety, please contact your PO or case management staff. You may also contact your nearest crisis centre, Austin Travis County Integral Care: 515-472-4357, 56 East Ave, Austin, TX.

This study has received clearance by the Carleton University Research Ethics Board-B (Research Ethics Approval \#16-097) 
Thank you for taking the time to participate in this study!

Your participation is greatly appreciated! 


\section{Appendix Q}

\section{Online Debriefing Form for Iowa Survey}

\section{What are we trying to learn in this research?}

Our ultimate goal is to improve current probation practices. The purpose of the current study is to examine how effective these self-directed workbooks are at helping to reduce technical violations and reoffending during probation by focusing on topics that are typical problem areas for probation clients, such as anger or substance use. We hope that your feedback can help us to improve the workbooks for future use.

\section{Why is this important to psychologists or the general public?}

In the interest of the clients, research is always interested in finding new ways to improve client success on probation. If these workbooks are found to be more successful (i.e., reducing reoffending and technical violations) than current practices alone, a larger scale implementation should be considered. As well, the user satisfaction survey responses will help to highlight any potential changes that may need to be made to the workbooks.

\section{How can I learn more?}

We hope to have a summary of the findings for this study prepared by August 2017. Please contact Ralph Serin if you would like a copy. We will also list any articles and post any presentations related to this study on Ralph Serin's lab website: https://carleton.ca/cjdml/

\section{What if I have questions later?}

If you wish to discuss this research further feel free to contact Stephanie Biro by email: stephaniebiro@cmail.carleton.ca and/or Ralph Serin by email: ralph.serin@carleton.ca; If you have any questions or concerns about this study please contact Dr. Shelley Brown (Chair of the Carleton University Research Ethics Board-B, 613-520-2600 ext. 1505, shelley.brown@carleton.ca), or contact the Carleton University Research Ethics Board-B (613-520-2517, ethics@,carleton.ca).

\section{What can I do if I experience discomfort or distress after participating in this study?}

If you find that after participating in this study you feel any sort of emotional, mental, or physical stress or anxiety, please contact your PO or case management staff. You may also contact your nearest crisis centre, Everly Ball Community Mental Health Services: 515-564-5742, 1420 Mulberry St, Des Moines, IA.

This study has received clearance by the Carleton University Research Ethics Board-B (Research Ethics Approval \#16-097). 
Thank you for taking the time to participate in this study!

Your participation is greatly appreciated! 